\title{
LAÍSE ANTON
}

Análise de desempenho ambiental da cogeração de energia elétrica a partir de adições sucessivas de biomassa em destilaria autônoma 


\section{LAÍSE ANTON}

Análise de desempenho ambiental da cogeração de energia elétrica a partir de adições sucessivas de biomassa em destilaria autônoma

Dissertação apresentada à Escola Politécnica da Universidade de São Paulo para a obtenção do título de Mestre em Ciências

Orientador:

Prof. Dr. Luiz Alexandre Kulay

São Paulo

2017 


\section{LAÍSE ANTON}

Análise de desempenho ambiental da cogeração de energia elétrica a partir de adições sucessivas de biomassa em destilaria autônoma

Dissertação apresentada a Escola Politécnica da Universidade de São Paulo para a obtenção do título de Mestre em Ciências

Área de Concentração:

Engenharia Química

Orientador:

Prof. Dr. Luiz Alexandre Kulay 
Este exemplar foi revisado e corrigido em relação à versão original, sob

responsabilidade única do autor e com a anuência de seu orientador.

São Paulo, 21 de fevereiro de 2017.

Assinatura do autor: baúse Outon

Assinatura do orientador:

\section{Catalogação-na-publicação}

Anton, Laíse

Análise de desempenho ambiental da cogeração de energia elétrica a partir de adições sucessivas de biomassa em destilaria autônoma / L. Anton - versão corr. -- São Paulo, 2017. $124 \mathrm{p}$.

Dissertação (Mestrado) - Escola Politécnica da Universidade de São Paulo. Departamento de Engenharia Química.

1.Biomassa 2.Cogeração 3.Avaliação de Ciclo de Vida 4.Ciclo Rankine 5.Análise Energética I.Universidade de São Paulo. Escola Politécnica. Departamento de Engenharia Química II.t. 
Dedico este trabalho a minha família. 


\section{AGRADECIMENTOS}

Em primeiro lugar, agradeço ao professor Dr. Luiz Alexandre Kulay pelo comprometimento no desenvolvimento desse trabalho, pela orientação e, sobretudo, pela amizade cultivada e, principalmente pela compreensão nos momentos mais difíceis.

Aos colegas do GP2 que de certa forma contribuíram para aelaboração desse trabalho: Alex, Letícia, Ana, Cristina, Hugo.

Ao professor Gil Anderi da Silva, pela ajuda no momento difícil.

A minha família e amigos pelo apoio e incentivo. 


\section{RESUMO}

Uma análise do setor sucroalcooleiro nacional revela sua autossuficiência energética que com investimentos adequados, pode evoluir para transformar tal característica em benefício por meio de exportação de energia elétrica. Atualmente, os sistemas de cogeração das usinas de etanol operam com bagaço-de-cana; no entantoesse quadro deve ser alterado devido ao grande aumento de disponibilidade de palha gerada no campo. Um acordo firmado entre o Governo do Estado de São Paulo e UNICA, que limita e condiciona queimadas durante a colheita na região ratifica essa condição. O presente estudo se propõe a estimar e discutir impactos ambientais associados à cogeração de energia elétrica em destilarias autônomas para situações diversas de operação do ciclo Rankine, modelo de termodinâmico adotado para representar o funcionamento daquele sistema. Para atender a tais propósitosforam verificadas diferentes condições de pressão de operação da caldeira (20, 45, 67, 80 e 100 bar), teor de umidade da palha $(10 \%, 15 \%, 25 \%, 35 \%$ e $50 \%)$, e taxa de adição dessa biomassa (10\%, $20 \%, 30 \%, 40 \%$ e 50\%) com relação ao total gerado no campo. A coordenação simultânea dessas variáveis resultou na formulação de cento e vinte e cinco cenários de análise. Os cenários foram analisados a partir de Análise Energética (Análise Termodinâmica de $1^{\mathrm{a}} \mathrm{e}$ $2^{a}$ Leis) e Avaliação de Ciclo de Vida (ACV). AACVocorreusob enfoque do tipo "berço-aoportão", e seguiu diretrizes metodológicas descritas na normaABNT NBR ISO 14044. Adotou-se como unidade funcional para o estudo "produzir10 t de etanol anidro $(99,5 \% \mathrm{w} / \mathrm{w})$ ". O sistema de produto compreende atividades realizadas nas etapas agrícola (de produção de cana-de-açúcar e palha) e industrial (obtenção de etanol e cogeração). A análise ocorreu em termos da geração específica deeletricidade, e de perfil de impactos ambientais, definido em termos dos potenciais de Mudanças Climáticas, Acidificação Terrestre, Eutrofização Aquática, e de Formação de Oxidantes Fotoquímicos e de Material Particulado.Os resultados obtidos indicam que a eficiência energética aumenta com a elevação das funções de estado do vapor superaquecido que é injetadona turbina. Em termos de desempenho ambiental, observou-se redução sistêmica de efeitos adversoscom o aumento da eficiência do ciclo termodinâmico. Os resultados também ratificaram como condição mais favorável em termos de desempenho ambiental aquela em que $50 \%$ da palha gerada no campo, com $10 \%$ de umidade, é aproveitada como fonte de energia térmica na caldeira, produzindo vapor superaquecido a 100 bar.

Palavras-chave: Biomassa. Cogeração. Ciclo Rankine. Análise energética. Avaliação do Ciclo de Vida 


\begin{abstract}
Analyzing the sugar-alcohol sector in Brazil, one can perceive that it is self-sufficient in energy terms and that, with adequate investments, it can evolve to transform this characteristic into a benefit through the export of electricity. Currently, the cogeneration systems of the ethanol plants operate with bagasse. However, this picture should be changed due to the large increase in availability of straw generated in the field. An agreement signed between the Government of the State of São Paulo and the federation of ethanol and sugar mills (UNICA) that limits and conditions burnings during harvesting in the region ratifies this condition. This study estimates and discusses environmental impacts associated with the cogeneration of power in autonomous distilleries for typical operational conditions of the Rankine cycle, a thermodynamic model adopted to represent the operation of that system. In order to meet these purposes, different boiler operating pressure (20, 45, 67, 80 and $100 \mathrm{bar})$, moisture content of the straw $(10 \%, 15 \%, 25 \%, 35 \%$ and $50 \%)$, and rate of biomass feeding $(10 \%, 20 \%, 30 \%, 40 \%$ and $50 \%)$ in relation to the total generated in the field have been verified.The simultaneous coordination of these variables resulted in the formulation of one hundred and twenty-five analysis scenarios, which were investigated in terms of Energy Analysis (Thermodynamic Analysis of $1^{\text {st }}$ and $2^{\text {nd }}$ Laws) and Life Cycle Assessment (LCA). The LCA was carried out under a "cradle-to-gate" approach and followed the methodological guidelines described in ABNT NBR ISO 14044. It was adopted as a Functional Unit for the study "to produce $10 \mathrm{t}$ of anhydrous ethanol $(99.5 \% \mathrm{w} / \mathrm{w})$ ". The product system comprises activities that occur in the agricultural (production of sugarcane and straw) and industrial (synthesis of ethanol and cogeneration) stages. The analysis took place in terms of the specific generation of electricity, and of environmental impact profiles have been defined in terms of the potential of Climate Change, Terrestrial Acidification, Aquatic Eutrophication, and Formation of Photochemical Oxidants and Particulate Material. The results indicate that the energy efficiency increases with the increase of the state functions of the steam that is injected into the turbine. Regarding the environmental performance, it was observed a systemic reduction of adverse effects with the increase of the efficiency of the thermodynamic cycle. The results also confirmed that the most favorable condition in terms of environmental performance is that one which $50 \%$ of the straw produced in the field, with $10 \%$ humidity, is used as a source of thermal energy in the boiler, producing superheated steam at 100 bar.
\end{abstract}

Keywords: Biomass. Cogeneration. Rankine cycle. Energy analysis. Life Cycle Assessment. 


\section{LISTA DE FIGURAS}

Figura 1 - Estrutura geral da cana-de-açúcar

Figura 2 -Representação de um ciclo Rankine com reaquecimento

Figura 3 - Prazo para eliminação da queima da palha no estado de São Paulo

Figura 4 -Representação esquemática genérica do ciclo de vida de um produto

Figura 5 - Etapas de ACV:diretrizes definidas pela norma ABNT NBR ISO 14040

Figura 6 - Representação de ciclo Rankine com reaquecimento

Figura 7 -Esquema ilustrativo da caldeira de força

Figura 8 -Desenho esquemático ilustrativo do arranjo turbina e gerador

Figura 9 - Ilustração do conjunto condensador e torre de resfriamento

Figura 10 -Detalhe da bomba de recalque de condensado

Figura 11 - Representação da unidade dedesaeração

Figura 12 -Sistema de produtopara geração de eletricidade a partir de biomassa de cana-de-açúcar 


\section{LISTA DE GRÁFICOS}

Gráfico 1 - Percentual de área total de cana-de-açícar por Unidade da Federação

Gráfico 2 -Perfil comparado de produtividade (t/ha) de cana-de-açúcar por região

Gráfico 3 -Produção de cana-de-açúcar por estado

Gráfico 4 -Produção total de etanol por região do Brasil

Gráfico 5 - Pressão vs. Adição de palha vs. Umidade da palhapara TAc

Gráfico 6 -TAc vs. Adição de palha vs. Umidade da palha para diferentes pressões

Gráfico 7 -Pressão vs. Adição de palha vs. Umidade da palha para FEu

Gráfico 8 -FEu vs. Adição de palha vs. Umidade da palha para diferentes pressões

Gráfico 9 - Pressão vs. Adição de palha vs. Umidade da palha para POF

Gráfico 10 -POF vs. Adição de palha vs. Umidade da palha para diferentes pressões 


\section{LISTA DE TABELAS}

Tabela 1 - Características dos cenários avaliados: pressão de vapor, taxa de adição e umidade de palha

Tabela 2 - Variação do consumo de eletricidade na unidade industrial em função da umidade da palha

Tabela 3 - Parâmetros gerais utilizados para estimativa e modelagem dos cenários de análise

Tabela 4 - Pressão de extração ótima de vapor a ser efetuada na turbina para os diferentes níveis de operação caldeira em termos de pressão de vapor superaquecido

Tabela 5 - Características e propriedades do bagaço e palha de cana-de-açúcar

Tabela 6 - Fatores de alocação para partição de cargas ambientais entre eletricidade exportada, eletricidade consumida no processo, e vapor de alta pressão (@ 20 bar)

Tabela 7 - Fatores de alocação para partição de cargas ambientais entre eletricidade exportada, eletricidade consumida no processo, e vapor de alta pressão (@ 45 bar)

Tabela 8 - Fatores de alocação para partição de cargas ambientais entre eletricidade exportada, eletricidade consumida no processo, e vapor de alta pressão (@67 bar)

Tabela 9 - Fatores de alocação para partição de cargas ambientais entre eletricidade exportada, eletricidade consumida no processo, e vapor de alta pressão (@80 bar)

Tabela 10 - Fatores de alocação para partição de cargas ambientais entre eletricidade exportada, eletricidade consumida no processo, e vapor de alta pressão (@100 bar)

Tabela 11 - Eletricidade Excedente gerada em cada cenário de análise

Tabela 12 - Aspectos ambientais associados à produção de 1,0 t de cana-de-açúcar para as condições de processamento agrícola exercitadas no Estado de São Paulo

Tabela 13 - Inventário produção de 10 t $_{2} \mathrm{H}_{6} \mathrm{O}\left(99,5 \%_{\mathrm{w} / \mathrm{w}}\right)$

Tabela 14 - Fatores de emissão para queima de óleo diesel em maquinários agrícolas

Tabela 15 - Inventário do sistema de cogeração para: $\mathrm{P}=20$ bar, $\mathrm{a}=10 \%$ palha, $\mathrm{u}=10 \%$

Tabela 16 - Análise da influência da pressão de operação do sistema sobre POF

Tabela 17 - Análise da influência da pressão de operação do sistema sobre PMF

Tabela 18 - Análise da influência da pressão de operação do sistema sobre CC 


\section{SUMÁRIO}

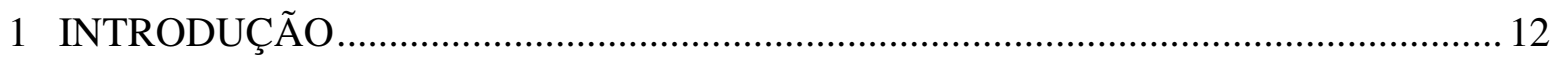

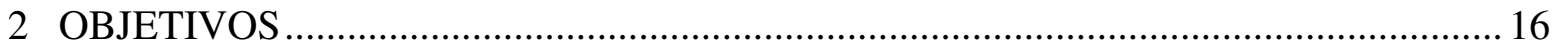

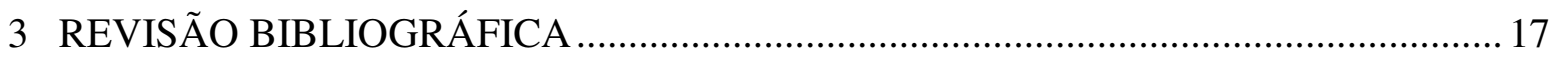

3.1 Cana-de-açúcar, etanol e eletricidade ................................................................17

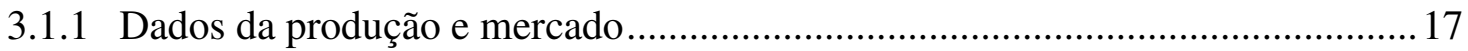

3.1.2 Produção de etanol e eletricidade ............................................................... 23

3.1.3 Impactos ambientais gerados pelo cultivo de cana...........................................35

3.2 Avaliação do Ciclo de Vida (ACV): conceito, aplicações e método.........................36

3.2.1 Definição do objetivo e escopo do estudo de ACV ........................................ 41

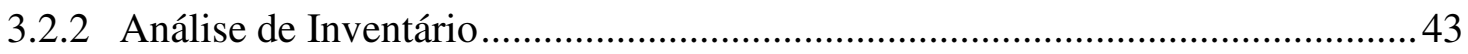

3.2.3 Avaliação dos impactos ambientais.................................................................. 44

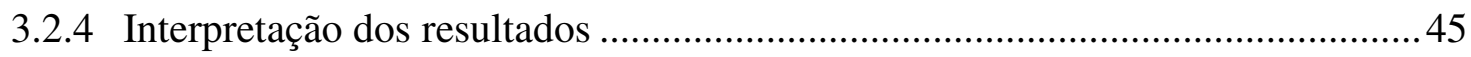

3.2.5 Estudos ACV voltados à cogeração de eletricidade .........................................46

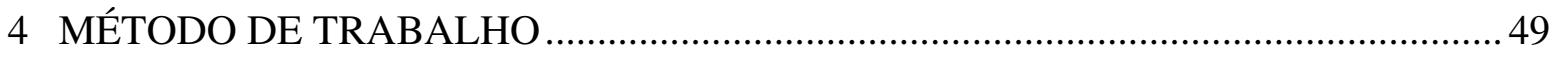

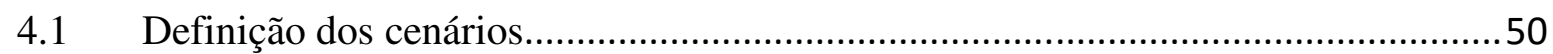

4.2 Modelagem Termodinâmica dos Cenários ........................................................52

4.2.1 Premissas e definição dos parâmetros operacionais dos cenários ..................52

4.2.2 Construção de modelos matemáticos ..........................................................54

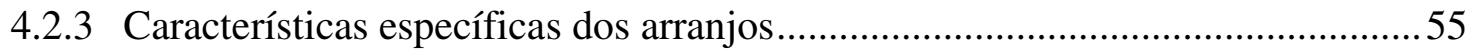

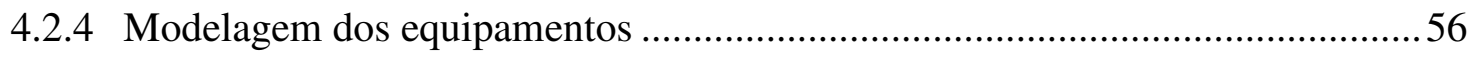

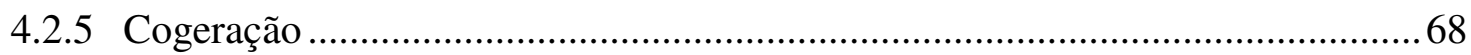

4.3 Aspectos Específicos da Avaliação Ambiental ......................................................70

4.3.1 Definição de Objetivo e Definição de Escopo: Função, Unidade Funcional e

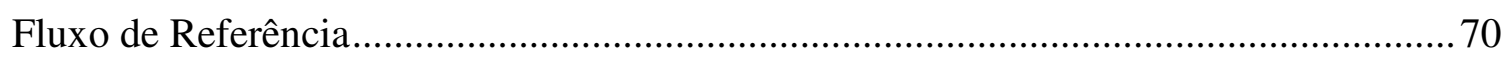

4.3.2 Sistema de produto e fronteiras do sistema ............................................... 71

4.3.3 Tipo e qualidade dos dados, e Tratamento de multifuncionalidades..................72

4.3.4 Método de Avaliação de Impactos e Categorias de Impacto Ambiental.............79 


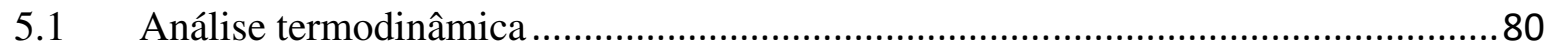

5.2 Análise Ambiental - Inventários de Ciclo de Vida - ICVs .....................................82

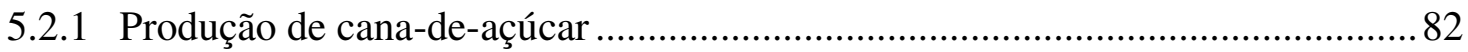

5.2.2 Tratamentos preliminares e transporte de cana-de-açúcar e palha .....................85

5.2.3 Tratamento e moagem de cana-de-açúcar ..................................................... 85

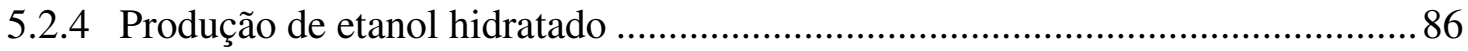

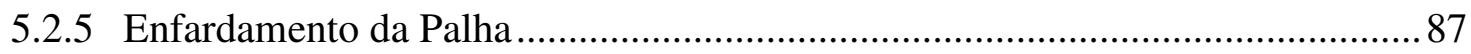

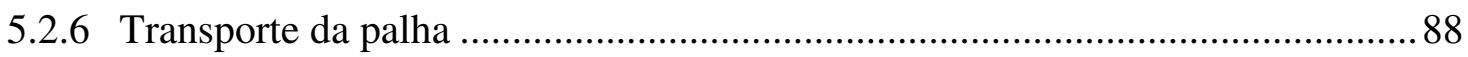

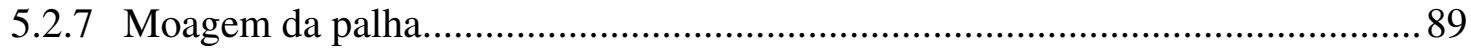

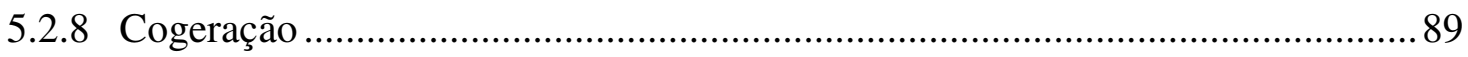

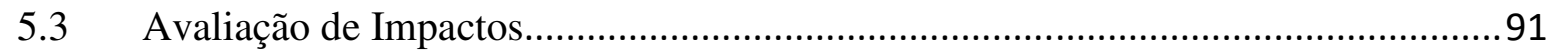

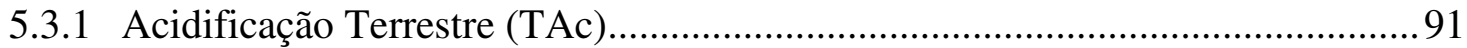

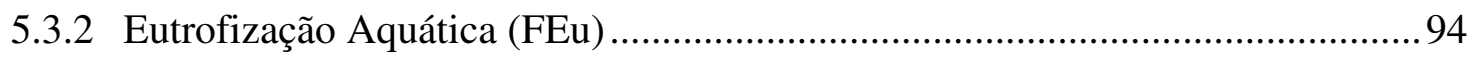

5.3.3 Formação de Oxidante Fotoquímico (POF) …..................................................96

5.3.4 Formação de Material Particulado (PMF) ..................................................... 98

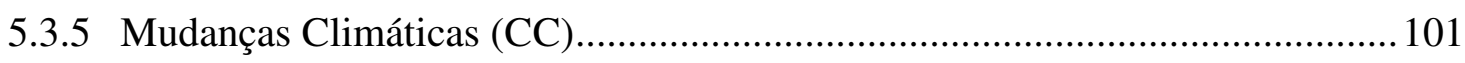

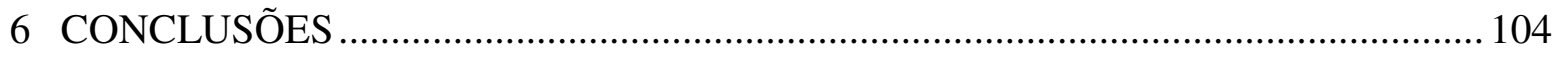

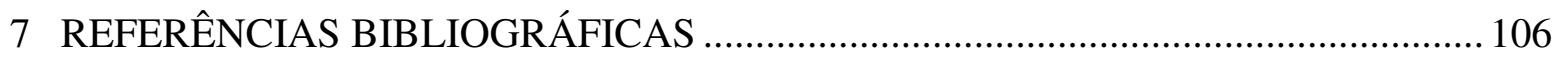

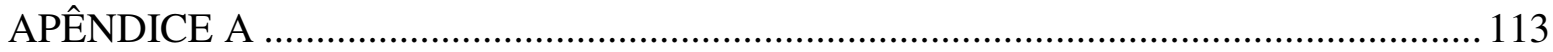




\section{INTRODUÇÃO}

A produção de açúcar e álcool se destaca como uma das principais atividades produtivas do Brasil. O setor sucroalcooleiro passa por um momento de modernização e crescimento, devido a mudanças no cenário econômico nacional que a cada ano, sobretudo em termos de commodities agrícolas e bioprodutos, busca reforçar posições no mercado internacional sem, no entanto, abrir mão de suprir as demandas internas.

No caso específico do segmento em questão, podem ser apontados como agentes propulsores de tais avanços a abertura do mercado externo para o etanol brasileiro; a consolidação da tecnologia flex-fuel junto ao mercado interno; e a criação de mecanismos para comercialização dos excedentes de energia elétrica gerados por usinas de autônomas e anexas, para a rede concessionária (UNICA, 2015).

Ainda assim, para perseverar em um meio cada vez mais exigente, as empresas que atuam no ramo precisam constantemente elevar seu nível de competitividade expandindo receitas e/ou reduzindo despesas. Sob o ponto de vista de gestão, tais resultados poderiam ser alcançados a partir de ações de duas naturezas, inclusive a serem implementadas, eventualmente, de forma simultânea.

O primeiro grupo de ações consiste das elevações da produtividade agrícola e do rendimento industrial dos processos que compõem essas cadeias produtivas, com vistas a intensificar a obtenção dos produtos principais de ambos os estágios: cana-de-açúcar e etanol. O segundo nível de atuação compreende a redução de perdas de processo, ação que em termos práticos poderia também ser entendida como intensificar o reaproveitamento de resíduos como vinhaça, torta de filtro e cinza gerados no ciclo industrial, e da palha remanescente daatividade agrícola.

Dentre as opções antes em destaque deve merecer atenção particular o reaproveitamento de resíduos agrícolas. O uso de material lignocelulósico - na forma de bagaço excedente e palha - vem se consolidando como uma importante fonte complementar de produção de etanol. Muito embora a tecnologia encontre-se ainda em fase de desenvolvimento, condição que por naturezaelevaos custos a ela associados a patamares superiores aosatingidos pela rota convencional, a produção do chamado etanol de segunda geração, ou etanol 2G, vem despertando cada vez mais interesse entre os usineiros (CORTEZ, 2010). 
Outra possibilidade palpável para o reaproveitamento de biomassa consiste do aproveitamento da palha como combustível complementar nas caldeiras que integram o ciclo de cogeração, com o intuito de incrementar a oferta de vapor e, por conta disso, de energia elétrica. O objetivo maior dessa ação é ser capaz de exportar para a rede concessionária quantidades cada vez mais elevadas do excedente de eletricidade produzida por aquele sistema.

Antes de um desenvolvimento, o reaproveitamento de palha pode ser interpretado como uma adequação de condições do processo já existentes em âmbito sistêmico. Ao viabilizar seu uso no ciclo Rankine muitas usinas reverteram uma relação que antes era de dependência com as redes concessionárias, e passaram a ser fornecedoras de energia elétrica. $\mathrm{O}$ nível de intervenção atual das organizações que optaram por seguir tal caminho é tão intenso, que a posição por elas adquirida lhes permite estabelecer bases para composição dos preços de eletricidade (UNICA, 2015).

Uma tendência franca de ampliação desse quadro pode ser esperada para os próximos anos. Estaprojeçãose fundamenta em dois fatores. O primeiro deles é de ordem tecnológica, e está associado ao fato de a palha poder ser usada, ainda que dentro de limites definidos, como agente de fornecimento de energia. $\mathrm{O}$ segundo fator remeteàoferta da mesma biomassa. $\mathrm{O}$ Protocolo Agroambiental, estabelecido entre o Governo do Estado de São Paulo - maior produtor em nível nacional de cana-de-açúcar - e a União da Agroindústria Canavieira (UNICA), antecipou os prazos legais para eliminação de queimadasna região. O acordo firmado em 2007 determinouque a extinção da prática em áreas passíveisde realização de colheita mecanizadaocorresse em 2014, e não mais no prazo em que fora originalmente concebido, de 2021. Dentro da mesma linha de abordagem, as queimadas de palha em zonas nas quais não existe tecnologia adequada para mecanização deveriam cessar em 2017, e não mais em 2031 (SÃO PAULO, 2007).

Um terceiro elemento, relacionado à forma de gestão das sobras de palha por parte do produtor, pode ainda ser considerado na mesma esfera de análise. Ao observar a questão com maior nível de detalhe percebe-se haver apenas dois encaminhamentos possíveis: (i) aquele estabelecidoa partir de uma ótica essencialmente reativa, em que os restos culturais devem ser tratados e dispostos de maneira inadequada, que hipoteca custos e desembolsos regulares; ou (ii) uma opção baseada em enfoque proativo, caminho em que investimentos seriam feitos 
com vistas a valorizar a biomassa como insumo de processo para produção de bens de consumo.

Nesse caso, muito embora se deva prever desembolsos mais vultosos do que aqueles realizados para efeito de tratamento da palha, as receitas alcançadas com os produtos derivados dessa ação levariam a resultados superavitários, mesmo acrescentando custos de tratamento de rejeitos e/ou de reaproveitamento de resíduos derivados desta conduta processual.

Além disso, o aproveitamento da palhagera um dividendo acessório importante para o segmento ao atribuir-lhe uma imagem de responsabilidade ambiental. Ao suprimir em caráter definitivo as queimadas, usinas e destilarias afastam, ao menos em tese, o estigma de poluidores que se criou junto ao grande público. Esses efeitos adversos acabam, de forma inexorável, incidindo sobre a aceitação do etanol brasileiro no mercado estrangeiro.

Dentro ainda da vertente ambiental o uso de ativos agrícolas em atividades antrópicas é visto como benefício, quando comparado aos sucedâneos de origem fóssil. Essa visão baseiase nos ganhos potenciais que estes proporcionam em termos de caráter de renovabilidade, e de balanço de carbono. No entanto, é fundamental não perder de vista que oconsumo indireto de recursos não renováveis (para, por exemplo, as produções de fertilizantes, agroquímicos e combustíveis), o aporte de agentes tóxicos à água e ao solo, a ocupação e transformação do solo, e a alteração da biodiversidade local, são também aspectos inerentes, e negativos, da mesma opção.

Há muitos estudos sobre reaproveitamento de palha disponíveis na literatura técnica. No entanto, essas abordagens concentram esforços principalmente no caráter termodinâmico dos processos de produção (FILHO e BADR, 2004; HASSUANI et al, 2005; SARTORI e FLORENTINO, 2007; ENSINAS, 2008; SEABRA, 2008; DIAS et al 2009; MOTA et al, 2009; DANTAS, 2010; OLIVÉRIO e FERREIRA, 2010; PELLEGRINI et al, 2010;SOUSA e MACEDO, 2010; DIAS et al 2011;PELLEGRINI e OLIVEIRA JR, 2011; SEABRA e MACEDO, 2011; LINERO, 2012; CARDOSO et al, 2013; LEAL, 2013).

Quando a mesma questão é investigada no mérito ambiental as análises restringem-seà magnificação de emissões atmosféricas (LORA e TEIXEIRA, 2001; RIPOLI e RIPOLI, 2009). Ainda, se uma verificação ambiental de amplitude sistêmica foi realizada (SUGAWARA, 2012; CALDEIRA-PIRES et al, 2013; GIL et al, 2013; GUERRA et al, 2014; 
GUERRA, 2014; MILANEZ et al, 2014; SIGNOR et al, 2014; SILVA et al, 2014) esta ocorreu para condições bem definidas de utilização de palha.

O levantamento em questão não identificou, portanto, pesquisas voltadas à avaliação do desempenho ambiental da cogeração de energia elétrica a partir da queima de palha envolvendo diferentes condições de operação do sistema e adições incrementais dessa biomassa, a qual se encontrasse inclusive em condições diversas.

O presente estudo se propôs a preencher, ainda que em parte, essa lacuna. Para tanto, fez uso de uma abordagem conjugada, em que se buscou coordenar de forma sinérgica, a aplicação de duas técnicas: a Análise Energética, que está fundamentada em conceitos termodinâmicos; e a Avaliação de Ciclo de Vida (ACV), a qual, por essência, se atém a compor diagnósticos de desempenho ambiental de sistemas antrópicos.

Com esta investigação de ordem acadêmico-científica espera-se dar uma contribuição para que os setores sucroalcooleiro, e de planejamento energético, possam dispor de mais subsídios para seguir atuando de maneira proativa, consciente e responsável sobretudo, no tocante ao trato da variável ambiental, dentro da interface que claramente se estabeleceu entre ambos. 


\section{OBJETIVOS}

Tendo em vista a problemática apresentada no capítulo anterior, este estudo se propõe, em termos de objetivo geral, a verificar os efeitosambientaisde adições sucessivas de palha de cana-de-açúcar na cogeração de energia elétrica.

Como propósitos adicionais, destacam-se ainda como interesses complementares do mesmo esforço de pesquisa:

- Elaborar um diagnóstico de avaliação do desempenho ambiental da exportação de eletricidade associada à produção de etanol;

- Juntar subsídios que permitam incorporar a variável ambiental a ações de planejamento energético para as quais o modal em análise seja parte integrante; e,

- Contribuir para o Banco de Dados brasileiro de apoio à elaboração de estudos de Avaliação de Ciclo de Vida. 


\section{REVISÃO BIBLIOGRÁFICA}

\subsection{Cana-de-açúcar, etanol e eletricidade}

\subsubsection{Dados da produção e mercado}

O Brasil é o maior produtor mundial de cana-de-açúcar e açúcar, além de ocupar o segundo posto no ranking internacional de produção de etanol atrás apenas dos Estados Unidos (RFA, 2016). Estes desempenhos ampliam as perspectivas do país em termos de captação de divisas junto aos mercados externos de alimentos e biocombustíveis (MAPA, 2015).Segundo a CONAB (2016), a estimativa para a safra 2016/2017 é que de que o Brasil atinja o patamar de 691 milhões de toneladas (Mt) de cana-de-açúcar, condição que, caso atendida, projetará um crescimento de 3,8\% em relação à safra anterior. Dos principais estados produtores do Centro-Sul do Brasil, São Paulo, Goiás, Minas Gerais, Paraná, Mato Grosso e Mato Grosso do Sul, apenas os dois últimos acusaram queda na produção de cana no período.

Em São Paulo, observou-se crescimento absoluto de pouco mais de 14 mil toneladas (kt) entre as safras. O acréscimo se justifica devido: (i) as condições climáticas registradas nos últimos meses serem bastante favoráveis ao desenvolvimento das lavouras; e (ii) ao excesso de chuva ocorrido no transcurso da safra passadaque dificultou - e em certas zonas, até impediu - a colheita da cana (CONAB, 2016).

Em 2016/2017 a área colhida foi pouco superior a 9,0 milhões de hectares (Mha), um aumento de 4,8\% com relação ao que ocorreu no período anterior. Uma parte desse avanço é resultado da cana bisada da safra 2015/2016. A cana bisada é aquela cuja colheita ocorreu na safra seguinte àquela em que ocorreu o plantio por falta de tempo, ou mesmo, devido a condições climáticas adversas. Essa cana passa, portanto, por dois ciclos de desenvolvimento (meses chuvosos de outubro a março). Por conta disso, apresenta brotos laterais isoporizados, com mais açúcares invertidos e, consequentemente, com menor potencial de produzir álcool e açúcar (DUFT, 2016).

De acordo com Cortez (2010), a época ideal para colheita da cana ocorre 12 meses após o corte da soca, período em que a planta cresce e matura. $\mathrm{Na}$ visão do autor, a cana bisada é um efeito indesejado, que se manifestaem virtude de problemas genéticos cujo aparecimento se dá no transcorrer da safra. Para Cortez, afalta de planejamento adequado das usinas para realizar a colheita pode intensificar a incidência deste problema. 
Outras causas do crescimento da área colhida em São Paulo foram: o aumento de área própria de algumas unidades de produção, e a expansão da lavoura sobre uma área produtiva existente no estado, que outrora já fora utilizada para esse mesmo cultivo, mas que há alguns anos encontrava-se desativada (CONAB, 2016).

Em termos de distribuição geográfica, São Paulo ocupa papel de destaque na indústria sucroalcooleira (Gráfico1), respondendo por 4,7 Mha, ou seja, pouco mais de $52 \%$ da área total de cultivo de cana do país. A este se seguem Goiás, Minas Gerais, Paraná, Mato Grosso do Sul, Alagoas e Pernambuco. Juntos, todos esses estados totalizam cerca de $92 \%$ da produção nacional do ativo agrícola (CONAB, 2016).

Gráfico 1 - Percentual de área total de cana-de-açúcar por Unidade da Federação

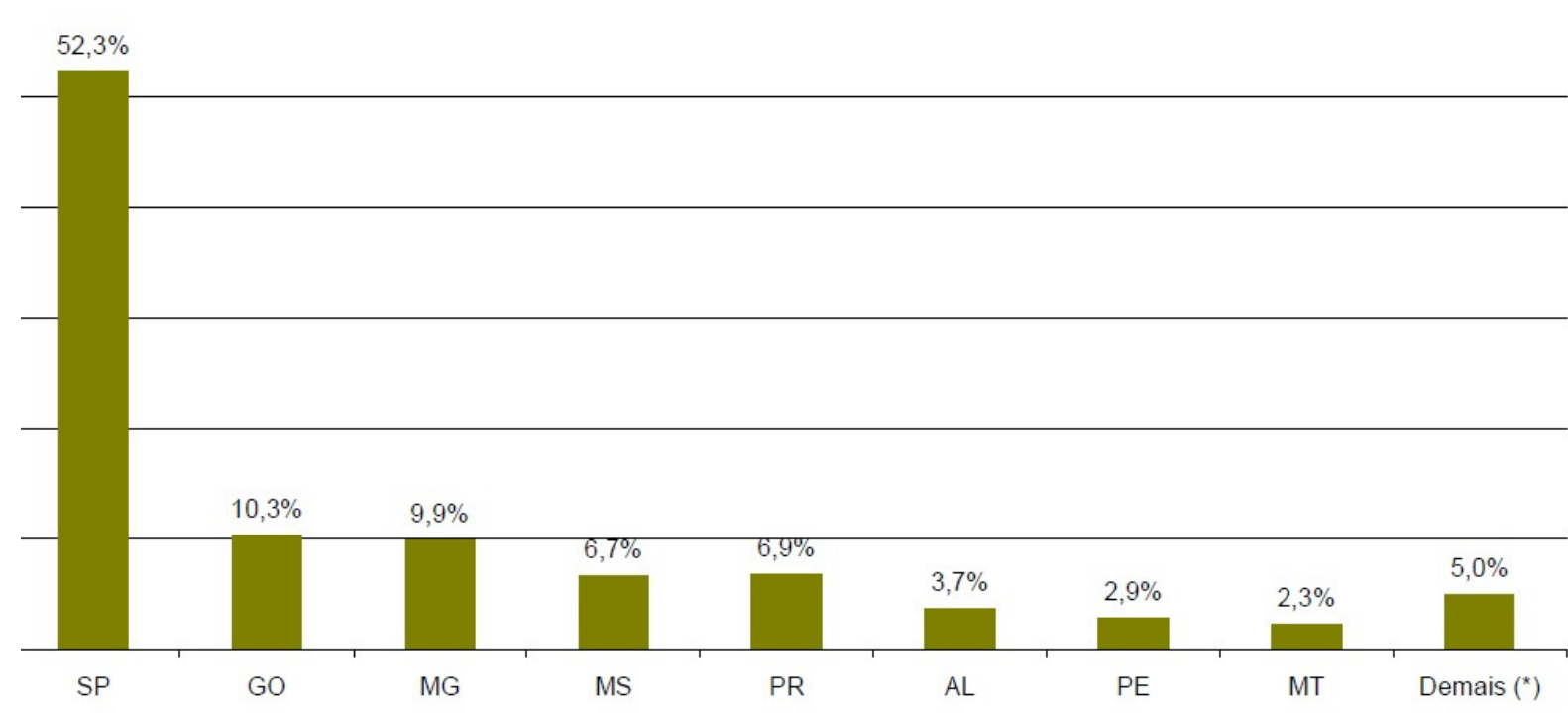

Amazonas, Bahia, Ceará, Espírito Santo, Maranhão, Pará, Paraíba, Piauí, Rio de Janeiro, Rio Grande do Norte, Rio Grande do Sul, Rondônia, Sergipe e Tocantins

Fonte: CONAB (2016)

A produtividade média estimada para todo o país na temporada 2016/2017 é de 76,2t/ha. A redução de 1,0\%, em relação à safra anterior (76,9 t/ha), é reflexo da redução de desempenho observada no Centro-Sul (São Paulo inclusive teve queda de 1,6\%), região na qual as lavouras alcançaram recordes de produtividades no período anterior (Gráfico 2). De qualquer forma, no Nordeste há expectativa de recuperação do potencial produtivo da cana, depois de a região sofrer com más condições climáticas em 2015/2016, sem poder sequer 
mitigar esses efeitos devido ao baixo nível tecnológico existentepara manejo e colheita (CONAB, 2016).

Gráfico 2 - Perfil comparado de produtividade (t/ha) de cana-de-açúcar por região

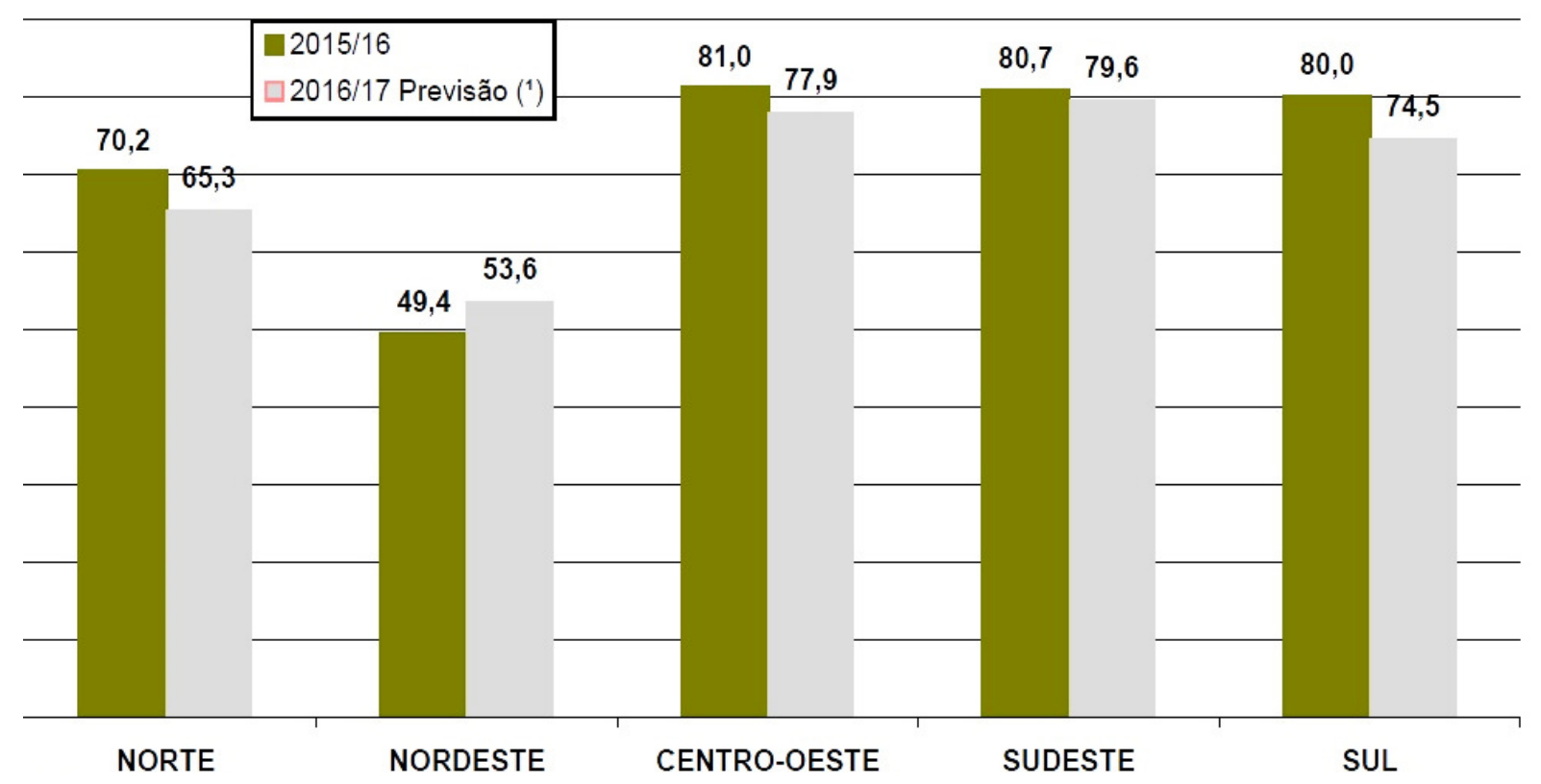

Fonte: CONAB (2016)

São Paulo lidera o ranking dos estados produtores de cana quanto à produtividade agrícola. O estado registrou um aumento acumulado de 1,3\% neste índicena segunda quinzena de julho de 2016.Uma análise mensal revela, porém, crescimento menor(de 0,60\%) entre Julho de 2016 (86,3 t/ha) e o mesmo período de 2015 (85,8 t/ha) (UNICA,2016).

Aprodução brasileira de açúcar elevou-se em 44\% entre as safras 2005/06 e 2010/2011, alcançando naquela ocasião 38 Mt. Esse limite foi mantido até a safra 2013/2014, se reduzindo para menos de 35 Mt nas duas edições seguintes. No período 2015/16 houve inclusive uma redução de 5,8\% no volume produzido, que chegou a 33Mt. Para a safra 2016/2017 espera-se um reaquecimento do mercado com retorno ao patamar de 38Mt. A previsão está baseada na forte expectativa de evolução na área plantada. Seis estados da federação devemresponder por este expressivo resultado: São Paulo, Minas Gerais, Paraná, Goiás, Alagoas, e Mato Grosso do Sul (CONAB, 2016).

Com relação aos subprodutos, há divergência entre as previsões da CONAB e aquelas feitas pela UNICA. A primeira instituição infere que o ATR (Açúcar Total Recuperável) médio da cana nesta safra seja de $130 \mathrm{~kg} / \mathrm{t}$ de cana-de-açúcar $\left(\mathrm{t}_{\mathrm{c}}\right)$, portanto mais baixo do que 
o obtido para a safra anterior $\left(138,8 \mathrm{~kg} / \mathrm{t}_{\mathrm{c}}\right)$. Desse quadro decorreria uma redução drástica de coprodutosderivados da cana, que são os casos específicos de açúcar, bagaço, melaço, vinhaça, óleo fúsel, álcool bruto, torta de filtro, e levedura seca.

No caso específico do açúcar, a agência estima queda de $2,8 \%$ da produção com relação ao ano anterior, ou seja, 617 kt (CONAB, 2016). Já a UNICA contabilizaelevação do ATR médio global, motivado principalmente por contado desempenho apresentado pelas lavouras paulistas no período (UNICA, 2016).

O elevado desempenho em termos de produtividade agrícola é apenas uma das razões da liderança do estado de São Paulo em termos de produção de cana. A outra razão, talvez ainda mais conclusiva para justificar esta posição, mesmo que guarde uma correlação biunívoca com a primeira é o volume de produção.

Tal como está descrito no diagrama do Gráfico 3 o estado acumulou, individualmente, mais de 55\% da produção nacional na safra 2015/2016. Esse desempenho, que corresponde ao dobro da somatória das performances de Goiás, Minas Gerais, e Mato Grosso do Sul estados que se seguem a São Paulo neste ranqueamento -, baseia-se em três fatores: (i) substituição maciça de áreas de pastoreio e de outros cultivos por lavouras de cana-de-açúcar; (ii) uso de engenharia genética avançada para formulação de cultivares que estejam plenamente adaptados às condições edafoclimáticas, de solo e relevo da região; (iii) adoção de mecanização não apenas para semeadura e tratos culturais, mas principalmente, para a colheita, motivado por questões ambientais e de saúde ocupacional associadas à queima da palha (CORTEZ, 2010).

Gráfico 3 - Produção de cana-de-açúcar por estado

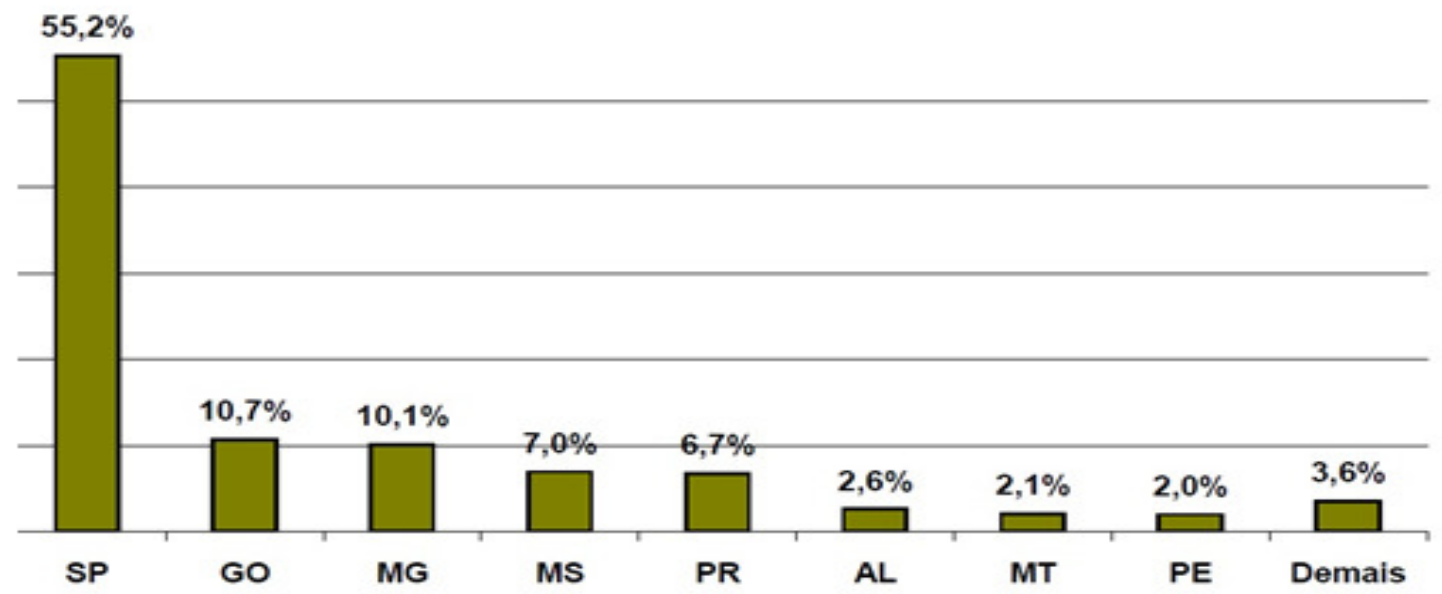

Fonte: CONAB (2016) 
O aumento no preço dos combustíveis vem mantendo aquecida a demanda por etanol nos últimos meses. O preço do açúcar também tem sido beneficiado pela conjuntura econômica internacional, devido à queda daprodução de importantes países produtores como Tailândia e China. Em ambos os casos a redução de oferta deve-se àestiagem queafetou significativamente a produtividade da cana naqueles países. Em termos de conversão de cana em produto final, a safra 2016/2017 projeta perfil mais equilibrado que os demonstrados em edições anteriores, com relação de distribuição percentual de 54:46 entre açúcar e etanol (UNICA, 2016).

A produção brasileira de etanol total na mesma safra deverá ser de aproximadamente 30 bilhões de litros, valor inferior àquelealcançado pelo exercício anterior em $0,40 \%$ (121 milhões de litros). Asregiões Centro-Oeste, Nordeste e Norte podem ser apontadas como principais responsáveis pelo decréscimo de desempenho. O volume produzido de etanol anidro, cuja aplicação mais comum é a mistura com gasolina, será aumentado em 4,7\% com relação ao resultado obtido em 2015/2016 de 11,2 bilhões de litros. Essa diferença deve ser proporcionada por intensificação da produção de destilarias autônomas e anexas localizadas na Bahia, no Mato Grosso do Sul, em Goiás, Minas Gerais, São Paulo e Paraíba.

Para o etanol hidratado, utilizado nos veículos flex-fuel, prevê-se aumento mais discreto, de 3,4\% da produção (649 milhõesde litros) da safra passada para esta. Esse ganho se justifica em virtude do aumento de produção de Alagoas, Rio Grande do Norte, Maranhão, Espírito Santo e Rio de Janeiro, estados que tradicionalmente detêm menores índices na produção do combustível.

Como já seria de se supor, a produção de etanol está concentrada no Sudeste do Brasil. De acordo com estimativas feitas pela $\mathrm{CONAB}$, a região irá contribuir com pouco mais de $60 \%$ do total produzido no país na safra 2016/2017 (Gráfico 4), um desempenho que inclusive supera o doano anterior em 1,8\%. Os mesmos levantamentosestabelecem o ranking dos demais envolvidos nesse mercado com a seguinteordem: Centro-Oeste; Sul e Nordeste, que estariam virtualmente empatados; e Norte, com uma participação mais discreta (CONAB, 2016).

Encerrada a moagem de cana-de-açúcar naregião Centro-Sul do Brasil apenas algumas usinas seguem produzindo eletricidade a partir de bagaço, ou de fontes alternativas de biomassas. Estatísticas realizadas pela Câmara de Comercialização de Energia Elétrica 
(CCEE) parao período compreendido entre Janeiro e Julho de 2016 dão conta, porém, que a cogeração energética realizada a partir dessa classe de matéria-prima aumentou em pouco mais de 7,0\% em todo o país, quando comparada com igual intervalo de tempo no ano anterior (CCEE, 2016).

Gráfico 4 - Produção total de etanol por região do Brasil

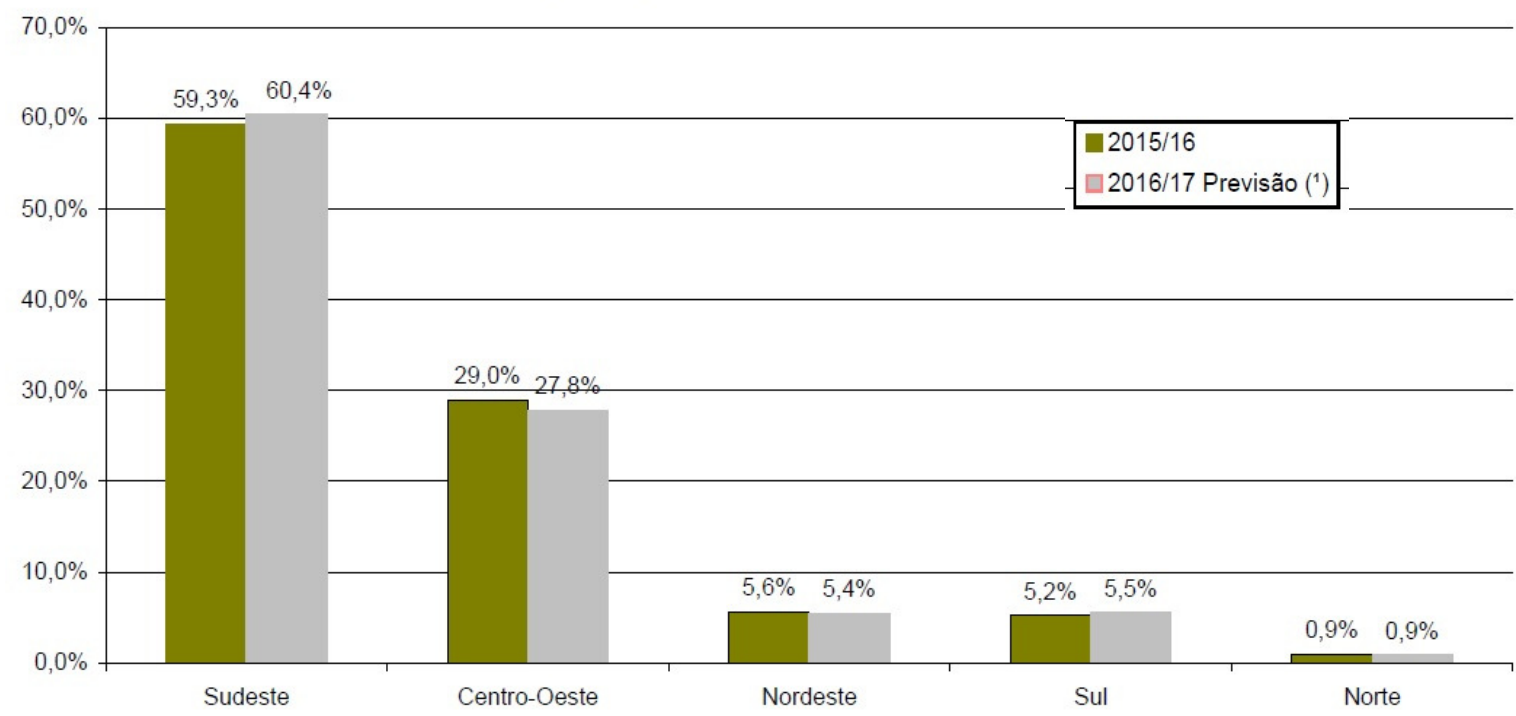

Fonte: CONAB (2016)

Apesar de expressiva, a maior parte da contribuição do setor não manteve o mesmo perfil de desempenho ao longo dos meses que se seguiram. Isso porque o ritmo de produção observadonasduas primeiras semanas de 2016 foi conseguido com estoques de matéria-prima (bagaço e palha) remanescentes de 2015. À época, o preço da energia no mercado atingiu a marca recorde de 822,00 R \$/MWh, valor teto alcançado no período pelo Preço de Liquidação de Diferenças (PLD), que serve de referência para o mercado livre do insumo.Durante o ano de 2016, vigorou um novo valor teto de remuneração para o produto - 388,00 R $\$ / \mathrm{MWh}$ - que acabou por refrear aquele movimento de ascensão econômica.Isso ocorreu porque um PLD tão atraente acabou inflacionando um mercado algo recente (compra e venda de biomassa) surgido dentro do setor sucroalcooleiro diante de oportunidadesfavoráveis de remuneração quanto aquelaspropagadas pelo cenário de 2015 (BATISTA, 2015).Apenas a título de ilustração de como oscilou este mercado, em Agosto de 2016 a energia atingiu o patamar de 117,44 R\$/MWh (CCEE,2016)

A despeito do aumento de capacidade instalada, a geração efetiva de energia elétrica em 2015 está condicionada a alguns fatores como: (i) oferta de cana-de-açúcar; (ii) ganhos de 
eficiência energética das usinas; (iii) investimento em aproveitamento da palha; e (iv) do preço da biomassa adquirida junto a terceiros. Essas questões influenciam diretamente a viabilidade donegócio de exportação de eletricidade, cuja gestão, expectativas e até mesmo, as limitações, variam de usina para usina.

Algumas mudanças nos leilões do mercado regulado realizados pela Agencia Nacional de Energia Elétrica (ANEEL) tendem a recompor, ainda que em parte, a atratividade do negócio para as usinas. Atendendo às demandas do setor, o Governo Federal lançou um leilão exclusivo de biomassa, que ocorreu em Abril de 2015, e para o qual foram cadastrados cerca de quatro dezenas de projetos voltados ao uso de biomassa. Juntas, todas essas iniciativas perfazem cerca de 2,1 PW (Peta Watts) de potência (BATISTA, 2015).

\subsubsection{Produção de etanol e eletricidade}

\subsubsection{A cana-de-açúcar}

A cultura de cana-de-açúcar tem um papel ambiental muito importante, uma vez que o etanol, seu principal produto derivado, ao menos em termos de volumes produzidos, se apresenta como alternativa concreta para redução de emissões de Gases de Efeito Estufa (GEE) A cana-de-açúcar (Saccharum L.) é uma gramínea semiperene de bom desenvolvimento em solos aerados e com drenagem, condições para as quais exige-se que a profundidade seja superior a 1,0 metro (EMBRAPA, 2014).

O desenvolvimento da cana ocorre em dois ciclos culturais. O primeiro destes ciclos se denomina de cana-planta, e ocorre quando a planta ainda não foi exposta ao primeiro corte; sua duração pode variar de 12 a 18 meses, dependendo a variedade cultivada (CONAB, 2014). Logo após ter sido realizado o primeiro corte, inicia-se formalmente o chamado ciclo da cana-soca, cuja duração se mantêm em torno de 12 meses a despeito da espécie plantada.

A semiperenidade da cana se aplica em virtude das perspectivas de serem realizados vários cortes sucessivos sem a necessidade de replantio. No entanto, no início de cada cultivo, tanto previamente como durante a semeadura e os tratos culturais, as quantidades de ativos agrícolas como fertilizantes, agroquímicos, condicionadores de solo, e maturadores, presentes no solo devem ser recompostas, a fim de que a cultura se sustente em patamares de produtividade economicamente vantajosos. Os cortes sucessivos reduzem a resposta da cultura à aplicação desses insumos, até que após cinco (ou, no máximo, seis) eventos, seja 
necessário proceder a renovação do canavial (CONAB, 2014). A Figura 1 apresenta e descreve de maneira esquemática dos principais constituintes estruturais da cana-de-açúcar.

Figura 1 - Estrutura geral da cana-de-açúcar

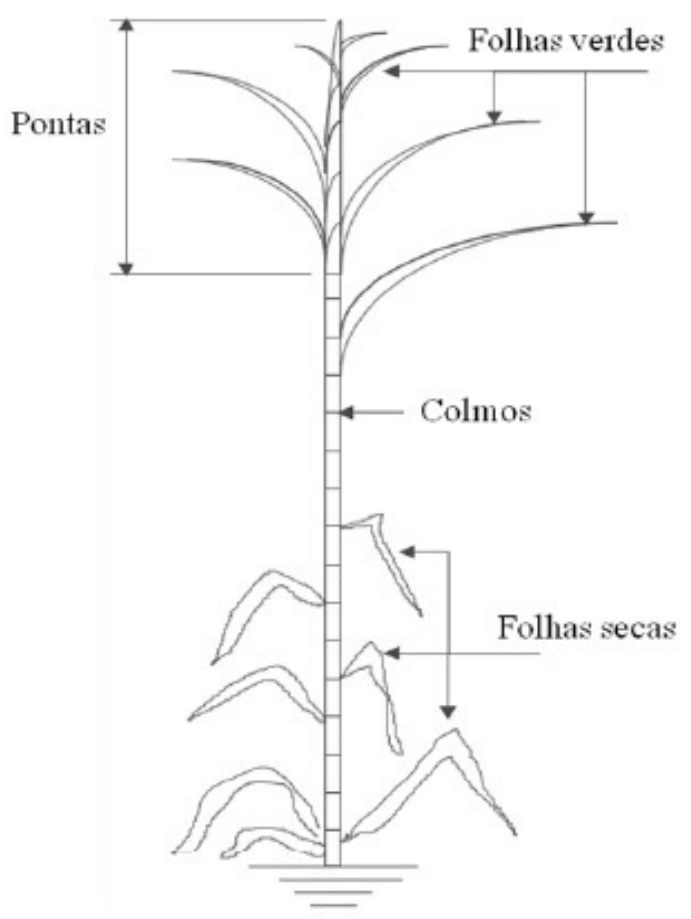

Fonte: Hassuani (2005)

A cana se divide em colmos - região na qual se concentra a maior parte da sacarose -, pontas, e folhas, chamadas genericamente de palha (ou palhada). Quando a colheita ocorre pela via manual a palha é em geral queimada a fim de viabilizar o avanço dos cortadores de cana pelo canavial para realizar a extração da planta (UNICA, 2015).

\subsubsection{Processamento da cana}

As plantas industriais que processam a cana-de-açúcar podem ser classificadas em dois grandes grupos: usinas e destilarias. As usinas (também chamadas de destilarias anexas) detêm tecnologia para gerar simultaneamente etanol e açúcar, enquanto as destilarias (ou destilarias autônomas) produzem apenas álcool. O direcionamento em favor de uma das opções de produto de uma usina depende principalmente da demanda do mercado. A decisão será influenciada também por períodos de precipitação (em duração e intensidade) que ocorrem ao longo do ano agrícola, dado que em épocas mais úmidas a sacarose na cana apresenta níveis de concentração mais baixos que naqueles de insolação constante. Nesses 
casos, de seguidos e/ou intensos intervalos de pluviosidade, é preferível potencializar a produção de etanol.

Em geral, a sacarose total contida na cana é repartida equitativamente entre as produções de etanol e açúcar; a substituição de um produto por outro pode aportar rebalanceamentos que variam entre 5,0 e 10\% (CORTEZ, 2010). Em uma usina típica, $1.0 \mathrm{t}$ cana-de-açúcar produz em média $57 \mathrm{~kg}$ açúcar, cerca de 51 L etanol anidro, $140 \mathrm{~kg}$ bagaço, e outros $140 \mathrm{~kg}$ palha, ambos em base seca (CORTEZ, 2010). No caso das destilarias a produção de etanol é proporcionalmente mais elevada; algumas dessas unidades têm capacidade de gerar até $86 \mathrm{~L}$ etanol anidro a partir da moagem de $1000 \mathrm{~kg}$ de cana (CGEE, 2009).

\subsubsection{Etanol}

Etanol ou álcool etílico são termos usados para designar uma substância orgânica, de massa molar 46,06 g/mol e fórmula química $\mathrm{C}_{2} \mathrm{H}_{6} \mathrm{O}$. O álcool empregado nas formulações de combustíveis, bebidas, produtos de limpeza, tintas, e outros bens de consumo é em geral obtido por uma rota bioquímica, caso de fermentação do açúcar da cana por Saccharomycescerevisiae, que é maciçamente praticada no Brasil; ou química, como hidratação do etileno, ou redução de acetaldeído. Como é de se supor, da primeira rota se obtém álcool de fonte renovável, enquanto dos outros arranjos de processo derivam produtos de origem fóssil. Potenciais diferenças entre as aplicações a que se destina o álcool ocorrem durante a destilação, necessária para usos que depreendem elevado grau de pureza do ativo, e nos processos de pós-produção (ou acabamento) do produto (CORTEZ, 2010).

Apesar de estar presente em diversos produtos do cotidiano, o etanol é mais utilizado atualmente no Brasil, como combustível. O caráter de sustentabilidade a ele associado, quando provindo de cana-de-açúcar em muito deriva do balanço neutro de carbono estabelecido entre a taxa de captura de gás carbônico $\left(\mathrm{CO}_{2}\right)$ da atmosfera, e aquela lançada a partir da queima do combustível em motores (operados segundo ciclo Otto), ou a queima de biomassa em sistemas de cogeração (cuja variação termodinâmica é regida pelo ciclo Rankine).

Outro benefício a ele associado reside no Coeficiente Energético $\left(\mathrm{C}_{\mathrm{e}}\right)$, que é calculado pela razão entre a quantidade de energia gerada por certa quantidade de etanol e aquela que 
foi despendidaem termos de ativos fósseis para produção do mesmototal (HAMMERSCHLAG, 2006). Segundo Macedo et al (2008) o processamento de etanol de cana-de-açúcar em um sistema que também exporta eletricidade apresenta $C_{e}=9,6$. Smeetset al (2008) projetaramque no futuro, após o ano 2030, os valores de $\mathrm{C}_{\mathrm{e}}$ para cultivos mecanizado e manual, caso esseúltimo ainda exista, poderiam variam respectivamente entre $13<\mathrm{C}_{\mathrm{e}, \mathrm{Mc}}<23$, e $14<\mathrm{C}_{\mathrm{e}, \mathrm{Mn}}<23$.

O processo de fermentação alcoólica consiste basicamente da adição de leveduras do tipo Saccharomyces cerevisiae ao caldo da cana, que foi separado da biomassa por prensagem, sofreu peneiramento para remoção de sólidos suspensos, e foi concentrado, para remoção de água (e consequentemente, concentração do teor de açúcares).

De acordo com CGEE (2009), o grau de extração dos açúcares durante a moagem pode variar entre $94-98 \%$. A ação dos microrganismos provoca cisão das moléculas de glicose $\left(\mathrm{C}_{6} \mathrm{H}_{12} \mathrm{O}_{6}\right)$ transformando-as em etanol $\left(\mathrm{C}_{2} \mathrm{H}_{5} \mathrm{OH}\right)$. Há ainda liberação de $\mathrm{CO}_{2}$ para o ambiente, o qual pode ser considerado produto complementar da reação por encontrar mercado junto ao segmento alimentício (CORTEZ, 2010).

O produto principal da fermentação é um substrato açucarado, conhecido como vinho, que deverá ser centrifugado para recuperação das leveduras antes de seguir para a destilação. A destilação do vinho é realizada em duas colunas de pratos. Da primeira delas obtém-se álcool com concentração variando entre $45^{\circ}-50^{\circ}$ GL (fração em volume), conhecido como flegma. A outra corrente que emana do processo, a vinhaça, deixa a unidade como efluente líquido.

Segundo Sousa apud Vianna (2006), os teores elevados de matéria-orgânica e potássio (K) da vinhaça a credenciam como fonte suplementar de nutrição da lavoura de cana, a ser aplicada por meio de fertirrigação. No entanto, CGEE (2009) sinaliza que a dosagem de vinhaça deve ser regulada, a fim de não provocar impactos ambientais negativos no solo, nascentes e lençóis freáticos.

O flegma é conduzido para a coluna de retificação, a fim de remover água e outros extrativos que coexistem com o etanol em solução, casos de óleo fúsel e flegmaça. A operação gera como produto final álcool hidratadoa cerca de $97^{\circ}$ GL (SILVA et al, 2014).Como última etapa da fase industrial (que para certos usos seria inclusive desnecessária), o álcool hidratado sofre desidratação. Assim, o teor de água na solução se 
reduz de $5 \%_{\mathrm{v} / \mathrm{v}}$ para $0,5 \%_{\mathrm{v} / \mathrm{v}}$ condição que caracteriza o ponto de anidro. Este produto é conhecido como etanol anidro.

Os resíduos gerados durante a fabricação do etanol são em geral aproveitados, tanto no próprio processo, como em outros segmentos de transformação. O exemplo mais trivial dessa prática consiste no reaproveitamento de bagaço para geração de energias elétrica e térmica. Vinhaça e cinzas, estas últimas, coletada nas caldeiras por sistemas de controle de poluição atmosférica, retornam para o campo. A decantação do caldo, que ocorre previamente ao seu aproveitamento na fermentação, gera lodo que, posteriormente, é submetido à filtração a vácuo.

A fração líquida dessa operação retorna ao processo, ao passo que a fração sólida, conhecida como torta de filtro,tem mercado constituído como substrato para produção de ração animal, ou simplesmente retorna para a lavoura para ser aproveitada como adubo. Como fora descrito anteriormente o $\mathrm{CO}_{2}$ emitido durante a fermentação do caldo pode ser usado na confecção de bebidas gasosas; já o óleo fúsel é absorvido pelas indústrias químicas, na qual será usado em ativos para formulação de cosméticos, e de fármacos (CORTEZ, 2010).

\subsubsection{Sistema de Cogeração a partir da biomassa}

Segundo Dantas (2010) a cogeração é a fonte responsável pelo suprimento de energia térmica e eletromecânica em usinas de cana-de-açúcar. Em linhas gerais, esta consiste de um processo no qual uma fonte de energia primária alimenta uma máquina ou aparelho térmico que, por combustão, irá transformar a energia química em mecânica (trabalho de eixo).Esta, de sua parte, será a seguir convertida em energia elétrica por meio da ação de geradores.

Segundo Moran e Shapiro (2008), cogeração é o método que produzsequencialmente potência (energia elétrica e/ou mecânica) além de transferir calor (energia térmica, ou vapor do processo) para certo uso.

A possibilidade da venda do excedente energético impulsionou a busca por melhores eficiências das unidades de cogeração, potência com ciclo a vapor, cujo fluido de trabalho, a água $\left(\mathrm{H}_{2} \mathrm{O}\right)$, escoa em estado estacionário, com auxílio de bombas, através da caldeira, turbina e condensador. Observe-se que nesse arranjo, não há contato entre o fluido de trabalho e a fonte de calor (PELLEGRINI et al. 2010). 
Os ciclos termodinâmicos que são responsáveis pela geração de energia tanto elétrica, como térmica para o processo, são constituídos por caldeira, turbina, condensador, bombas, desaerador, dessuperaquecedor e purgador. A forma como cada qual desses elementos da planta de cogeração se interconecta aos demais está descrita de maneira esquemática na Figura 2.

Figura 2 -Representação de um ciclo Rankine com reaquecimento

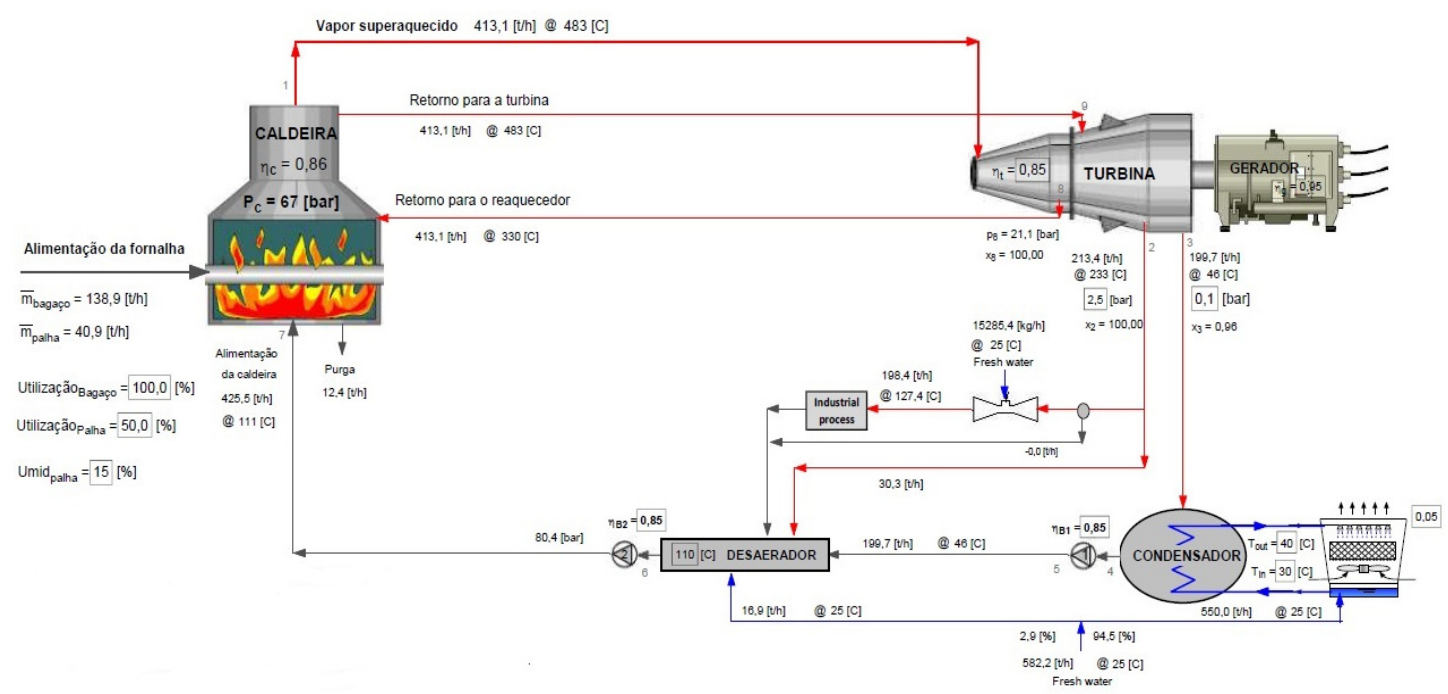

Fonte: Adaptado de Guerra (2014)

As unidades geradoras de potência instaladas nas destilarias de etanol operam segundo o ciclo Rankine. A produção de energia a partir desse arranjo considera por transformações termodinâmicas os estágios de aquecimento isobárico, expansão adiabática, condensação e produção de líquido subresfriado.

Em centrais termelétricas é usualrealizar modificações no ciclo Rankine com o objetivo de aumentar a eficiência térmica da unidade. Uma dessas adequações consiste da interrupção da expansão do vapor na turbina para adição de mais calor. A esse processo dá-se o nome de Reaquecimento (MORAN e SHAPIRO, 2008). Outras formas de promover melhorias de eficiência térmica na planta compreendem (i) o aumento da temperatura média do fluído introduzido no ciclo, e (ii) a redução da diferença de temperatura entre a fonte quente e o líquido comprimido que é alimentado na caldeira. Esse processo de aquecimento gradual do líquido recebe o nome de Regeneração (Guerra et al 2014). Uma última possibilidade seria o ciclo Resultante, que consiste da coordenação das duas variações, do que decorre um ciclo do tipo regenerativo com reaquecimento. 
A eletricidade obtida a partir da queima do bagaço é vista como importante opção para o planejamento energético nacional, uma vez que esta poderia suprir, ao menos em parte, as necessidades da população em épocas nas quais as usinas hidrelétricas sejam forçadas a reduzir sua capacidade de produção. A colheita da cana ocorre em uma época de, necessariamente, baixa pluviosidade (entre Junho a Novembro), quando os reservatórios costumam atingir seus níveis mais baixos. Dessa forma, o aproveitamento de energia contida na biomassaevitaria uma descontinuidade no fornecimento de energia elétrica (SOUSA e MACEDO, 2010).

Para Sousa e Macedo (2010), outro ponto a favor da geração de eletricidade a partir de cana reside no fato de a maior parte das usinas estarem localizadas no estado de São Paulo, uma situação que reduz perdas (e, por conseguinte, custos) de transmissão e distribuição, que são inerentes ao transporte da energia para principal centro consumidor brasileiro.

Atualmente, a eletricidade é gerada apenas pelo processamento do bagaço; com isso, um enorme potencial energético contido na palha não é ainda aproveitado. O bagaço obtido namoagem da cana é enviado para a planta de utilidades, onde será queimado nas caldeiras. Cerca de 5,0\% desse material é armazenado como reserva técnica para partida do sistema.Segundo Pellegrini (2011), os sistemas de cogeração usados na grande maioria das usinas brasileirasse compõemde caldeiras,cujo vapor gerado encontra-se superaquecido a 21 bar de pressão, e de turbinas de contrapressão (as quais o vapor de escape está a 2,5 bar). Aproximadamente $50 \%$ do vapor demandado pelo processo expandem nas turbinas de acionamento das moendas. Estes equipamentos apresentam eficiência isentrópica é inferior a $60 \%$ e consumo específico variável entre $14-16 \mathrm{~kg}$ vapor/kWh. Algumas usinas produzem vapor apressões mais elevadas (entre 42 e 66 bar), condição da qual decorre, naturalmente, uma geração excedente de eletricidade, que será comercializada em mercados livres ou regulados.

Nestes casos, é recomendável o uso que além de turbinas de contrapressão sejam usadas também turbinas de condensação a fim de se obter-se uma eficiência termodinâmica mais elevada do ciclo Rankine. Outra alternativa é fazer uso apenas de turbinas de condensação com extração. Nesse caso, o vapor excedente é enviado para a unidade de condensação na qual utiliza-se água de resfriamento em grandes quantidades (PELLEGRINI e OLIVEIRA JR, 2011). 
Cada tonelada de cana-de-açúcar requer $12 \mathrm{MWh}$ de energia para ser processada. Este total é facilmente gerado nos sistemas de cogeração instalados nas usinas. O aumento do preço da energia comercializada pelas agências públicas, que conduziu as usinas à autossuficiência e à valorização do bagaço tanto para venda, como para outros fins, foi o agente motivador das indústrias para explorar de maneira mais intensa a comercialização de excedentes de energia gerada. Tal constatação foi feita por Dantas (2010), mas permanece válida até hoje. Segundo o mesmo autor, até 2020 a biomassa de cana-de-açúcar tem capacidade de adicionar até $15 \mathrm{GW}$ de eletricidade ao sistema elétrico brasileiro. Esse aporte seria equivalente a incorporar uma nova Itaipu ao parque gerador nacional, condição que apena ratifica a importância do setor como alternativa para o suprimento da (crescente) demanda de energia do país.

Para cogerar energia nas usinas, caldeiras e turbinas trabalham sequencialmente com os geradores de energia elétrica. Hoje, quase todas as usinas e destilarias possuem um sistema de geração de vapor que opera a partir da queima do bagaço e algumas delas já vêm adicionando a palha à queima devido ao seu grande potencial energético. $\mathrm{O}$ bagaço ainda é o combustível mais utilizado, pois praticamente metade da quantidade da palha permanece nas lavouras, onde é utilizada como restos vegetais, embora haja a tendência de mudar esse conceito por questões ambientais (GUERRA, 2014).

Ripoli (2009) estimou em 7 milhões o número de cidadãos brasileiros que poderiam ser beneficiados a cada ano com energia elétrica proveniente da queima de palha. Em um estudo considerado como referência no mesmo segmento, Beeharry (2001) concluiu que a produção de energia poderia ser aumentada em até $50 \%$ caso fossem empregadas como combustíveisno ciclo de cogeração, fontes de biomassa como pontas, folhas secas e folhas verdes.

Tradicionalmente as destilarias de etanol consomem $28 \mathrm{kWh}$ de eletricidade e $500 \mathrm{~kg}$ de vapor para cada tonelada de cana processada (CGEE, 2008; MILANEZ et al, 2014). As tecnologias para cogeração tornaram-se mais eficiente com a utilização de caldeiras de alta pressão. Hoje em dia são utilizadas instalações capazes de produzir vapor superaquecido a 105 bar de pressão e $300-525^{\circ} \mathrm{C}$ de temperatura, dependendo da necessidade de energia excedente. 
Sistemas de cogeração que operam a 105 bar e $525^{\circ} \mathrm{C}$ têm potencial para produzir até $158 \mathrm{kWh} / \mathrm{t}_{\mathrm{c}} \mathrm{de}$ energia excedente, reduzindo a demanda de vapor para $280 \mathrm{~kg} / \mathrm{t}_{\mathrm{c}}$ e utilizando, além da totalidadedo bagaço disponível, também de $50 \%$ da palha produzidano campo(ou seja, $140 \mathrm{~kg} / \mathrm{t}_{\mathrm{c}}$ ). O potencial de produção de bioeletricidade de cada planta irá dependertanto do tipo, comoda configuração de operação (temperatura e pressão) dos sistemas de cogeração (KHATIWADAet al, 2012).

Prabhakar et al (2010) relatam a realização de ensaios para análise de eficiência de sistemas de cogeração que se valem exclusivamente da palha como combustível. O autor constata ter havido um acréscimo de 9,0 MW no fornecimento de energia de unidades que operam a 43 bar (abs), e de até 20 MW para sistema cuja pressão de operação foi elevada até 87 bar (abs). O consumo de vapor de processo em ambos os casos foi reduzido para $350 \mathrm{~kg}$ $/ t_{\mathrm{c}}$.

O sistema de cogeração é responsável por quase $65 \%$ da exergia total destruída na usina, a qual é da ordem de $460 \mathrm{kWh} / \mathrm{t}_{\mathrm{c}}$. Segundo Pellegrini (2011), a caldeira é a principal fonte desse efeito, com uma contribuição de 97\%. Guerra (2014) sustenta que as turbinas mais modernas usadas nas usinas brasileiras podem alcançar $88 \%$ de eficiência isentrópica, quando o vapor emanado da caldeira encontra-se a $520^{\circ} \mathrm{C}$ e 120 bar. Para Pellegrini (2011), excesso de palha utilizado em geral nesses casos impõe grandes perdas exergéticas à etapa de moagem.

Olivério (2010) aponta que a introdução de 50\% de palha (para uma moagem de 500 t/h de cana) no sistema de cogeraçãoresulta em uma produção excedente de energia de até 84 MW. Para uma situação hipotética em que fosse utilizada $100 \%$ de palha, o excedente projetado seria de $112 \mathrm{MW}$. No entanto, o mesmo autor alerta para o risco de exposição da integridade física do sistema, proporcionado por incrustação por acumulo de sílica, ou corrosão, dada a presença de cloretos, em situação em que a adição de palha supere $50 \%$ da quantidade gerada no campo.

Seabra (2011) e Dias et al (2011) estimam que quando 40 - 50\% da palha disponível no campo é utilizada como combustível adicional ao bagaço, o saldo total de energia elétrica a partir da queima da cananas usinas pode variar de 468 - $670 \mathrm{MJ} / \mathrm{t}_{\mathrm{c}}$, (ou de $130-186$ $\mathrm{kWh} / \mathrm{t}_{\mathrm{c}}$ ). 


\subsubsection{Palha da cana-de-açúcar e seu aproveitamento como combustível}

As atividades de colheita, limpeza e transporte da cana-de-açúcar geram expressivas quantidades de restos vegetais, que como consequência do método de colheita (em especial, da colheita manual) são queimados na própria lavoura. Esse quadro trouxe implicações bastante negativas para o setor, sobretudo quando os desempenhos ambientais das produções de açúcar e álcool passaram a ser questionados. Como reação a essa posição desfavorável foi criado o Protocolo Agroambiental do Setor Sucroalcooleiro.

O protocolo, firmado em meados de 2007, entre a ÚNICA - neste ato representando a indústria paulista produtora de açúcar, etanol e bioeletricidade - e o Governo do Estado de São Paulo antecipa os prazos legais para encerramento da colheita da cana-de-açúcar com queimada (UNICA, 2015). A Figura 3 compara, em termos temporais, a evolução desse processo quando o mesmo é gerido sob as bases do Protocolo Agroambiental, com aquela que fora originalmente estabelecida na Lei Estadual 11.241 - 2002, promulgada com o intuito de atender aos mesmos propósitos.

Abandonando a prática das queimadas pré-colheita, parte da palha deixada sobre o terreno em decorrência da colheita mecanizada poderia ser usada como fonte de energia em sistemas de cogeração. O restante permanece como matéria vegetal remanescente no solo com os intuitos de repor nutrientes e dar proteção à planta e ao solo de efeitos naturais adversos como erosão, desgaste, compactação e assoreamento.

Como mencionado anteriormente, cada tonelada de cana gera $140 \mathrm{~kg}$ de palha em base seca. Hassuani (2005) e Cortez (2010) advertem para a importância de que ao menos metade desse material seja deixado no campo pelos motivos apontados no parágrafo anterior.

Diversas alternativas de recolhimento da palha já foram investigadas. Entre aquelas mais bem aceitas estão a colheita integral da cana-de-açúcar, o fardo cilíndrico, o picado a granel, e o fardo prismático. Para Guerra (2014), o método que apresenta menores custos específicos é o recolhimento da palha por meio de enfardamento. 
Figura 3 - Prazo para eliminação da queima da palha no estado de São Paulo

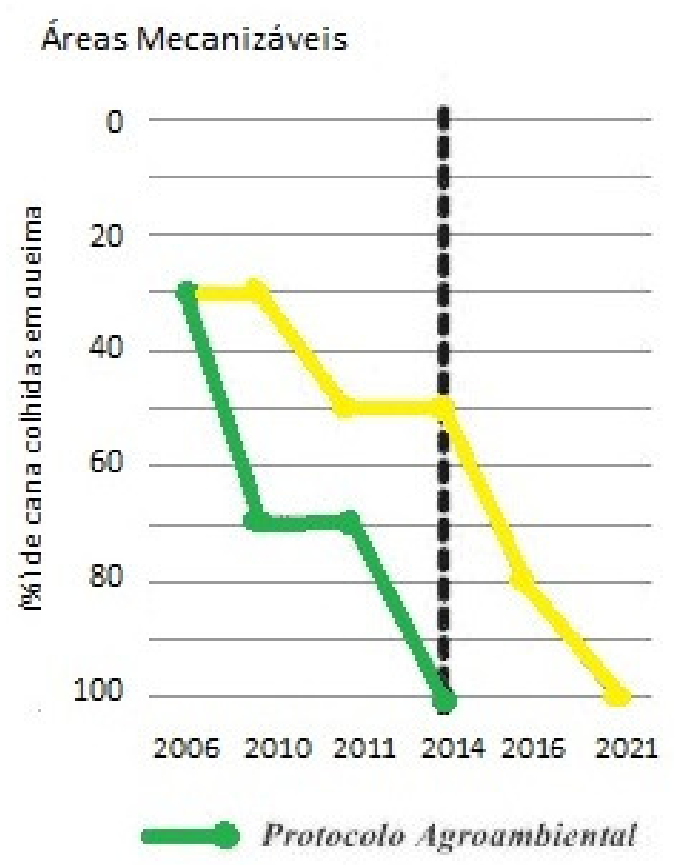

Áreas não-Mecanizáveis

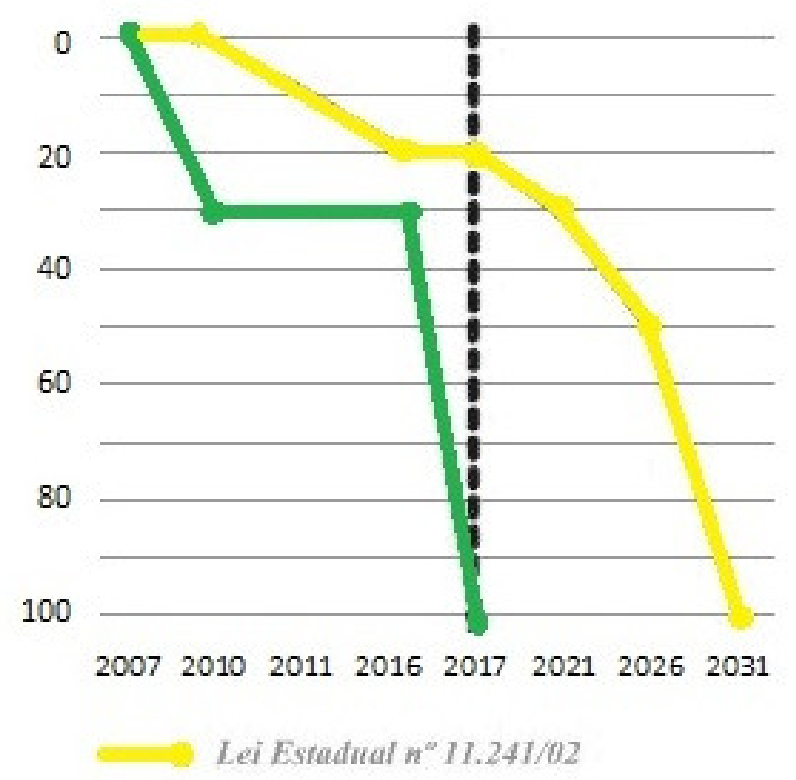

Fonte: UNICA (2015)

Existe pouca informação sobre a operação de caldeiras que utilizam a palha da cana, bem como, de problemas e de ações mitigatórias que fossem relacionadas a tal aproveitamento. De qualquer forma, sabe-se que elevados teores de terra incorporada à palha podemoriginar depósitos sobre as superfícies dos trocadores de calor da caldeira comprometendo seriamente sua operação (CGEE, 2009). Outro problema já diagnosticado refere-se às elevadas quantidades de óxidos presentes na palha em comparação ao bagaço. Por conta disso, o uso da palha pode expor o funcionamento dos equipamentos que tenham contato direto com esse material. A caldeira aparece novamente como foco mais crítico desse distúrbio. Por se tratar de um vaso de pressão esta pode sofrer com deposição de cinzas em seu interior dependendo das temperaturas interna da instalação, e de fusão do material (CTC, 2014).

De acordo com dados do CGEE (2009), experimentos conduzidos em usinas brasileiras mostraram baixa efetividade em termos de geração de energia, quando quantidades superiores a $25 \%_{\mathrm{w} / \mathrm{w}}$ do total de palha gerada no campo foram adicionadas ao bagaço. No entanto, Sartori (2007) e um registro anterior do próprio CGEE (2008) defendem que o uso de palha em vasos de pressão pode chegar até a $50 \%$ w/w da capacidade produção na etapa agrícola sem que haja risco de comprometer a integridade física de seus elementos internos da 
caldeira e de outras unidades e equipamentos que compõem o ciclo Rankine. Guerra (2014) e Milanez et al (2014) recomendam que a palha seja cominuída previamente ao uso na cogeração.

Com relação a emissões atmosféricas existe consenso entre os especialistas de que a utilização de biomassa leva a baixas emissões líquidas de carbono, na forma de $\mathrm{CO}_{2}$, o qual seria inclusive desconsiderado a partir da adoção do conceito de carbono neutro (EVANS et al, 2010). O conceito de carbono neutro está diretamente ligado ao ciclo de carbono na atmosfera. Trata-se do produto (ou processo) cujo balanço de emissões é nulo (ou mesmo, negativo) em que os lançamentos para o ar que derivam de carbono e ocorram na forma de $\mathrm{CO}_{2}$ dito, biogênico, foram, portanto, integralmente compensados. Esta neutralização se dá por meio do plantio da cana (que durante o crescimento captura $\mathrm{CO}_{2}$ do ar para incorporar o carbono à sua estrutura). Outros Gases de Efeito Estufa (GEE) como o metano $\left(\mathrm{CH}_{4}\right)$ e o óxido de dinitrogênio $\left(\mathrm{N}_{2} \mathrm{O}\right)$, são lançados no ambiente em quantidades menores - de $2,0 \%$ ou menos do total de emissões do sistema (EVANS et al, 2010).

Com relação às emissões a partir do solo, a abordagem mais usual volta a ser de carbono neutro. Nesse caso, as emissões de $\mathrm{CO}_{2}$ do solo não são contabilizadas para efeito de inventário de emissão de GEE na agricultura, uma vez que este gás é proveniente da respiração das raízes das plantas e de atividade microbiana de decomposição, condição que caracteriza a circulação de carbono no ambiente (EVANS et al, 2010). Signor (2014) adverte para o fato do balanço de carbono ser elaborado considerando-se variações nos estoques desse elemento no solo ao longo do tempo, independentemente das condições de manejo a que a colheita esteja submetida.

\subsubsection{Valor energético}

Olivério (2010) relata que energia contida na cana não foi integralmente explorada até 2003. À época as usinas brasileiras atinham-se apenas a extração do valor energético contido no caldo de cana e negligenciando o potencial que está intrínseco à biomassa (bagaço e palha).

Ao restringir-se ao suco, apenas a terça parte da energia contida na cana é utilizada de forma eficiente. $\mathrm{O}$ autor afirma ainda que a energia associada ao bagaço era subutilizada pelo fato de a eficiência dos sistemas de cogeração disponíveis no período ser inferior ao patamar 
de 50\%.Em relação à palha, este potencialera completamente desperdiçado pelo fato da tônica ser de queimada no campo pré-colheita.

Somando-se as três componentes energéticas contida em 1,0 t de cana será possível obter-se um potencial correspondente a 1,2 de barris de óleo cru. Mantida essa relação, um hectare de cana cultivada pode gerar de 95 a 114 barris desse recurso fóssil. Ao expressar em termos energéticos a produção nacional de cana-de-açúcar de 2010, Olivério obteve 1,17Ecal (Exa calorias) disponíveis. Este total representa $80 \%$ da energia fóssil consumida na Alemanha, ou $42 \%$ da demanda do Japão. Destaque-se por fim que em níveis normais de umidade - de $50 \%_{\mathrm{w} / \mathrm{w}}$ para o bagaço, e $15 \%_{\mathrm{w} / \mathrm{w}}$ para palha - os conteúdos energéticos dessas biomassas atingem respectivamente 7.560 e $12.960 \mathrm{~kJ} / \mathrm{kg}$ (CTC,2014).

\subsubsection{Impactos ambientais gerados pelo cultivo de cana}

A agroindústria da cana-de-açúcar pode causar diversos impactos sobre o meio ambiente. Segundo Mota (2009), dentre os principais desdobramentos adversos derivados dessa prática é possível citar:

- Redução da biodiversidadedevido ao desmatamento e a implantação da monocultura;

- Expansão da fronteira agrícola sobre áreas de floresta nativa;

- Contaminação do solo, águas superficiais e subterrâneas por efluentes, devido à adoção de prática de adubação química, fertirrigação com vinhaça, aplicação de agroquímicos e dosagem de maturadores e corretivos de solo de origem mineral;

- Compactação e desgaste do solo em virtudedo tráfego de máquinas pesadas durante o plantio, tratos culturais e principalmente, da colheita;

- Assoreamento de corpos d'água em função da erosão do solo, e adoção de práticas de desflorestamento (muitas vezes ilegais) sobrematas ciliares;

- Alteração da qualidade do ar e do microclima local por conta de queimadas;

- Emissão de fuligem e GEE em decorrência da queima de palha no campo antes e durante a colheita;

- Danos à flora e fauna causados, sobretudo, pela perda de habitats naturais originada também por conta daqueimada de palha sem controle; e, 
- Aumento de poluição atmosférica a partir do consumo de dieselem máquinas agrícolas por ocasião de operações de semeadura e plantio, tratos culturais, e transporte de cana, bem como, na colheita, quando esta ocorre com auxílio de mecanização.

\subsection{Avaliação do Ciclo de Vida (ACV): conceito, aplicações e método}

Embora as primeiras ideias de análise de ciclos de vida de produtos remontarem ao século XIX, elas apenasse consolidaram no século XX. A metodologia de ACV foi então elaborada, tendo como base diversas aplicações em países ao redor do mundo. A Society of Environmental Toxicology and Chemistry (SETAC), por intermédio de organizações "irmãs" nos Estados Unidos e na Europa, desempenhou papel fundamental no desenvolvimento e na padronização da metodologia da $\mathrm{ACV}$ mediante a agregação de praticantes e usuários (WEIDEMA, 1997).

De acordo com Rojas (2012), “a Avaliação de Ciclo de Vida (ACV) é uma ferramenta analítica usada para estimar, avaliar e interpretar impactos ambientais atribuíveis ao ciclo de vida de um produto. ACV é uma técnica da área de ecologia industrial padronizada pela Organização Internacional para Normalização (ISO) nas séries da norma ISO 14040, que se propõe a dar sustentação a decisões nos segmentos de políticas públicas, design de produtos, compras, melhorias nos processos produtivos e projetos sempre dentro de uma perspectiva ambiental".

Segundo Caldeira-Pires et al (2002) a norma ISO 14040 define ACV como compilação dos fluxos de entradas e saídas e avaliação dos impactos associados a um produto ao longo do seu ciclo de vida. A mesma diretriz interpretao termo 'ciclo de vida' como estados consecutivos e interligados de um produto, desde a extração de matérias-primas ou transformação de recursos naturais, até a deposição final do produto na natureza.

A ACV é um método estruturado, abrangente e padronizado internacionalmente. Quantifica emissões pertinentes e recursos consumidos, bem como, estimaa magnitudede impactos ambientais e sobre a saúde, relacionados com questões de recursos e de esgotamento que estão associados a quaisquer bens ou serviços (VILELA et al, 2013).

A ACV do produto completo desde a extração de recursos, produção, uso e reciclagem, até a eliminação dos resíduos está ilustrada pela Figura 4. Os estudos de ACV podem indicar 
incongruências e contrassensos ocorridos durante a tentativa de se tentar resolver um problema ambiental. Não é incomum que uma ação nesse sentido origine acréscimo em outros impactos ambientais.

Figura 4 - Representação esquemática genérica do ciclo de vida de um produto

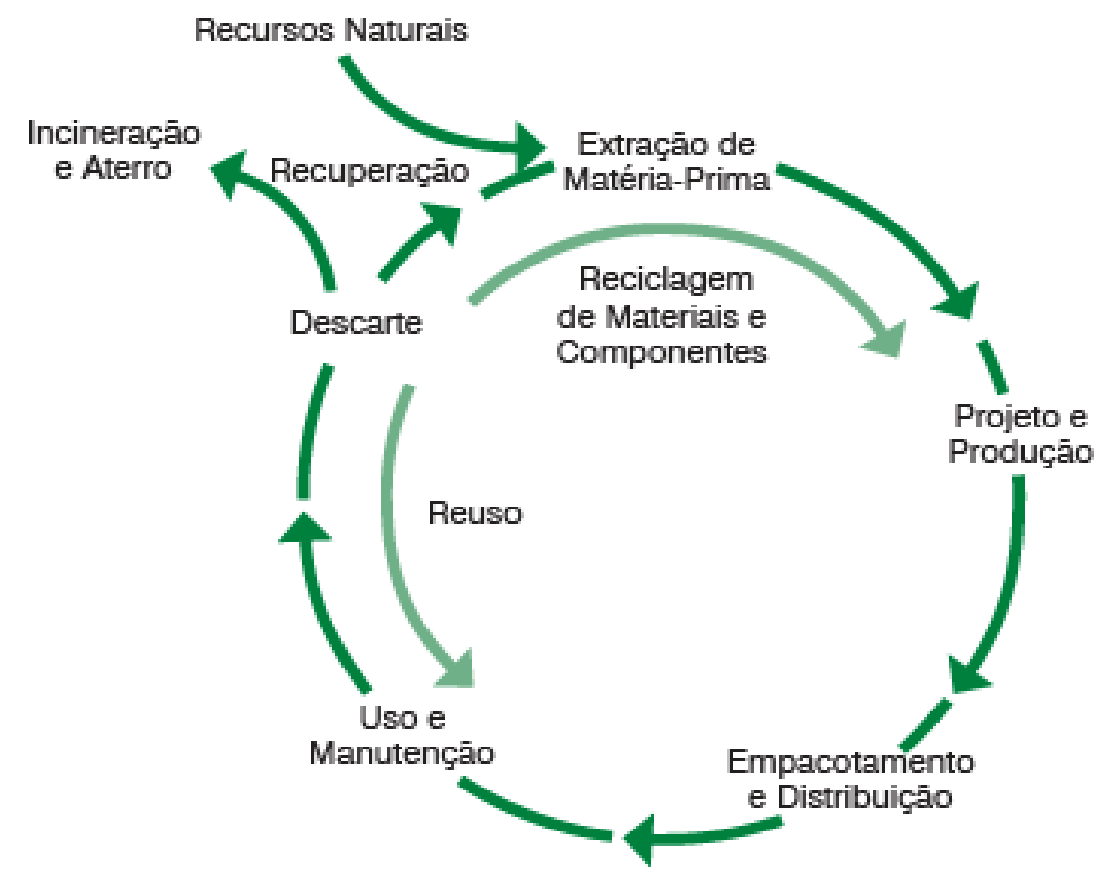

Fonte: IBICT (2014)

Conforme definição da "United States Environmental Protection Agency" (EPA), "a Avaliação de Ciclo de Vida (ACV) emprega uma abordagem holística para investigar sistemas industriais ao longo de toda sua vida útil. O objetivo dessa ação éconhecer as consequências ambientais associadas a um produto, processo ou atividade, desde a sua criação (extração de matéria-prima), até a disposição final”.

As possibilidades de aumentar a consciência coletiva da importância de proteger o ambiente, e identificar os potenciais impactos associados a um produto (fabricado e consumido) reforçou o interesse no desenvolvimento de métodos para melhor compreender e conter esses impactos ao longo do seu ciclo vida (UNEP/SETAC, 2011). Um estudo de ACV proporciona uma visualização abrangente dos fluxos de matéria e energia que circulam do ambiente para o ciclo de vida e vice-versa fornecendo uma base holística e objetiva de comparação entre alternativas que cumpram (ou atendam) a mesma função (ou necessidade). 
ACV analisa sequências de transformações antrópicas que se encontram interconectados por correntes materiais e energéticas (VILELA et al, 2013). Os resultados de um estudo dessa natureza compreendem um diagnóstico quantitativo dos impactos ambientais potenciais do sistema em análise (MALÇA e FREIRE, 2006).

A ACV se presta a (i) identificar oportunidades de melhoriado desempenho ambiental dos produtos em vários pontos do seu ciclo de vida; (ii) informar e subsidiar os tomadores de decisões de organizações governamentais, indústria ou não governamentais; (iii) selecionar indicadores relevantes de desempenho ambiental, incluindo técnicas de medição; (iv) fazer marketing ambiental consistente, consciente e proativo (UNEP/SETAC, 2011). Diante dessa gama de possibilidades de aplicação pode-se entender a ACV como uma abordagem essencial para melhoria de eficiência dos recursos, que permite que as empresas e stakeholders possam identificar "pontos fracos" ao longo da cadeia de suprimentos, bem como os riscos potenciais e as oportunidades de melhorias (LUO et al, 2009).

Weidema (1997) e Curran (2012) apresentam conceitos e definições de uso regularpela $\mathrm{ACV}$ que têm importância determinante para compreensão da técnica. São eles:

- Ambiente: meio que envolve as operações da organização (empresa, atividade) analisada;

- Impacto ambiental: qualquer mudança no ambiente adversa ou benéfica, resultado de atividades ou produtos da organização;

- Intervenções: são corrente de entrada (na forma de recursos), e saída (emissões para o ar, água e solo) que serão, respectivamente, consumidas e produzidas pelo mesmo sistema, alémde relações ambientais não diretamente ligadasàs mesmas entradas e saídas, casos de (i) uso do solo, (iii) impactos físicos,(iv) aspectos relacionados a saúde ocupacional e bem-estar de trabalhadores,(v) preservação (também com viés de manutenção do bem-estar) de animais domésticos em atividades agropecuárias, entre outros;

- Produto: é um bem físico ou serviço não-material que cumpre uma ou mais funções definidas; 
- Sistema de produto: conjunto de processos elementares, serviços e demais atividades antrópicas que ao serem conectados perfazem o ciclo de vida de um, ou mais, bens de consumo e/ou produção.

- Processo elementar: em um sistema de produto, o processo elementar é considerado o menor nível de arranjo antrópico sobre o qual será possível efetuar coleta de dados com vistas a quantificar consumos e gerações associadas a um certo ciclo de vida.

Curran (2012) agrupa as aplicações de ACV em quatro áreas:

a) Análises não comparativas de produtos já existentes: são relevantes para produzir relatórios ambientais de produtos, com o objetivo de melhorar o nível de informação dos consumidores, ou para pesquisa que vise identificar áreas ambientalmente mais críticas do ciclo de vida de um produto. Essas análises são baseadas em ambientes específicos (empresas ou localidades) ou em informações médias regulares.

b) Análises comparativas de produtos existentes: visam a influenciar os atores envolvidos com um produto (fornecedores, produtores ou consumidores). Uma avaliação de produtos similares produzidos por diferentes fornecedores pode revelar que alguns deles podem ser superiores do ponto de vista ambiental. Uma empresa pode comparar seus próprios produtos com os de seus concorrentes. A comparação pode ser usada também como estratégia de marketing ou para rotulagem ambiental.

c) Análises comparativas de produtos potenciais (desenvolvimento de produtos): nesse caso, a tarefa é como identificar melhorias no produto, tais como, a substituição de ingredientes, a aplicação de diferentes tecnologias no processo de produção, a redução dos resíduos na fase de distribuição, entre outras.

d) Análises estratégicas de produtos em relação a gestão ambiental: tipicamente comparam diferentes tipos de produtos a fim de obter um quadro de como eles funcionarão na perspectiva de um objetivo ambiental de longo prazo. Isso pode ser usado para determinar as prioridades de longo prazo de uma empresa do ponto de 
vista ambiental, agrupar as diretrizes gerais de desenvolvimento de produtos ou pensar ajustes de longo prazo no alcance do produto.

Os itens "a" e "b" são classificados como aplicações táticas. O item "c" é uma aplicação prospectiva, e o item "d" é exemplo de aplicação estratégica. Cada classe de aplicações exige que a informação tenha níveis próprios de aprofundamento, exatidão, agregação e incerteza. Dessa forma é essencial estar atento para o planejamento da aplicação da ACV antes de realizá-la (WEIDEMA, 1997).

Conforme indicado na norma ABNT NBR ISO 14040 (ABNT, 2009a) a condução da ACV leva em conta as etapas de definição de objetivos, definição de escopo, análise de inventário, avaliação de impacto e interpretação. A Figura 5 apresenta as referidas etapas, além de mostrar a forma como essas se interconectam durante a aplicação da técnica.

Figura 5 - Etapas de ACV: diretrizes definidas pela norma ABNT NBR ISO 14040

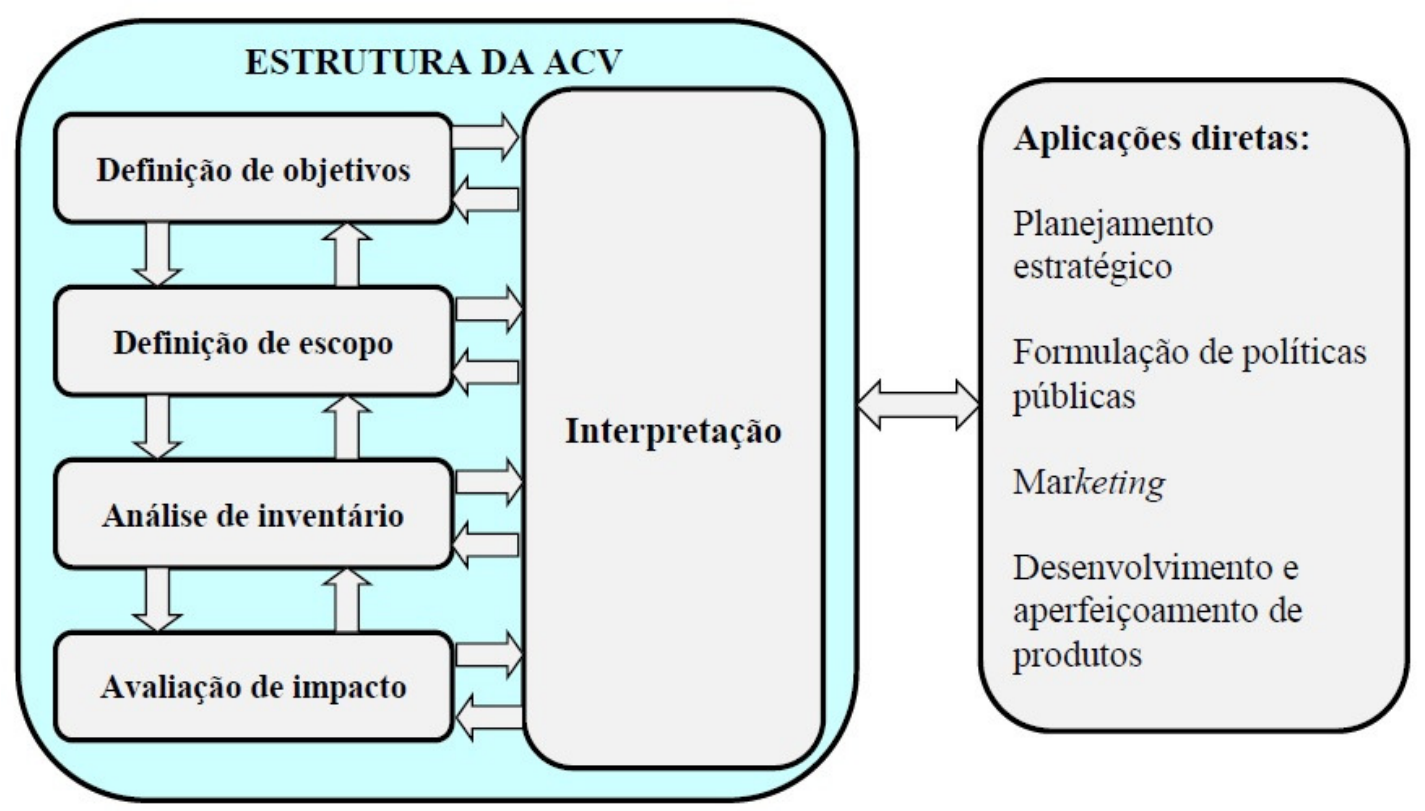

Fonte: adaptado de ABNT NBR ISO 14040 (ABNT, 2009a).

O arcabouço estrutural da técnica de ACV pode ser repetido mais de uma vez ao longo de um estudoaté que as incertezas a ele associadas são eliminadas, ou se reduzam a níveis compatíveis com os objetivos a que se presta a iniciativa. Cada uma das fases constituintes da técnica passa a ser descrita a seguir de maneira sucinta, mas com grau de aprofundamento suficiente para subsidiar as discussões empreendidas mais adiante nesse estudo. 


\subsubsection{Definição do objetivo e escopo do estudo deACV}

É a fase de planejamento da ACV. Nela são determinados os objetivos, o públicoalvo (interessados), os recursos necessários e os participantes do estudo. A definição do escopo envolve a descrição do produto a ser pesquisado e de possíveis produtos alternativos. Outras atividades que ocorrem nessa fase são (i) delimitação da pesquisa (base de referência para a análise, ou seja, sua unidade funcional; o sistema de produto e seus processos elementares; procedência e características geográfica, temporal, tecnológica dos dados; nível de detalhe da análise, etc.); (ii) escolha das categorias e dos parâmetros ambientais que serão analisados; (iii) definição da estratégia de coleta de informação; (iv) forma de tratamento de situações em que ocorram multifuncionalidades. Essas definições são fundamentais para que os resultados da ACV possam ser utilizados (JRC, 2010).

A primeira tarefa a realizar no planejamento de uma ACV é determinar o objetivo do estudo, em função das diversas aplicações possíveis. Uma ACV executada, por exemplo, com o intuito de situar o produto em relação a um determinado padrão ambiental pode não ter umâmbito adequadamente amplo para ser utilizado no desenvolvimento de um novo produto. Uma análise pode ser produzida para determinado local ou situação (país ou continente), ou ter uma perspectiva mundial. Análises podem ser conduzidas com vistas a subsidiar decisões cotidianas (tais como troca de fornecedores); ou podem sustentar decisões mais amplas (como a compra de um equipamento, ou uma mudança de legislação). A tendência é que horizonte de tempo do estudo seja maior para situações em que o diagnóstico da ACV sirva a propósitos táticos e estratégicos.

A Definição do Escopo consiste de estabelecer os limites e a abrangência do estudo. O escopo determina para quais produtos e processos elementares deverá se coletar dados, bem como a localização geográfica e o nível tecnológico desses processos. Deve-se também decidir como fixar os limites do sistema de produto em análise com outros sistemas antrópicos, e com o meio ambiente. A definição do escopo compreende ainda escolher parâmetros ambientais e os métodos para determinação e interpretação dos impactos (MARTINHO, 2014).

Sugawara (2012) reforça que o escopo de uma ACV tem como resultado a definição da estratégia para coleta de informação e a lista de informações essenciais para o estudo. Adicionalmente, este pode determinar se haveránecessidade de uma avaliação verificação de 
conteúdo do estudo por parte independente ('peer review') e, em caso afirmativo, como ocorre essa ação e quem a realizará. Finalmente, a definição de escopo deve também descrever o tipo e o formato do relatório a ser produzido.

O produto pode ser descrito tanto como um produto físico (por exemplo, uma máquina de lavar), um processo (produção da lavadora), ou um serviço (serviço de lavanderia). É importante especificar o graude qualidade (ou detalhamento) mínima que o objeto de estudodeve ter já que essas especificações trazem associadas demandas para os processos e materiais utilizados no ciclo do produto, os quais se desdobram inexoravelmenteem impacto ambiental (SILVA e KULAY, 2006).

O produto deve ser definido não apenas por suas características intrínsecas e funcionais, e pela qualidade inerente, mas tambémem função do uso (ou atendimento da necessidade) a que se destina ou que seja verificada pela ACV. A essa aplicação dá-se o nome de 'Função' e sua a quantificação denomina-se "Unidade Funcional (UF)". Em estudos nos quais haja interesse em comparar os desempenhos ambientais de distintos produtos, o praticante deve se certificar que todos estes cumpram de fato a mesma função, independentemente do grau de eficiência com que isso ocorra.

Em geral, um processo elementar gera frequentemente mais do que um único produto. Essa situação caracteriza uma multifuncionalidade. Nesses casos, não é razoável considerar o produto em estudo como único responsável por todas as intervenções ambientais de um processo, e dos estágiosque o precedem no ciclo de vida. Portanto, é necessário decidir como essas intervenções ambientais serão distribuídas entre os diferentes subprodutos doprocesso. Uma das alternativas mais usuais é a aplicação do procedimento de alocação (JRC, 2010).A alocação consiste em repartir as cargas ambientais entre produtos que caracterizama situação de multifuncionalidade a partir de um critério. Este, pode ser de duas naturezas: (i) físico, como quantidades de massa ou volume, total de energia associada, teor de um componente, entre outros; e (ii) econômico, que será definido em função do preço de mercado, ou mesmo, dos custos de produção de cada produto (JRC, 2010).

Outra possibilidade seria a expansão de fronteiras. Nesse caso, as cargas ambientais da geração dos coprodutos do processo elementar são atribuídas ao produto em estudo. No entanto, as cargas ambientais relacionadas à supressão de bens que sejam substituídos pelos coprodutos do mesmo sistema quando estes atuam em outros sistemas de produto devem ser 
igualmente debitadas. A estas se denominam genericamente de cargas evitadas (JRC, 2010).

A delimitação final a ser produzida antes da coleta da informação refere-se à definição de quais parâmetros ambientais ou categorias de informação o estudo irá envolver. Em princípio, não há objeção formal a que uma ACV se concentre em apenas certa substância $\left(\mathrm{CO}_{2}\right.$, por exemplo), ou mesmo um tema ou categoria de impacto (Mudança Climática). Inclusive, na busca por simplificação, muitos pesquisadores e praticantes têm defendido a limitação dos parâmetros ambientais pesquisados nos estudos de ACV. No entantohá também uma corrente contrária a essa simplificação, que postula a introdução de grande número de parâmetros com o intuito de habilitar a ACV a manejar a complexidade plena do debate em voga debate sobre meioambiente (MARTINHO, 2014).

Os parâmetros ambientais que serão incluídos no estudo dependerão do seu peso final na fase de determinação dos impactos ambientais. Para isso, é útil que se realize uma análise de custo/benefício, em termos de factibilidadeda coleta de informações, e benefícios que um eventual aprofundamento desta pode proporcionar em termos de precisão dos resultados. A estratégia de coleta de informação auxilia na estruturação da fase de inventário, de forma que não se deve coletar um dado a menos que se conheça sua importância. Ela deve descrever também a qualidade dos dados. A qualidade da informação necessária pode variar em função das diferentes partes do ciclo de vida do produto, ou seja, aquelas que têm grande influência no resultado final, necessitam de informação mais precisas que as outras etapas do sistema de produto, que por ventura exerçam menor influência (SUGAWARA, 2012).

\subsubsection{Análise de Inventário}

$\mathrm{Na}$ Análise de Inventário, os dados representativos de aspectos ambientais, ou seja, correntes materiais e energéticasque cruzam as fronteiras entre o sistema de produto e o meio ambiente são coletados. É usual que sejam quantificados também (i) bens de consumo e seus eventuais subprodutos, (ii) fluxos intermediários (que interligam dois processos elementares em análise), e (iii) fluxos de produto (que são utilizados no processo em análise, mas advêm outros processos antrópicos Os dados utilizados podem ser obtidos em campo (dados primários) ou na de literatura (dados secundários). Dados quantitativos utilizados para comparação de materiais ou processos, bem como, aqueles de ordem qualitativa, que se prestamà descrição de aspectos ambientais ou estágios de ciclo que vida que não podem ser quantificados, podem ser selecionados a partir da aplicação dos critérios de exclusão de 
dados. Tais critérios permitem identificar aspectos ambientais a serem considerados em cada processo elementar; ou seja, no menor nível de um sistema de produto para o qual é possível quantificar correntes de matéria e energia de entrada e saída (ABNT, 2009b).

A coleta de dados gera um conjunto de informações que estão na forma bruta. Estes devem então ser tratados para compor o Inventário de Ciclo de Vida (ICV), cabendo então ao executor da ACV (i) verificar se os requisitos de qualidade de dados foram de fato atendidos, (ii) aplicar balanços de matéria e energia com o intuito de aferir (e validar) a consistência dos parâmetros coletados, (iii) correlacionar tais valores à UF, e (iv) decidir e aplicar procedimentos que permitam lidar adequadamente com situações de multifuncionalidade. Todo este conjunto de ações, iniciativas, e procedimento é conhecido no âmbito da técnica como Tratamento dos Dados (SILVA e KULAY, 2006).

Como já fora comentado anteriormente na descrição das ações de Definição de Escopo, as situações de multifuncionalidade devem ter um encaminhamento durante a elaboração de uma ACV. Isso ocorre exatamente no transcurso da Análise de Inventário. Muito embora seja um procedimento de uso recorrente para abordagens de processos multifuncionais, a alocação é uma questão controversa. Por conta disso, recomenda-seque, sempre que possível, a alocação seja evitada. Para tanto há dois caminhos: (i) a subdivisão do processo até níveis em que seja possível separar perfeitamente consumos e emissões associados a cada coproduto; ou (ii) expandindo os limites do sistema de maneira a incluir as funções adicionais a ele relacionadas; ou seja, expansão de fronteiras (VAN DER VOET, 2009; MUNIZ, 2012).

\subsubsection{Avaliação dos impactos ambientais}

A Avaliação de Impactos Ambientais do Ciclo de Vida (AICV) analisa as magnitudes e significâncias dos efeitos potenciais causados pelo ciclo de vida do produto sobre o meio ambiente e sobre o ser humano, no âmbito do atendimento da função (MARTINHO, 2014).

De acordo com a norma ABNT NBR ISO 14044 (ABNT, 2009b), a etapa de AICV é composta por elementos obrigatórios e opcionais. São elementos obrigatórios: a (i) Seleção de categorias de impactos e de seus respectivos indicadores; a (ii) Classificação; a (iii) Caracterização; e, (iv) a Definição do Perfil de Impacto Ambiental. 
A Seleção das Categorias de Impacto Ambiental baseia-se nos resultados do ICV, em particular, nos aspectos ambientais de maior relevância para o estudo. De qualquer forma, são categorias de impactos de uso mais frequentes em estudo desta natureza: Mudança Climática; Depleção da Camada de Ozônio; Acidificação; Depleção de Recursos Abióticos; Eutrofização, Formação de Foto-oxidantes, Depleção de Recursos Hídricos, de Metais, e de ativos de origem Fóssil, Transformação e Ocupação do Solo, e Toxicidades Humana e do ambiente.

As categorias de impacto devem ser correlacionadas com resultados gerados pelo ICV. Esta ação ocorre em dois momentos; o primeiro deles é essencialmente qualitativo e se dá sob a forma de procedimento de Classificação. No segundo momentoocorre uma interação de ordem quantitativa, Caracterização (SILVA e KULAY, 2006).

A norma ABNT NBR ISO 14044 (2009b) especifica como sendo elementos opcionais os procedimentos de Normalização e Ponderação. A Normalização compreende a conversão dos resultados gerados pela Caracterização para uma base única de referência. O procedimento de Normalização está condicionado à disponibilidade de fatores confiáveis, que reflitam (ou se aproximem em termos de rigor e consistência) das condições gerais em que ocorre a avaliação.

A Ponderação trata de atribuir pesos às diferentes categorias de impacto, com base na percepção de profissionais que estejam direta ou indiretamente ligados à análise em realização (SILVA, 2012). Da aplicação deste procedimento decorre a formulação do chamado Indicador Único de desempenho ambiental do produto, ou serviço em análise. Dadas suas características, tanto a Normalização como a Ponderação são tratadas como elementos opcionais de AICV por conta da subjetividade que lhe é inerente (SUGAWARA, 2012).

\subsubsection{Interpretação dos resultados}

A última das etapas da ACV é conhecida como Interpretação. Em linhas gerais esta ação compreende uma verificação dos resultados obtidos pelo estudo com vistas ao estabelecimento de recomendações e conclusões. A interpretação é uma análise crítica, que tem como objetivo combinar, resumir e discutir constatações que tenham ocorrido durante arealização da Análise de Inventário e a Avaliação de Impactos. 
Segundo Martinho (2014) é fundamental para o sucesso da Interpretação que todas as percepções e leituras, assim como, as decisões e condutas, que ocorreram durante as etapas executivas da ACV sejam confrontadas (inclusive de maneira iterativa, se necessário for) com os objetivos e itens de escopo definidos como alicerces para o estudo.

As conclusões e recomendações geradas por qualquer estudo de ACV devem refletir objetivamente os resultados de suas três fases executivas (Análise de inventário, Avaliação de impacto e Interpretação). Para tanto estes não podem estar baseadas em interpretações pessoais, uma vez que estas poderiam influenciar futuros processos de tomadas de decisão para os quais, imagina-se, o diagnóstico gerado pela ACV venha fornecer subsídios (SUGAWARA, 2012).

\subsubsection{Estudos ACV voltados à cogeração de eletricidade}

AACV tem sido amplamente empregada para avaliaçãode impactos ambientais que decorrem de processamentos industriais. Ainda que com menor incidência do que para outras ações produtivas a técnica foi também aplicada para análise de unidades e sistema de cogeração de energia elétricaque se valessem de biomassa de cana-de-açúcar como fonte de energia para seu funcionamento (GAUDREAULT et al., 2010).

Silva et al (2014) identificaram que para a condição brasileira, os principais impactospotenciais dessa classe de geração de energia elétrica se dãocomo Oxidação fotoquímica e Toxicidade Humana, e se originam principalmente da queima de palha, e aplicação de produtos químicos. Os autores afirmam ainda que o uso de recursos renováveis e não-renováveis, e o consumo de energia são questões igualmente importantes no âmbito da matéria ambiental.

Guerra et al (2014) observaram que a melhoria do rendimento energético do sistema de cogeração é acompanhada pela redução nos impactos ambientais em muitas categorias. Nesse contexto, um cenário de produção de vapor a 100 bar e $520^{\circ} \mathrm{C}$ proporciona ganhos ambientais mais expressivos, tanto em termos absolutos quanto relativos, quando comparado a um cenário homólogo em termos de adição de biomassa, mas que se desenvolve a 20 bar e $350^{\circ} \mathrm{C}$.

Os resultados de uma ACV realizada por Gil et al (2013) em sistema de cogeração de uma indústria de açúcar em Cuba mostraram que a redução das emissões para o ar, a água e o 
solo tiveram um efeito favorável sobre as categorias de Carcinogênese, Radiação ionizante e não-ionizante, Ecotoxicidade e Uso do solo. Impactos que se manifestam sob a forma de danos à saúde humana atingiram patamares elevados na fase de cogeração, que representou cerca de $80 \%$ dos efeitos adversos associados ao processo. As maiores contribuições para esta categoria estiveram associadas à lançamentos para o ar de material particulado proveniente da queima do bagaço.

Para Kiatkittipong et al (2009), o principal benefício da queima da biomassa reside na capacidade de a biomassa substituir combustíveis fósseis em sistema de incineração.Para os impactos ambientais analisados noestudo (Aquecimento Global, Acidificação e Eutrofização) a queima de bagaço é mais benéfica ao ambiente do que as usina termelétricas. A exceção ficou por conta da Formação de oxidantes fotoquímicos para a qual este diagnóstico se inverte.

O uso da palha na cogeração não é ainda uma unanimidade em termos ambientais. Por isso muitos pesquisadores têmdedicado esforços ao tema. Cardoso et al (2013) realizaram uma avaliação técnica e econômica sobre a recuperação da palha da cana para produção de bioenergia, concluindo que o uso de biomassa enfardada apresenta maior custo por unidade de massa em comparação ao sistema em que a palha seja colhida e transportada junto com colmos da cana.

Vilela (2013) constatou que o aumento na capacidade de moagem, e de uso de palha na cogeração, elevam as emissões de $\mathrm{CO}_{2}$. Para o autor o fenômenose relacionaà intensificação da queima de biomassa na caldeira. Em contrapartida, este assina-laque um consumo maior de biomassa irá também elevar a quantidade de energia vendida. Quando a ACV foi aplicada segundo o conceito de expansão de fronteiras para tratamento de multifuncionalidades, Vilela observou que os impactos proporcionados pelo sistema quanto a Mudança Climática tornaram-se negativos. O autor reputa esse resultadoao fato de fontes marginais de provimento de energia elétrica que compõem a o grid brasileiro terem sido evitadas.

Ensinas et al (2008) estudaram a redução da demanda de vapor no processo de produção de açúcar e etanol, e alternativas de sistemas de cogeração em usinas, com objetivo de aumentar a capacidade de geração de eletricidade. Os autores concluíram que a demanda de vapor nos processos investigados pode ser reduzida via integração térmica. $\mathrm{Na}$ análise 
comparativa entre alternativas de cogeração, a configuração do tipo BIG-CC (Biomass Integrated Gaseification Combined Cycle) apresentou o maior potencial de geração de eletricidade. A partir do momento em que barreiras técnico-econômicas sejam efetivamente superadas e o BIG-CC se viabilize, este arranjo poderia proporcionar um aumento de $70 \%$ na geração líquida de eletricidade.

Desse encadeamento de ideias resulta uma constatação importante: além da eletricidade em si, a cogeração de biomassa é capaz de proporcionar ao setor sucroalcooleiro nacional mais um subproduto. Nesse contexto, sempre que realizado dentro de limites técnicos adequados, o aproveitamento de palha, passa a ser condição necessária para atrair investimentos que resultem em modernizaçãoe/ou ampliação do sistema. 


\section{MÉTODO DE TRABALHO}

A fim de atender de maneira satisfatória aos objetivos a que se propôs originalmente, este estudo foi estruturado na forma das seguintes ações operacionais:

a. Revisão de bibliográfica: esta etapa compreende levantamento junto à literatura técnico-científica de dados e informações capazes de subsidiar a avaliação do desempenho ambiental de unidades de cogeração operando com biomassa nas formas de bagaço e palha, bem como, de conteúdos que permitam conhecer em elevado nível de detalhe aspectos tecnológicos, operacionais e construtivos desse processo produtivo;

b. Definição de cenários: com base nos levantamentos efetuados na etapa de Revisão Bibliográfica foram selecionados parâmetros essenciais para o funcionamento do ciclo Rankine com reaquecimento em uma destilaria autônoma. Estes foram variados dentro de limites técnicos bem definidos. Cada qual dessas condições de operação originou um cenário de análise;

c. Análise Energética: cada cenário foi verificado quanto ao desempenho energético. Para tanto, parâmetros e demais condições operacionais que caracterizassem cada cenário foram alimentados a um modelo matemático que fora concebido com o propósito único de simular o comportamento termodinâmico do ciclo de cogeração;

d. Análise Ambiental: esta etapa consistiu em aplicar a técnica de ACV a um sistema de produto que caracterizasse adequadamente a produção de eletricidade via cogeração de biomassa de cana-de-açúcar. Com isso, esperava-se obter um diagnóstico sistêmico equantitativo, do desempenho ambiental daquele arranjo. Para a elaboração do modelo de sistema de produto procedeu-se um amplo levantamento de consumos e emissões associadas ao ciclo de vida em análise para cada cenário de operação. Os resultados obtidos da Análise Energética também foram incorporados ao acervo de informações que caracterizou cada situação sob investigação. A Análise Ambiental foi conduzida dentro de um escopo de aplicação da ACV do tipo 'berço-ao-portão', e levou em conta apenas categorias de impacto que fossem aderentes com as circunstâncias examinadas. Para esse desenvolvimento, fixou-se a produção de etanol gerada pela 
destilaria, a fim de que essa variável não exercesse influência direta sobre os resultados obtidos;

e. Análise crítica: de posse dos resultados alcançados realizou-se uma análise de tendência que se propôs a identificar o grau de influência de cada parâmetro essencial sobre os demais de sua classe, no tocante aos efeitos ambientais selecionados para o estudo. Além de eventualmente conhecer os valores de cada parâmetro essencial que resultassem nos mínimos impactos ambientais gerados pelo sistema de produto, esta verificação buscou ainda conhecer, e ser capaz de justificar, tendências de oscilação desses efeitos a partir da alteração de comportamento de condições de processo específicas para a cogeração.

\subsection{Definição dos cenários}

A partir das informações obtidas na Revisão Bibliográfica foram definidos os cenários possíveis de cogeração elétrica para modelagem da Análise Energética e posteriormente, da Análise Ambiental. Os parâmetros denominados de essenciais (ou inerentes) à análise, quecaracterizam e distinguem cada uma das possibilidades são: (i) taxa de aproveitamento da palha gerada no campo como combustível para a cogeração; (ii) teor de umidade da palha; e (iii) função de estado do vapor emanado da caldeira.A Tabela 1descreve os valores selecionados para cada parâmetroessencial.

Tabela 1 - Características dos cenários avaliados: pressão de vapor, taxa de adição e umidade de palha

\begin{tabular}{ccc}
$\begin{array}{c}\text { Pressão da caldeira } \\
\text { P (bar) }\end{array}$ & $\begin{array}{c}\text { Adições da palha } \\
\text { A }(\%)\end{array}$ & $\begin{array}{c}\text { Umidade da palha } \\
\mathrm{u}(\%)\end{array}$ \\
20 & 10 & 10 \\
45 & 20 & 15 \\
67 & 30 & 25 \\
80 & 40 & 35 \\
100 & 50 & 50 \\
\hline
\end{tabular}


Um cenário hipotético $\left(\mathrm{C}_{\mathrm{n}}\right)$ será caracterizado para condições específicas de Pressão do vapor que deixa a caldeira (P), Taxa de Adição de Palha (A) e Umidade da palha (u). Ou seja,

$$
\mathrm{C}_{\mathrm{n}}=\mathrm{f}[\mathrm{P}(\mathrm{bar}) ; \mathrm{A}(\%) ; \mathrm{u}(\%)]
$$

O caráter de independências dos parâmetros essenciais fez com que fossem constituídos exatos cento e vinte e cinco cenários de análise. As bases teóricas para proposição de tais arranjos provem da descrição detalhada de ganhos de efetividade em usinas termelétricas, cuja cogeração ocorre em ciclos Rankine de elevada eficiência térmica por conta da inclusão de reaquecimento, aos quais se acoplam turbinas de extração-condensação. Estes conteúdos e conhecimentos foram adquiridos junto a Moran e Shapiro (2008).

A palha é enfardada no próprio local de produção e transportada para a destilaria. Chegando ao destino esta será picada e adicionada ao bagaço para compor a mistura a ser queimada na caldeira. Para cada tonelada de cana-de-açúcar produzida são gerados $280 \mathrm{~kg}$ de bagaço com umidade média $\mathrm{u}_{\mathrm{b}}=50 \%$, e outros $164,7 \mathrm{~kg}$ de palha. Nesse caso admitiu-se como valor de referência para projeto de ciclo de cogeração que a umidade da palha seja de $\mathrm{u}_{\mathrm{p}}=15 \%$ (CORTEZ, 2010; GUERRA, 2014).

Foram definidas cinco condições operacionais de produção de vapor superaquecido à saída da caldeira. Essas variaramentre $20<\mathrm{P}$ (bar) $<100$ e, por hipótese, mantem o mesmo grau de superaquecimento em todos os casos. Essa especificação procurou reduzir o número de graus de liberdade associados ao sistema, e ao mesmo tempo enfatizar o foco na variação de pressão da caldeira e alimentação da turbina.

A escolha dos valores das pressões $(20,45,67,80$ e 100 bar) foi baseada em Guerra (2014). Após levantamento realizado junto à literatura especializada o autor constatou que a maioria das caldeiras ainda operacom baixas pressões para produção de vapor. Guerra adverte, porém, que esse quadro vem se alterando ao longo dos anos, e que os projetos mais recentes de ciclo Rankine geram vapor a pressões mais elevadas. Todos os valores de pressão selecionados constam da literatura como possibilidades reais para operação da caldeira.

Com relação à quantidade de palha utilizada como combustível, cinco condições foram definidas, entre $10<\mathrm{A}(\%)<50$ de toda a palha gerado durante o cultivo da cana-deaçúcar. O limite superior da faixa foi determinado em função de dois fatores: (i) quantidades superiores a $50 \%$ de palha poderiam comprometer a estabilidade operacional da caldeira, 
mais especificamente, dos tubos de circulação de água, ao gerar depósitos sobre esses, devido ao teor de sílica na palha; ou mesmo, os expor a corrosão, dada a presença de cloretos no mesmo combustível; (ii) os especialistas em cultivo de cana sugerem que ao menos a metade da palha gerada permaneça no campo a fim de proteger a superfície do solo de efeitos naturais adversos (erosão, desgaste, compactação).

Variações de umidade da palha, entre 10 e 50\%, definem mais cinco condições. Um $\mathrm{u}_{\mathrm{p} \text { máx }}=50 \%$ foi considerado com o intuito de verificar os impactos ambientais associados ao sistema de produto quando toda a biomassa (bagaço e palha) apresentasse a mesma quantidade de água superficial em sua estrutura. Já o $u_{p}=10 \%$ foi ensaiado com o objetivo de fornecer conclusões para casos em que a palha fosse secada previamente ao seu uso, passando assim a deter uma taxa de água inferior ao padrão usual de projeto. Nesse caso, considerou-se que a secagem da palha ocorreria de forma natural, simplesmente por exposição ao sol, sem, portanto, predispor consumo de recursos e/ou geração de rejeitos.

\subsection{Modelagem Termodinâmica dos Cenários}

\subsubsection{Premissas e definição dos parâmetros operacionais dos cenários}

Todos os ciclos Rankine que definem os cenários de análise detêm a mesma concepção construtiva, sendo constituídos pelos seguintes equipamentos: caldeira, turbina, condensador, bombas, desaerador e purgador. Amodelagem termodinâmica foi realizada admitindo que sua operação ocorreria em regime permanente. Além disso, estabeleceu-se por premissa que todo bagaço gerado na etapa de moagem da cana é consumido na caldeira.

Para todos os cenários, considerou-se que uma fração de vapor na forma saturada, com título $(\mathrm{x})=1,0$ e $\mathrm{P}=2,5$ bar é extraída da turbina para ser usada na produção do etanol. Esta é chamada, convencionalmente, de vapor de escape. Além disso, o vapor que deixa a turbina (vapor de cauda) também estaria saturado, mas com $\mathrm{x}=0,89$ e a $\mathrm{P}=0,1$ bar. Este fluído segue diretamente para o condensador, onde muda de fase antes de retornar á caldeira. Foram desprezadas perdas de carga das tubulações responsáveis pelo transporte do fluido de trabalho ao longo do ciclo termodinâmico. Os balanços de energia realizados nos equipamentos auxiliares (bombas, desaerador, dessuperaquecedor, purgadores e tubulações) não consideraram possíveis perdas energéticas nessas unidades. 
Os cálculos adotados nas simulações tomaram por premissa a produção de etanol anidro $(99,5 \%$ w/w $)$ em destilaria autônoma, com capacidade de moagem de 2,5 Mt de cana-deaçúcar por safra (210 dias). Partindo-se das estimativas realizadas por Dias et al (2009) e Cavalett et al (2012) para destilarias autônomas que operam no estado de São Paulo, adotouse um consumo específico de $400 \mathrm{~kg} / \mathrm{t}_{\mathrm{c}}$ de vapor saturado (2,5 bar) para o atendimento da demanda térmica da planta industrial (que compreende tanto a destilaria, como a própria cogeração).

O consumo total de eletricidade na planta industrial oscila entre $31,06 \mathrm{kWh} / \mathrm{t}_{\mathrm{c}}$ para o cenário I quando $\mathrm{u}_{\mathrm{p}}=10 \%$, e $39,56 \mathrm{kWh} / \mathrm{t}_{\mathrm{c}}$, (cenário $\mathrm{V}$ com $\mathrm{u}_{\mathrm{p}}=50 \%$ ) (Tabela 2). Assim como já fora indicado antes a produção de etanol foi mantida constante. Essa decisão traz imediatamente dois desdobramentos fundamentais para o desenvolvimento do estudo: (i) a quantidade de cana-de-açúcar permanece constante; e (ii) a quantidade de bagaço gerado na etapa de moagem será igualmente invariável para todos os cenários.

Tabela 2 - Variação do consumo de eletricidade na unidade industrial em função da umidade da palha

\begin{tabular}{ccc} 
Cenário & $\begin{array}{c}\text { Eletricidade } \\
(\mathrm{kWh} / \mathrm{tc})\end{array}$ & $\begin{array}{c}\text { Umidade da palha } \\
\mathrm{u}(\%)\end{array}$ \\
\hline & 31,06 & 10 \\
31,12 & 15 \\
I & 31,27 & 25 \\
& 31,47 & 35 \\
& 31,91 & 50 \\
\hline \multirow{3}{*}{ II } & 32,12 & 10 \\
& 32,25 & 15 \\
& 32,55 & 25 \\
& 32,94 & 35 \\
& 33,82 & 50 \\
\hline \multirow{3}{*}{ III } & 33,18 & 10 \\
& 33,37 & 15 \\
& 33,82 & 25 \\
& 34,41 & 35 \\
& 35,73 & 50 \\
& &
\end{tabular}




\begin{tabular}{lll}
\hline & 34,24 & 10 \\
34,50 & 15 \\
IV & 35,10 & 25 \\
& 35,88 & 35 \\
& 37,65 & 50 \\
\hline & 35,31 & 10 \\
& 35,62 & 15 \\
& 36,37 & 25 \\
& 37,35 & 35 \\
& 39,56 & 50 \\
\hline
\end{tabular}

Essa decisão permitiu que os efeitos ambientais das sucessivas adições de palha, e da taxa de umidade a esta associada fossem verificados sem quaisquer interferências que pudessem ser proporcionadas pela outra fonte de biomassa (bagaço) que foi introduzida no sistema.

\subsubsection{Construção de modelos matemáticos}

Os modelos elaborados para representar o funcionamento termodinâmico da cogeração basearam-se em análises de $1^{\mathrm{a}}$.e $2^{\mathrm{a}}$. Leis. O programa computacional Engineering Equation Solver - EES $^{\circledR}$ foi empregado como ferramenta de apoio à elaboração dessas lógicas. Além das premissas descritas na seção anterior, diversos parâmetros de caráter geral foram considerados para efeito de elaboração dos modelos. Aqueles considerados mais significativos para essa ação aparecem descritos a seguir na Tabela 3.

Além de conferir homogeneidade a análise, e reduzir a níveis instantâneos a velocidade das estimações, a opção pelo EES se sustenta em virtude de sua capacidade de solucionar com elevado grau de precisão, um conjunto extenso de equações lineares. As equações são inseridas pelo operador para efeito de composição do modelo em estudo. A interface de simulação também deve ser construída, permitindo com isso que a apresentação se tornecustomizada e assim, facilite a interpretação dos resultados obtidos.

Com as propriedades de estado bem definidas e respeitando os graus de liberdade, pode-se usar o $\mathrm{EES}^{\circledR}$ para estimar parâmetrostanto físico-químicos como termodinâmicos do fluido de trabalho, viabilizando a realização de simulações em diversas condições 
operacionais (EES, 2016). Serão apresentados a seguir, mais detalhes quanto a características e especificidades dos modelos termodinâmicos. Além disso, serão apresentadas ainda as equações elaboradas para compor os referidos modelos.

Tabela 3 - Parâmetrosgeraisutilizados para estimativa e modelagem dos cenários de análise

\begin{tabular}{|c|c|c|}
\hline Parâmetros & Valores & Unidades \\
\hline Cana moída total & 2.500 .000 & $\mathrm{t}$ \\
\hline Dias de safra (destilaria em operação) & 210 & dias \\
\hline Eficiência térmica da caldeira & \multicolumn{2}{|c|}{ variável: f (cenário) } \\
\hline Eficiência isentrópica da turbina & \multicolumn{2}{|c|}{ variável: f (cenário) } \\
\hline Eficiência do gerador & 95 & $\%$ \\
\hline Eficiência isentrópica das bombas & 85 & $\%$ \\
\hline Temperatura no desaerador & 110 & ${ }^{\circ} \mathrm{C}$ \\
\hline Bagaço produzido na destilaria & 280 & $\mathrm{~kg} / \mathrm{tc}$ \\
\hline Teor de umidade do bagaço $\left(\mathrm{u}_{\mathrm{b}}\right)$ & 50 & $\%$ \\
\hline Teor de umidade da palha $\left(\mathrm{u}_{\mathrm{p}}\right)$ & \multicolumn{2}{|c|}{ variável: f (cenário) } \\
\hline Palha produzida no campo $\left(\mathrm{u}_{\mathrm{p}}=0 \%\right)$ & 140 & $\mathrm{~kg} / \mathrm{tc}$ \\
\hline Consumo de vapor na destilaria & 400 & $\mathrm{~kg} / \mathrm{tc}$ \\
\hline Consumo de eletricidade nadestilaria & 30 & $\mathrm{kWh} / \mathrm{tc}$ \\
\hline Consumo de eletricidade na moagem da palha & \multicolumn{2}{|c|}{ variável: f (cenário) } \\
\hline Pressão do vapor superaquecido que deixa a caldeira & \multicolumn{2}{|c|}{ variável: f (cenário) } \\
\hline Pressão de extração na turbina para uso no processo (vapor de escape) & 2,5 & bar \\
\hline Pressão de extração na turbina para condensação (vapor de cauda) & 0,1 & bar \\
\hline
\end{tabular}

Fonte: Ensinas (2008); Seabra (2008); Dias et al. (2009); Dias et al. (2010); Oliveira Jr. (2012); Cardoso et al. (2013); e Cavalett et al. (2012); CONAB (2014); Guerra (2014).

\subsubsection{Características específicas dos arranjos}

Foram utilizados dados reais para os parâmetros de desempenho dos equipamentos da planta de cogeração, como bombas, turbina, caldeira e gerador. Tal como já fora mencionado, assumiu-se que a produção de etanol anidro seria constante, que todo o bagaço gerado a partir do processamento da cana-de-açúcar é utilizado na cogeração, e que a destilaria opera no estado estacionário. 
Figura 6 - Representação de ciclo Rankine com reaquecimento

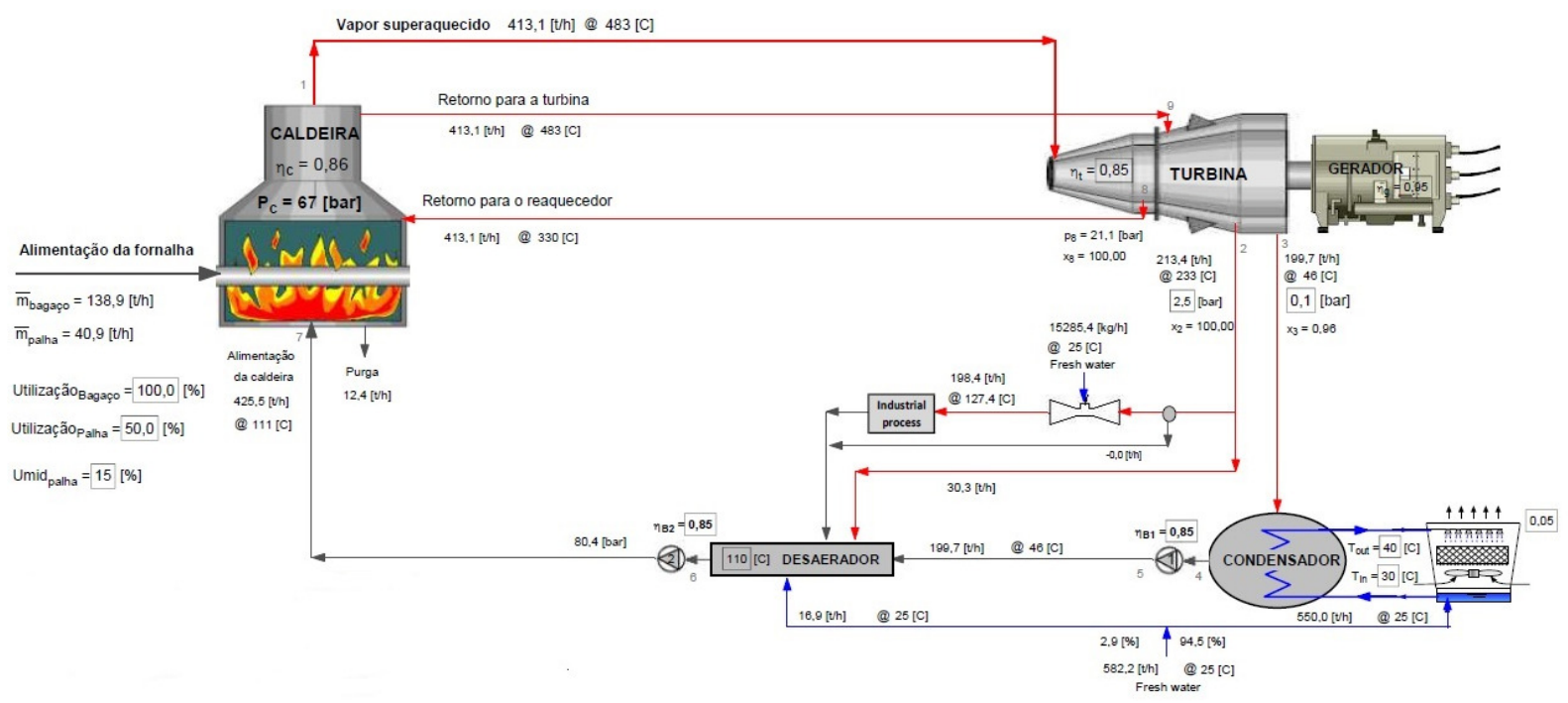

Fonte: adaptado de Guerra (2014)

Assim, parâmetros como as quantidades de cana-de-açúcar produzida, vapor gerado, e etanol obtido na destilaria, assim como, o consumo de eletricidade na planta industrial, mantiveram-se constantes para todos os cenários.

A Figura 6 apresenta uma ilustração do ciclo Rankine com reaquecimento operando em um sistema de cogeração, que foi construído no programa $E E S^{\circledR}$. A pressão em que parte do vapor é extraído na turbina com o intuito de reaquecê-lo no superaquecedor da caldeirafoi determinada via otimização das condições de processo, tendo em conta as diferentes pressões de operação da caldeira $(20,45,67,80$ e 100 bar).

\subsubsection{Modelagem dos equipamentos}

A modelagem termodinâmica de cada equipamento que constitui o ciclo Rankine foi baseada na aplicação de princípios de conservação de matéria e energia (particularmente, de entalpia (sistema aberto) e trabalho de eixo, que são típicos da $1^{\mathrm{a}}$. Lei da Termodinâmica) e balanços entrópicos (usados para introduziram componentes da $2^{\mathrm{a}}$. Lei na análise). Funções de estado dos fluídos envolvidos na cogeração foram empregadas para determinar as propriedades termodinâmicas das mesmas substâncias. Valores de entalpia e entropias foram calculadas a partir da biblioteca de propriedades termodinâmicas do EES $^{\circledR}$. O desempenho técnico da caldeira, turbina, bombas, e do gerador elétrico foi representado por dados 
coletados junto à literatura técnica (ENSINAS, 2008; SEABRA 2008; DIAS et al, 2009 e 2010; OLIVEIRA JR, 2012; CARDOSO et al, 2013; FLORIO e OLIVEIRA JR, 2014; GUERRA et al, 2014).

Os resultados teóricos da modelagem foram confrontados a parâmetros reais, obtidos de um ciclo de cogeração que opera a $\mathrm{P}=67$ bar, para duas condições de dosagem de biomassa em termos de palha: $\mathrm{A}=0 \%$, e $\mathrm{A}=50 \%$. No caso em que o ativo foi dosado em associação ao bagaço, seu teor de umidade era de $\mathrm{u}_{\mathrm{p}}=15 \%$.

Os principais indicadores de desempenho determinados pelo modelo para as condições de cada cenário foram: eficiência energética $(\%)$, Geração específica de eletricidade $\left(\mathrm{kWh} / \mathrm{t}_{\mathrm{c}}\right)$, Eletricidade exportada $\left(\mathrm{kWh} / \mathrm{t}_{\mathrm{c}}\right)$, consumo de água na torre de resfriamento $\left(\mathrm{kg} / \mathrm{t}_{\mathrm{c}}\right)$, consumo de água deionizada $\left(\mathrm{kg} / \mathrm{t}_{\mathrm{c}}\right)$.

\subsubsection{Caldeira}

A caldeira é o equipamento que responde pela transferência do calor dos produtos da combustão para o fluido de trabalho. Trata-se de um dos elementos mais importantes do ciclo Rankine quando analisado sob o ponto de vista da $2^{\mathrm{a}}$. Lei da Termodinâmica, pois é ali que residem as maiores irreversibilidades do sistema. Estas derivam justamente dos processos de combustão e de transferência de calor (BRÄSCHER, 1991; TSATSARONIS e PARK, 2002).

Vapor é gerado na caldeira pela transformação da energia química do combustível em energia térmica (calor). A queima da biomassa da cana-de-açúcar ocorre na fornalha; o calor que é produzido dessa operação será transferido por radiação para feixes de tubos que compõem as paredes internas da caldeira. No interior destes circula água que, devido ao contato indireto com a energia em um equipamento conhecido como superaquecedor, muda sucessivamente de fase até atingir a condição de vapor superaquecido (na qual sua temperatura será elevada acima da temperatura de saturação).

Mesmo depois de ceder energia para o fluido de trabalho, os gases de combustão ainda possuem temperatura elevada. Por conta disso os geradores de vapor dispõem de equipamentos para aproveitar melhor essa energia remanescente. Dentre estes se incluem os reaquecedores, economizadores, e pré-aquecedores de ar (BRÄSCHER, 1991; ANON, 2005). A temperatura do vapor à saída do superaquecedor é dada pela equação (Eq 1): 


$$
\mathrm{T}_{1}=\mathrm{T}_{\text {sat }}\left(\text { water; } \mathrm{P}=\mathrm{P}_{\mathrm{c}}\right)+\mathrm{G}_{\text {super }}
$$

Onde:

$\mathrm{T}_{1}=$ temperatura do vapor superaquecido $\left({ }^{\circ} \mathrm{C}\right)$;

$\mathrm{T}_{\text {sat }}\left(\right.$ water; $\left.\mathrm{P}=\mathrm{P}_{\mathrm{c}}\right)=$ temperatura de saturação da água na pressão da caldeira $\left({ }^{\circ} \mathrm{C}\right)$;

$\mathrm{G}_{\text {super }}=$ grau de superaquecimento $\left({ }^{\circ} \mathrm{C}\right)$

$\mathrm{P}_{\mathrm{c}}=$ pressão de operação da caldeira (bar).

A quantidade de calor gerada na caldeira é dada pela vazão mássica de biomassa, ou seja, bagaço e palha. A essa quantidade de calor dá-se o nome deenergia disponível, ao passo que o total de energia efetivamente absorvida pelo fluido de trabalho denomina-se energia útil. A diferença entre energia disponível e energia útil se deve a perdas que ocorrem ao longo dos diversos equipamentos da instalação (SINGER, 1981).

No ciclo Rankine com reaquecimento o vapor superaquecido passar pelo estágio de alta pressão da turbina, e retorna para o reaquecedor a fim de recompor a temperatura inicial. Nesta condição o fluido retorna mais uma vez para a turbina onde segue naturalmente o processo de expansão. A Figura 7 representa um esquema da caldeira desenvolvido com auxílio do $\mathrm{EES}^{\circledR}$.

Figura 7 - Esquema ilustrativo da caldeira de força

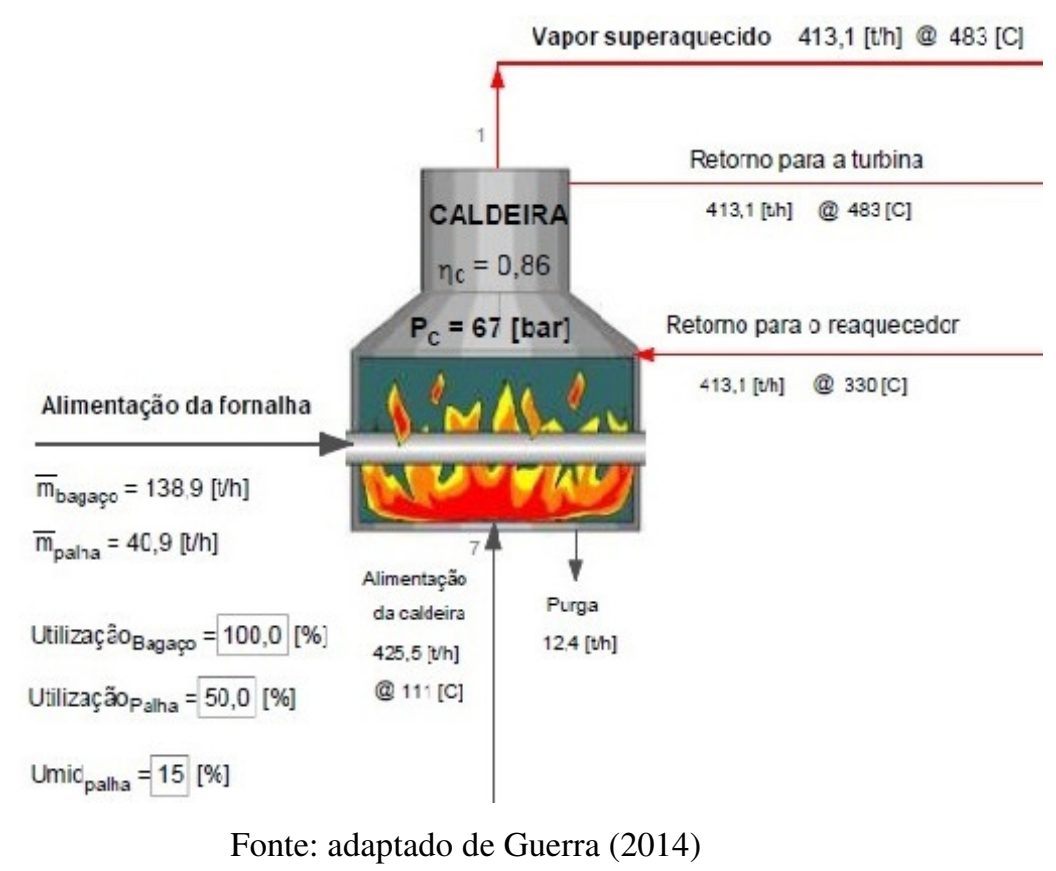


Tomando como referência a Figura 7, o balanço de massa na caldeira pode ser estimado pelas equações Eq. 2 e Eq. 3:

$$
\begin{aligned}
& \dot{\mathrm{m}}_{\text {água }}=\dot{\mathrm{m}}_{\text {vapor }}+\dot{\mathrm{m}}_{\text {purga }} \\
& \dot{\mathrm{m}}_{\text {purga }}=\mathrm{Y}_{\text {purga }} \cdot \dot{\mathrm{m}}_{\text {vapor }}
\end{aligned}
$$

Onde:

$\dot{m}_{\text {água }}=$ vazão mássica da água de alimentação da caldeira $(\mathrm{t} / \mathrm{h})$;

$\dot{\mathrm{m}}_{\text {vapor }}=$ vazão mássica de geração de vapor superaquecido $(\mathrm{t} / \mathrm{h})$;

$\dot{\mathrm{m}}_{\text {purga }}=$ vazão mássica de purga da caldeira $(\mathrm{t} / \mathrm{h}) ;$

$\mathrm{Y}_{\text {purga }}=$ taxa de purga $(\%)$;

O balanço de energia na caldeira esta descrito a seguir na forma das equações Eq 4 a Eq 6:

$$
\begin{aligned}
& \dot{\mathrm{m}}_{\text {água }} \cdot \mathrm{h}_{7}+\mathrm{Qc}=\dot{\mathrm{m}}_{\text {vapor }} \cdot \mathrm{h}_{1}+\dot{\mathrm{m}}_{\text {purga }} \cdot \mathrm{h}_{\text {purga }}+\mathrm{Q}_{\text {reaq }} \\
& \mathrm{Q}_{\mathrm{c}}=\left(\mathrm{m}_{\text {bagaço }} \cdot \mathrm{PCI}_{\text {bagaço }}+\mathrm{m}_{\text {palha }} \cdot \mathrm{PCI}_{\text {palha }}\right) \cdot \mathrm{\eta}_{\mathrm{c}} \\
& \mathrm{\eta}_{\mathrm{c}} \cdot \mathrm{Q}_{\text {reaq }}=\dot{\mathrm{m}}_{\text {vap.reaq }} \cdot\left(\mathrm{h}_{9}-\mathrm{h}_{8}\right)
\end{aligned}
$$

Onde:

$\mathrm{Q}_{\text {reaq }}=$ energia consumida no reaquecimento do vapor que retorna para o reaquecedor $(\mathrm{kJ} / \mathrm{kg})$;

$\mathrm{h}_{8}=$ entalpia específica do vapor que segue para o reaquecedor $(\mathrm{kJ} / \mathrm{kg})$;

$\mathrm{h}_{9}=$ entalpia específica do vapor que retorna para a turbina após ser reaquecido $(\mathrm{kJ} / \mathrm{kg})$;

$\mathrm{h}_{\text {purga }}=$ entalpia específica da purga da caldeira $(\mathrm{kJ} / \mathrm{kg})$;

$\mathrm{Q}_{\mathrm{c}}=$ energia útil $(\mathrm{kJ} / \mathrm{kg})$

$\dot{\mathrm{m}}_{\text {bagaço }}=$ vazão mássica de bagaço na fornalha $(\mathrm{kg} / \mathrm{h})$;

$\dot{\mathrm{m}}_{\text {palha }}=$ vazão mássica de palha na fornalha $(\mathrm{kg} / \mathrm{h})$;

$\eta_{c}=$ eficiência térmica da caldeira $(\%)$;

$\mathrm{PCI}_{\text {bagaço }}=$ poder calorífico inferior do bagaço $(\mathrm{kJ} / \mathrm{kg})$;

$\mathrm{PCI}_{\text {palha }}=$ poder calorífico inferior da palha $(\mathrm{kJ} / \mathrm{kg})$. 
Conhecendo a eficiência témica da caldeira e a energia disponível da biomassa, podese então obter a energia útil. Uma estimativa aceitável para a taxa de purga é que esta totalize 3,0\% da vazão de vapor (MORAN e SHAPIRO, 2008). A partir disso estimam-se as vazões mássicas de vapor superaquecido e purga.

Uma estimativa de perdas energéticas na caldeira pode ser realizada a partir de $\mathrm{Eq} 7 \mathrm{e}$ Eq 8:

$$
\begin{aligned}
& \text { Boiler }_{\text {losses }}=\mathrm{POT}_{\text {entrada }} \cdot\left(1-\eta_{\mathrm{c}}\right) \\
& \text { Boiler }_{\text {losses, perc }}=\underline{\text { Boiler }_{\mathrm{POT}_{\text {entrada }}}} \cdot 100 \%
\end{aligned}
$$

Onde:

$\mathrm{POT}_{\text {entrada }}=$ potência de entrada ou energia disponível $(\mathrm{kJ} / \mathrm{kg})$;

Boiler losses $=$ perdas energéticas na caldeira $(\mathrm{kJ} / \mathrm{h})$;

Boiler losses.perc $=$ perda energética percentual na caldeira $(\%)$.

A estimativa da pressão ótima de extração do vapor para o reaquecimento está baseada em hipóteses formuladas por Guerra (2014) que, de sua parte, se fundamentam na aplicação do Método de Aproximações Quadráticas.

Tabela 4 - Pressão de extração ótima de vapor a ser efetuada na turbina para os diferentes níveis de operação caldeira em termos de pressão de vapor superaquecido

\begin{tabular}{ccc} 
Pressão da caldeira (bar) & $\begin{array}{c}\text { Pressão de extração ótima para reaquecimento } \\
\text { do vapor (bar) }\end{array}$ \\
20 & 9,10 \\
45 & 15,8 \\
67 & 21,1 \\
80 & 23,5 \\
100 & 27,4 \\
\hline
\end{tabular}

A otimização dos cenários com reaquecimento mostrou que cada condição de pressão da caldeira possui um ponto bem definido de extração. Esses valores aparecem indicados na Tabela 4. 


\subsubsection{Turbina}

A turbina é o equipamento responsável pela conversão de energia térmica em energia cinética, do que resulta energia mecânica de eixo que, de sua parte, irá acionar o gerador. Cada estágio da turbina é projetado para produzir uma quantidade de trabalho a partir de um montante estabelecido de energia térmica (SHLYAKHIN, 2005). A eficiência de uma turbina real, conhecida como eficiência isentrópica, é definida pela razão entre o trabalho de eixo real e o trabalho de eixo na expansão isentrópica (ideal), para as mesmas funções de estado de entrada na turbina e mesma pressão de saída. Essa relação, entre trabalho produzido e energia térmica disponível, resulta na eficiência interna do estágio (SALISBURY, 1974; MORAN e SHAPIRO, 2008).

A definição matemática da eficiência isentrópica da turbina está indicada a seguir em Eq 9:

$$
\eta_{\mathrm{t}}=\frac{\underline{\mathrm{h}}_{1}-\mathrm{h}_{2}}{\mathrm{~h}_{1}-\mathrm{h}_{2, \text { iso }}}
$$

Onde:

$\mathrm{h}_{1}=$ entalpia específica do vapor na entrada de um determinado estágio da turbina $(\mathrm{kJ} / \mathrm{kg})$;

$\mathrm{h}_{2}=$ entalpia específica do vapor na saída de um determinado estágio da turbina $(\mathrm{kJ} / \mathrm{kg})$

$\mathrm{h}_{2 \text { iso }}=$ entalpia na condição ideal de expansão à saída de um estágio da turbina $(\mathrm{kJ} / \mathrm{kg})$

$\eta_{\mathrm{t}}=$ eficiência isentrópica da turbina $(\%)$

A Figura 8 descreve o conjunto turbina e gerador para um dos modelos construídos com auxílio de $E E S^{\circledR}$. A turbina é alimentada pela corrente de vapor superaquecido proveniente da caldeira. No ciclo Rankine com reaquecimento, há três correntes de vapor de saída: (i) corrente do vapor de escape a 2,5 bar (Figura 8: corrente C2), que será empregada como fonte de energia térmica no processo; (ii) corrente de vapor de cauda (Figura 8: C3), a qual é extraída a 0,1 bar, e encaminhada para o condensador; e (iii) corrente de vapor que retorna para a caldeira (Figura 8: C8). Partindo da expressão de cálculo de $\left(\eta_{\mathrm{t}}\right)$ é possível determinar a entalpia real do vapor extraído para o processo (MORAN e SHAPIRO, 2008; LI e CALISAL, 2010). 
Figura 8 - Desenho esquemático ilustrativo do arranjo turbina e gerador

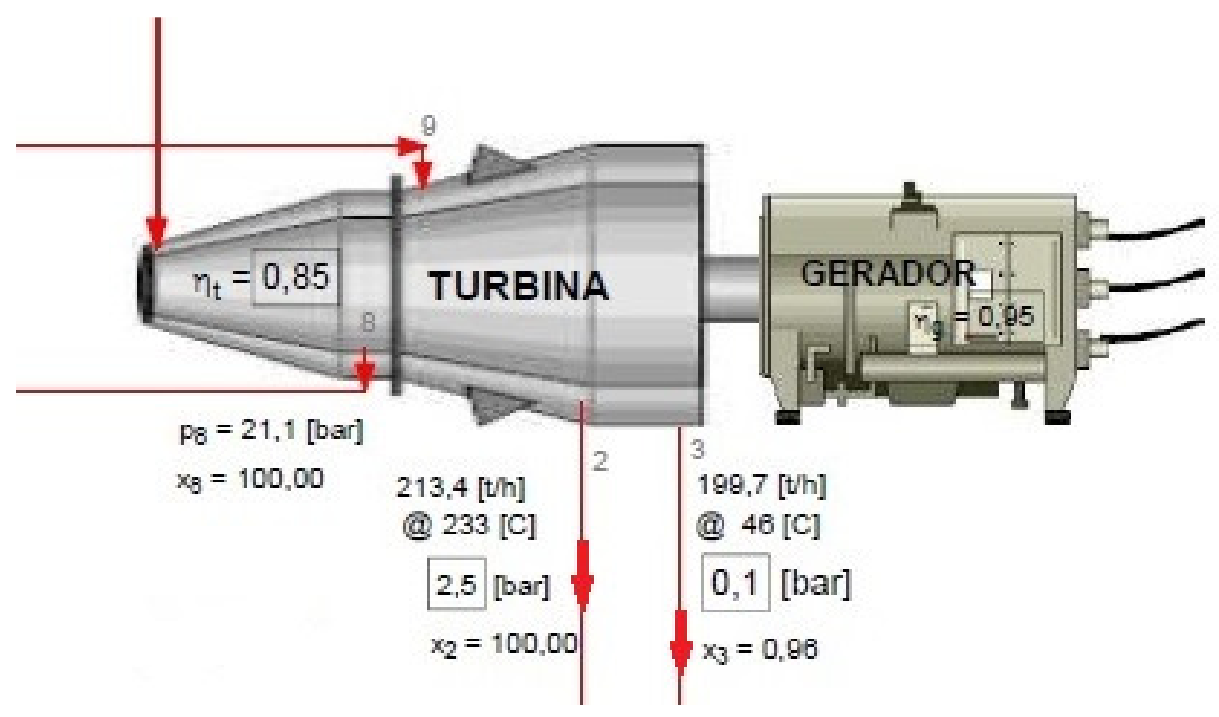

Fonte: adaptado de Guerra (2014)

Complementarmente à Eq 9 está a Eq. 10:

$$
\eta_{\mathrm{t}}=\frac{\underline{\mathrm{h}}_{1}-\mathrm{h}_{3}}{\mathrm{~h}_{1}-\mathrm{h}_{3 \text { iso }}}
$$

Onde:

$\mathrm{h}_{1}=$ entalpia específica do vapor na entrada na turbina $(\mathrm{kJ} / \mathrm{kg})$;

$\mathrm{h}_{3}=$ entalpia específica do vapor de cauda da turbina $(\mathrm{kJ} / \mathrm{kg})$;

$\mathrm{h}_{3 \text { iso }}=$ entalpia específica do vapor de cauda na condição ideal de expansão isentrópica $(\mathrm{kJ} / \mathrm{kg})$;

$\eta_{\mathrm{t}}=$ eficiência real da turbina.

O balanço de massa na turbina pode ser calculado pela Eq 11:

$$
\dot{\mathrm{m}}_{\text {vapor }}=\dot{\mathrm{m}}_{\text {vap.escape }}+\dot{\mathrm{m}}_{\text {vap.cauda }}
$$

\section{Onde:}

m vapor = vazão mássica do vapor superaquecido de alimentação da turbina $(\mathrm{t} / \mathrm{h})$;

$\dot{\mathrm{m}}$ vap.escape = vazão mássica do vapor de escape $(\mathrm{t} / \mathrm{h})$;

$\dot{\mathrm{m}}$ vap.cauda $=$ vazão mássica do vapor de cauda $(\mathrm{t} / \mathrm{h})$. 
As potências elétricas do sistema foram determinadas pelas equações Eq 12 a Eq 14:

$$
\begin{aligned}
& \mathrm{POT}_{\text {eletr.gerada }}=\left(\mathrm{POT}_{1}+\mathrm{POT}_{2}\right) \cdot \eta_{\mathrm{g}} \\
& \mathrm{POT}_{1}=\dot{\mathrm{m}}_{\text {vap.escape }} \cdot\left(\mathrm{h}_{1}-\mathrm{h}_{2}\right) \\
& \mathrm{POT}_{2}=\dot{\mathrm{m}}_{\text {vap.cauda } .}\left(\mathrm{h}_{1}-\mathrm{h}_{3}\right)
\end{aligned}
$$

Onde:

$\mathrm{POT}_{\text {eletr.gerada }}=$ potência elétrica gerada no turbogerador $(\mathrm{kJ} / \mathrm{h})$;

$\mathrm{POT}_{1}=$ potência elétrica gerada associada ao vapor de escape $(\mathrm{kJ} / \mathrm{h})$;

$\mathrm{POT}_{2}=$ potência elétrica gerada associada ao vapor de cauda $(\mathrm{kJ} / \mathrm{h})$;

$\eta_{\mathrm{g}}=$ eficiência do gerador $(\%)$.

\subsubsection{Condensador}

A unidade de condensação se encarrega de descartar calor excedente do sistema para o meio ambiente ao condensar o vapor de cauda da turbina até que este atinja limites de líquido saturado. $\mathrm{O}$ condensador é projetado de modo a proporcionar a pressão de condensação desejada (STOECKER, 1989; MAULBETSCH \&DI FILIPPO, 2006). Para este estudo admitiu-se que a pressão de condensação seria de 0,1 bar. Este valor é frequentemente empregado no dimensionamento de unidades de cogeração que operam no setor sucroalcooleiro com turbinas do tipo extração-condensação (MAULBETSCH eDI FILIPPO, 2006). A Figura 9 mostra o funcionamento do conjunto formado por condensador e torre de resfriamento do ciclo Rankine com reaquecimento que foi elaborado no $E E S^{\circledR}$.

Figura 9 - Ilustração do conjunto condensador e torre de resfriamento.

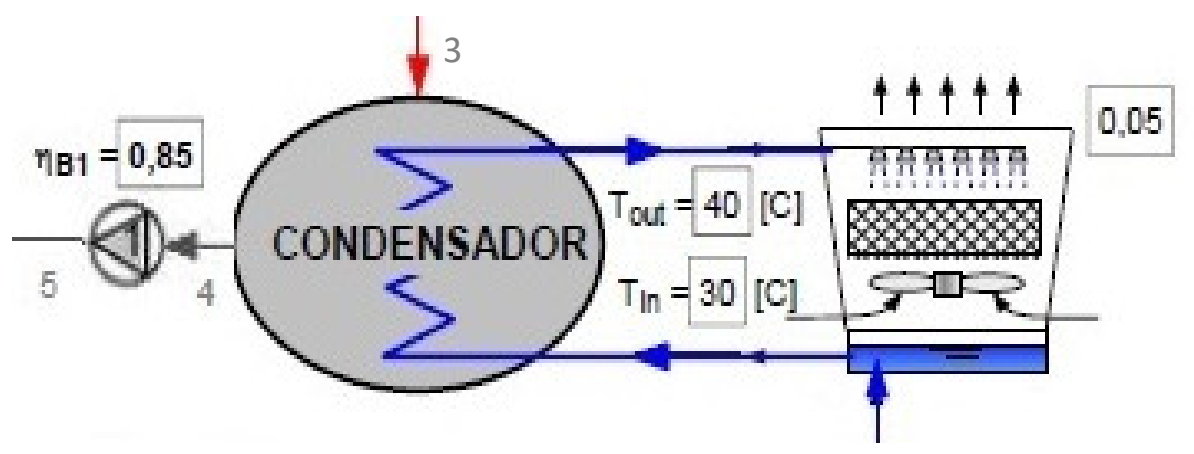

Fonte: adaptado de Guerra (2014) 
O vapor de cauda circula através do condensador (Figura 9: C3 e C4). As temperaturas de entrada e saída da água de recirculação na torre de resfriamento $\left(\mathrm{T}_{\text {in }}\right.$ e $\left.\mathrm{T}_{\text {out }}\right)$ são parâmetros de projeto desse equipamento. Seu dimensionamento leva em conta considerações econômicas e restrições impostas pelo sistema. No projeto, deve-se garantir a remoção da carga térmica do vapor de processo, além de assegurar uma temperatura mínima para a água resfriada. $\mathrm{O}$ valor dessa temperatura compreende uma das considerações essenciais de projeto da torre, pelo fato de exercer grande impacto sobre seu custo (CORTINOVIS, 2004).

$\mathrm{Na}$ modelagem de todos os cenários estudados, adotou-se temperaturas da água de saída da torre $\mathrm{T}_{\text {in }}=30^{\circ} \mathrm{C}$, e de retorno para ela $\mathrm{T}_{\text {out }}=40^{\circ} \mathrm{C}$. Essa consideração determinou a vazão de recirculação da bomba, uma vez conhecido a taxa de transferência de energia térmica da corrente quente (vapor de cauda) para a corrente fria (água de recirculação).

Os balanços de massa e de energia no condensador podem ser realizados a partir da aplicação de Eq 15 e Eq 16:

$$
\begin{aligned}
& \dot{\mathrm{m}}_{\text {vap.cauda }}=\dot{\mathrm{m}}_{4} \\
& \mathrm{Q}_{\text {out }}=\dot{\mathrm{m}}_{\text {vap.cauda }} \cdot\left(\mathrm{h}_{3}-\mathrm{h}_{4}\right)
\end{aligned}
$$

Onde:

$\mathrm{Q}_{\text {out }}=$ calor transferido do vapor de cauda para água de recirculação da torre $(\mathrm{kJ} / \mathrm{h})$;

$\mathrm{h}_{3}=$ entalpia específica da corrente de vapor de cauda na entrada do condensador $(\mathrm{kJ} / \mathrm{h})$;

$\mathrm{h}_{4}=$ entalpia específica da corrente de líquido saturado na saída do condensador $(\mathrm{kJ} / \mathrm{h})$;

$\dot{\mathrm{m}}_{4}=$ vazão mássica de líquido saturado na saída do condensador $(\mathrm{kJ} / \mathrm{h})$.

Já os balanços material e energético na torre de resfriamento originam-se de Eq 17 e Eq 18:

$$
\begin{aligned}
& \mathrm{Q}_{\text {out }}=\dot{\mathrm{m}}_{\text {recirculação }} \cdot\left(\mathrm{h}_{\text {out }}-\mathrm{h}_{\text {in }}\right) \\
& \dot{\mathrm{m}}_{\text {repos.torre }}=\mathrm{Y}_{\text {perdas }} \cdot \dot{\mathrm{m}}_{\text {recirculação }}
\end{aligned}
$$

Onde:

$\mathrm{h}_{\text {in }}=$ entalpia específica da corrente de água de resfriamento na entrada do condensador (kJ/kg);

$\mathrm{h}_{\text {out }}=$ entalpia específica da corrente de água de resfriamento na saída do condensador $(\mathrm{kJ} / \mathrm{kg})$; 
$\dot{m} r_{\text {ecirculação }}$ vazão mássica da água de recirculação da torre $(\mathrm{kg} / \mathrm{h})$;

$\dot{\mathrm{m}}_{\text {repos.torre }}=$ vazão mássica da água de reposição da torre $(\mathrm{kg} / \mathrm{h})$;

$\mathrm{Y}_{\text {perdas }}=$ percentual de perda de água na torre de resfriamento em relação à recirculação (\%).

Faz-se necessária uma reposição de água na torre de resfriamento a fim de suprir perdas de processo que ocorrem por evaporação, arraste e purga (OLIVEIRA JR, 2012). O balanceamento do equipamento admitiu que este operasse em regime permanente. Por conta disso, a vazão de água reposição é igual ao somatório de todas as perdas da torre.

Oliveira Jr (2012) aponta que as perdas de água na torre podem alcançar $10 \%$ da vazão de água que circula no sistema. Tendo em vista tal observação, adotou-se para modelagem dos cenários em estudo uma perda de 5,0\% da vazão de água que recircula entre o condensador e a torre de resfriamento. As perdas de energia que ocorrem no condensador foram determinadas pelas equações Eq 19 e Eq 20.

$$
\begin{aligned}
& \mathrm{POT}_{\text {condensador }}=\mathrm{Q}_{\text {out }} \\
& \mathrm{POT}_{\text {condensador,perc }}=\frac{\mathrm{POT}_{\text {condensador }}}{\mathrm{POT}_{\text {entrada }}} \cdot 100 \%
\end{aligned}
$$

Onde:

$\mathrm{POT}_{\text {condensador }}=$ potência perdida no condensador $(\mathrm{kJ} / \mathrm{h})$;

$\mathrm{POT}_{\text {condensador,perc }}=$ potência percentual perdida no condensador $(\%)$.

\subsubsection{Bombas}

Uma ação de bombeamento é necessária para que a água de alimentação que é extraída da unidade de condensação retorne à caldeira. Dessa intervenção decorre uma elevação natural de pressão. Na cogeração o bombeamento é realizado em dois estágios: no primeiro estágio, encontra-se um grupo de bombas conhecido como bomba de condensado, que se encarrega da extração da água saturada da unidade condensadora. No segundo estágio de bombeamento, atua outro grupo de bombas, que elevará a pressão da água de alimentação até a pressão final. Em geral essa condição de bombeamento é submetida a grandes diferenciais 
de pressão (OLIVEIRA JR, 2010). Por conta disso, definiu-se para os cenários em análise que a pressão de alimentação é em $20 \%$ superior à pressão de operação da caldeira.

Trabalho deve ser fornecido para que as bombas desloquem o líquido de baixa até alta pressão. Parte desse trabalho é perdido por conta de irreversibilidades do processo. A eficiência de uma bomba pode ser definida como sendo o inverso da eficiência de uma turbina; ou seja, a razão entre o trabalho isentrópico e o trabalho real, a ser fornecido quando se opera entre duas pressões (MORAN e SHAPIRO, 2008). A Figura10 traz um detalhe da bomba 1, que desloca líquido saturado do condensador para o desaerador.

Figura 10 - Detalhe da bomba de recalque de condensado

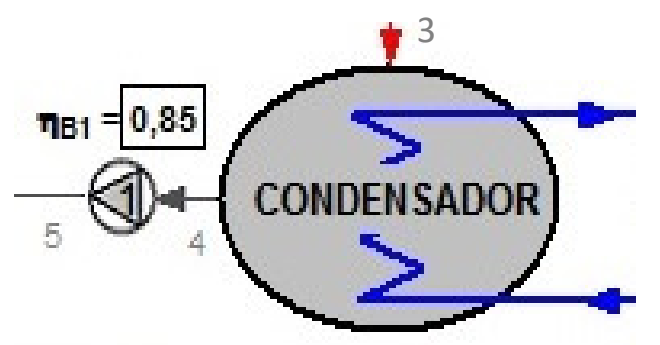

Fonte: adaptado de Guerra (2014)

A eficiência isentrópica da bomba será calculada pela equação Eq 21:

$$
\eta_{\mathrm{B} 1}=\underline{\mathrm{h}}_{4}-\frac{\mathrm{h}_{5 \text { iso }}}{\mathrm{h}_{4}-\mathrm{h}_{5}}
$$

Onde:

$\mathrm{h}_{4}=$ entalpia específica do líquido saturado na saída do condensador $(\mathrm{kJ} / \mathrm{kg})$;

$\mathrm{h}_{5}=$ entalpia específica do líquido na saída da bomba $(\mathrm{kJ} / \mathrm{kg})$;

$\mathrm{h}_{5 \text { iso }}=$ entalpia específica do líquido à saída da bomba medida na condição ideal de compressão isentrópica $(\mathrm{kJ} / \mathrm{kg})$;

$\eta_{\mathrm{B} 1}=$ eficiência isentrópica da bomba.

Uma consulta a catálogos de equipamentos levou a adotar uma eficiência isentrópica da bomba $\eta_{\mathrm{B} 1}=85 \%$. O trabalho perdido pela bomba, que corresponde à diferença $\left(\mathrm{h}_{5}-\mathrm{h}_{5 \text { iso }}\right)$ será reduzido à medida que a pressão de descarga se aproxima da pressão isentrópica de descarga. A potência consumida na bomba B1 pode ser estimada por Eq 22: 


$$
\mathrm{POT}_{\mathrm{B} 1}=\dot{\mathrm{m}}_{\text {vap.cauda }} \cdot\left(\mathrm{h}_{5}-\mathrm{h}_{4}\right)
$$

Sendo:

$\mathrm{POT}_{\mathrm{B} 1}=$ potência consumida pela bomba B1 $(\mathrm{kJ} / \mathrm{h})$;

A bomba de alimentação da caldeira (B2) foi modelada com conceitos idênticos àqueles apresentados para a modelagem da bomba do condensador (B1).

\subsubsection{Desaerador}

O desaerador é um equipamento projetado para remover gases não condensáveis do sistema, e para realizar o pré-aquecimento da água de alimentação da caldeira. A Figura 11 apresenta um esquema do desaerador construído no EES.

Figura 11 - Representação da unidade de desaeração

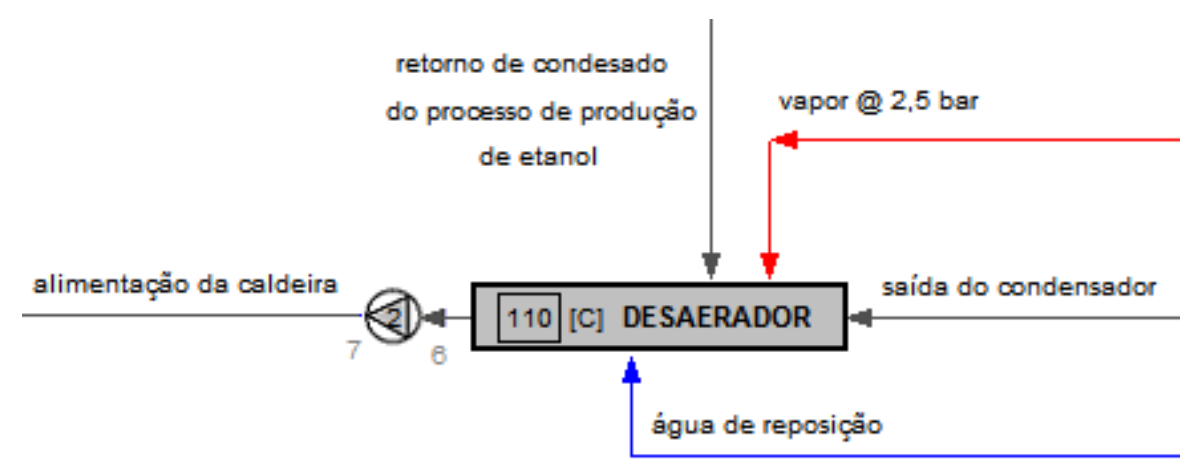

Fonte: adaptado de Guerra (2014)

Os balanços de massa e energia no desaerador estão sintetizados nas equações Eq 23 e Eq 24.

$\dot{\mathrm{m}}_{\text {retorno }}+\dot{\mathrm{m}}_{\text {vap.desaerador }}+\dot{\mathrm{m}}_{\text {vap.cauda }}+\dot{\mathrm{m}}_{\text {rep.desaerador }}=\dot{\mathrm{m}}_{\text {água }}$

$\dot{\mathrm{m}}_{\text {retorno }} \cdot \mathrm{h}_{\text {cond. }}+\dot{\mathrm{m}}_{\text {vap.desaerador }} \cdot \mathrm{h}_{2}+\dot{\mathrm{m}}_{\text {vap.cauda }} \cdot \mathrm{h}_{5}+\dot{\mathrm{m}}_{\text {rep.desaerador }} \cdot \mathrm{h}_{\text {rep.des }}=\dot{\mathrm{m}}_{\text {água }} \cdot \mathrm{h}_{6}$

Onde:

$\dot{\mathrm{m}}_{\text {retorno }}=$ vazão mássica de condensado de retorno para o processo de produção do etanol $(\mathrm{kJ} / \mathrm{h})$;

$\dot{\mathrm{m}}_{\text {vap.desaerador }}=$ vazão mássica do vapor usado para atingir o set point de desaeração $(\mathrm{kJ} / \mathrm{h})$; 
$\dot{\mathrm{m}}_{\text {vap.cauda }}=$ vazão mássica do vapor de cauda da turbina a ser bombeado para o desaerador $(\mathrm{kJ} / \mathrm{h})$;

$\dot{\mathrm{m}}_{\text {rep.desaerador }}=$ vazão mássica de reposição de água no desaerador $(\mathrm{kJ} / \mathrm{h})$;

$\dot{\mathrm{m}}_{\text {água }}=$ vazão mássica da água de alimentação da caldeira $(\mathrm{kJ} / \mathrm{h})$;

$\mathrm{h}_{\text {cond }}=$ entalpia específica do condensado de retorno para a produção de etanol $(\mathrm{kJ} / \mathrm{h})$;

$\mathrm{h}_{2}=$ entalpia específica da corrente de vapor a 2,5 bar que alimenta o desaerador $(\mathrm{kJ} / \mathrm{h})$;

$\mathrm{h}_{5}=$ entalpia específica da corrente do condensado procedente do condensador $(\mathrm{kJ} / \mathrm{h})$;

$\mathrm{h}_{\text {rep.des }}=$ entalpia específica da corrente de água de reposição do desaerador $(\mathrm{kJ} / \mathrm{h})$;

$\mathrm{h}_{6}=$ entalpia específica da corrente de água na saída do desaerador $(\mathrm{kJ} / \mathrm{h})$.

Do ponto de vista de modelagem, a vazão de água de alimentação da caldeira pode ser conhecida via balanços de massa e energia. Assim como já fora apresentado na seção 4.2.1 'Premissas e definições de parâmetros usados na construção de cenários' a vazão de retorno de condensado desde a produção de etanol está também identificado, pelo fato de a vazão de vapor saturado seco a $\mathrm{P}=2,5$ bar usado no processamento de $\mathrm{C}_{2} \mathrm{H}_{6} \mathrm{O}(99,5 \% \mathrm{v} / \mathrm{v})$ ter sido fixado em $400 \mathrm{~kg} / \mathrm{t}_{\mathrm{c}}$ (Tabela 3). Admitiu-se que $90 \%$ do vapor saturado que foi utilizado pelo processo retorna na forma de condensado para o desaerador; o restante se perde na forma de emissões atmosféricas e efluentes líquidos ao longo do processo.

Como as propriedades de estado das mesmas correntes são conhecidas, determinou-se então a vazão da água de reposição do desaerador, e o consumo de vapor utilizados para atingir o set point de $110^{\circ} \mathrm{C}$ no equipamento. Essa consideração resultou em fechamento dos balanços. Por fim, o balanço energético do desaerador desprezou perdas de calor para o ambiente (ou seja, este foi tratado como adiabático).

\subsubsection{Cogeração}

A cogeração compreende um ciclo Rankine, com sistema de reaquecimento, comum em unidades elétricas de alto desempenho instaladas no estado de São Paulo (GUERRA et al, 2014). A Tabela 5 traz as propriedades da biomassa utilizada nesta etapa do processo. A variabilidade em torno desses dados é bastante elevada. Isso se deve às diferentes características do solo nas regiões em que a cana é cultivada. Este estudo baseou suas 
condicionantes em valores propostos por Leal (2013) pelo fato destes serem típicos para as características atuais da cana-de-açúcar processada no estado de São Paulo.

Tabela 5 - Características e propriedades do bagaço e palha de cana-de-açúcar

\begin{tabular}{lcc} 
Propriedade & Bagaço & Palha ${ }^{(* * *)}$ \\
Poder Calorífico Inferior (PCI) $(\mathrm{kJ} / \mathrm{kg})$ & 7565 & 12960 \\
Umidade absoluta (\%) & 50 & 15 \\
C (\%) & $44,6^{(*)}$ & $45,7^{(* *)}$ \\
H $(\%)$ & $5,80^{(*)}$ & $6,20^{(* *)}$ \\
O $(\%)$ & $44,5^{(*)}$ & $42.8^{(* *)}$ \\
\hline
\end{tabular}

Fonte: Leal et al (2013)

Observações: ${ }^{(*)}$ base seca; ${ }^{(* *)}$ folhas verdes; ${ }^{(* * *)}$ dados padronizados para palha, que foram empregados para efeito de estimativas realizadas para cada cenário.

A quantidade de energia excedente do processo foi determinada para cenário em análise, a partir do conjunto de equações lineares (Eq 25 a Eq 27) apresentado a seguir.

$E_{e}=E_{T}-E_{P T}$

$\mathrm{E}_{\mathrm{T}}=\left(\mathrm{HVAP}_{\mathrm{V}}-\Sigma \mathrm{H}_{\mathrm{VBP}}\right) . \eta$

$\mathrm{E}_{\mathrm{PT}}=\Sigma\left(\mathrm{E}_{\mathrm{P}}\right)_{\mathrm{i}}$

(Eq 27)

Sendo:

$\mathrm{E}_{\mathrm{e}}=$ energia excedente $(\mathrm{MWh})$

$\mathrm{E}_{\mathrm{T}}=$ energia total gerada (MWh)

$\mathrm{E}_{\mathrm{PT}}=$ energia total consumida no processo $(\mathrm{MWh})$

$\left(\mathrm{E}_{\mathrm{P}}\right)_{\mathrm{i}}=$ energia consumida em cada etapa do processo $(\mathrm{MWh})$

$\mathrm{HvAP}_{\text {val }}$ entalpia do vapor de água de alta pressão

$\mathrm{H}_{\mathrm{VBPi}}=$ entalpia do vapor de água de baixa pressão

$\eta=$ Eficiência 
O processo de cogeração foi modelado a partir de dados secundários, obtidos junto a Dias et al (2009 e 2011), Oliveira Jr (2012), Florio e Oliveira Jr (2014) e Guerra et al (2014), sempre com apoio do programa computacional EES ${ }^{\circledR}$. Tal como aparece indicado na seção 4.2.4 os resultados dessa incursão teórica foram comparados a dados reais no intuito de validar o modelo.

Depois de serem efetuados os ajustes necessários verificou-se que os desvios existentes entre os dados hipotéticos e aqueles que foram coletados durante visitas de campo apresentavam uma variação inferior a 2,5\% para todos os indicadores de desempenho (vide mais uma vez a seção 4.2.4), condição considerada aceitável para efeito dos fins a que este estudo se propõe.

\subsection{Aspectos Específicos da Avaliação Ambiental}

\subsubsection{Definição de Objetivo e Definição de Escopo: Função, Unidade Funcional e Fluxo de Referência}

Este estudo foi conduzido de acordo com as diretrizes estabelecidas pela norma ABNT NBR ISO 14044 (ABNT, 2009b). A modelagem do ciclo de vida ocorreu a partir de abordagem atribucional. Assim, no que se refere à Definição de Objetivos a iniciativa se propôs a efetuar uma análise ambiental de ações para melhoria de desempenho de unidades de cogeração de energia elétrica a partir de queima de bagaço e de palha da cana-de-açúcar. Quanto ao enfoque metodológico decidiu-se por um escopo de aplicação da técnica de ACV do tipo "berço-ao-portão". Por conta disso, processamentos que ocorrem nas etapas de pósprodução do ciclo de vida foram desconsiderados pela análise.

Em termos de Definição de Escopo foram estabelecidos os requisitos que se seguem:

Função: produzir energia elétrica excedente em sistema de cogeração movido por bagaço e palha de cana-de-açúcar em condições desta ser absorvida pela rede concessionária;

Unidade Funcional (UF): dado que o estudo foi desenvolvido segundo escopo do tipo 'berçoao-portão', não há sentido em arbitrar-se um valor de UF, mas sim, e antes, de estabelecer um Fluxo de Referência (FR) para levar adiante a análise. Admitiu-se por conta disso que o sistema de produto em análise deveria se capaz produzir $10 \mathrm{t}$ de etanol $\left(\mathrm{C}_{2} \mathrm{H}_{6} \mathrm{O}, 99,5 \% \mathrm{v} / \mathrm{v}\right)$. 


\subsubsection{Sistema de produto e fronteiras do sistema}

Muito embora o FR remetesse à produção de etanol, o foco da ACV permaneceu voltado para cogeração de eletricidade via queima de biomassa. Nesses termos o sistema de produto compreendeu as etapas de (i) produção agrícola de cana-de-açúcar, (ii) enfardamento da palha, (iii) transporte de ambas as matérias-primas agrícolas até a destilaria, (iv) produção de etanol, (v) moagem da palha e (vi) cogeração de eletricidade. O diagrama completo do sistema de produto é apresentado na Figura 12.

O modelo agrícola adotado nesse estudo seguiu os procedimentos, condutas e práticas convencionais exercitadas no estado de São Paulo. A partir de indicações contidas em CONAB (2014), definiu-se em 85,6 t t $_{\mathrm{c}}$ ha o nível de produtividade agrícola da cana-de-açúcar na região. Este valor refere-se à média de desempenhos no período compreendido entre 2005 e 2013.

O grau de mecanização das lavouras é tal que $85 \%$ do preparo da área e outros $90 \%$ da colheita ocorrem com o auxílio de máquinas (GUERRA, 2014). Resíduos industriais, como torta de filtro, vinhaça e cinzas da caldeira são reutilizados como fonte de fornecimento de nutrientes para o cultivo agrícola. Quanto à utilização da palha, considerou-se a hipótese de que a fração não utilizada na cogeração seria deixada no campo para cumprir funções de proteção do solo e da cana, como já havia sido adiantado na seção 3.1.2.5.

$\mathrm{Na}$ etapa de cultivo foram considerados: (i) uso de fertilizantes para efeito de suprimento de macronutrientes primários (N, P, K), (ii) ajuste de acidez com calcário; e (iii) controle de pragas para manutenção das taxas de desempenho agrícola. A administração para o solo dos resíduos industriais de processo foi considerada fonte complementar de nutrição.

A produtividade de 83,3 L de etanol/t cana é obtida por meio da fermentação alcoólica do caldo da cana a temperatura $\left(26-32^{\circ} \mathrm{C}\right)$ e a acidez $(4,5<\mathrm{pH}<5,5)$ controladas. $\mathrm{O}$ etanol gerado neste processo é destilado, retificado e desidratado até atingir 99,5\% $\%_{\mathrm{v} / \mathrm{v}}$. Para tanto, serão necessários $1030 \mathrm{~kg}$ de caldo de cana, e $30 \mathrm{kWh}$ de eletricidade, obtidos integralmente a partir de queima de biomassa. Desse total, exatos $17 \mathrm{kWh} / \mathrm{t}_{\mathrm{c}}$ são consumidos na moagem da cana, e os demais $13 \mathrm{kWh} / \mathrm{t}_{\mathrm{c}}$ sustentam demandas elétricas da destilaria e da própria cogeração (SEABRA e MACEDO, 2011). 


\subsubsection{Tipo e qualidade dos dados, e Tratamento de multifuncionalidades}

O estudo foi baseado em dados primários e secundários. Os Inventários do Ciclo de Vida (ICV) para as produções de cana e etanol, que compreendem os dados primários, foram obtidos por intermédio de parceria técnico-científica estabelecida com o Laboratório Nacional de Ciência e Tecnologia do Bioetanol (CTBE) (CAVALETT et al, 2013; BONOMI et al, 2016).

A Cobertura Temporal compreendeu o período de 2008 a 2015 para os dados da etapa agrícola, quando foi possível obter uma série histórica consistente e representativa da realidade a que o estudo se propõe a examinar. Quanto à Cobertura Geográfica esta remeteu ao estado de São Paulo em função de sua prevalência em termos de produção nacional de cana-de-açúcar e de etanol. Finalmente, no tocante à Cobertura Tecnológica admitiram-se as características, condicionantes, bem como os aspectos construtivos e de processo descritos em diferentes seções deste documento.

As multifuncionalidades foram tratadas sempre por meio do procedimento de alocação. A primeira dessas situações ocorre na etapa agrícola, exatamente entre cana-deaçúcar e palha. Para a referida situação fez-se uso do critério mássico. Por conta disso, as cargas ambientais relativas a cada produto variam em função do valor de $u_{p}(\%)$ para a palha.

A segunda situação de multifuncionalidade ocorre na destilaria entre etanol, condensado de retorno, vinhaça e torta de filtro. Esta foi tratada por alocação mássica, e os fatores atribuídos a cada coproduto são: etanol 4,86\%, condensado de retorno $26,5 \%$, vinhaça $66,7 \%$ e torta de filtro $1,92 \%$.

A última das situações de multifuncionalidade ocorre na cogeração. Esta remete as correntes de eletricidade exportada, eletricidade para o processo, vapor de baixa pressão e cinzas. Para essa situação decidiu-se por alocação energética e, com isso, a cinza de retorno para o campo não acumulou cargas ambientais. Já os fatores de alocação estabelecidos para os demais coprodutos variaram em função das quantidades de eletricidade exportada e eletricidade consumida no processo. Estes aparecem indicados a seguir nas Tabelas 6 a 10. 
Figura12 Sistema de prodıtos para cogeração de eletricidade a partir de biomassa de cana-de-açicar.

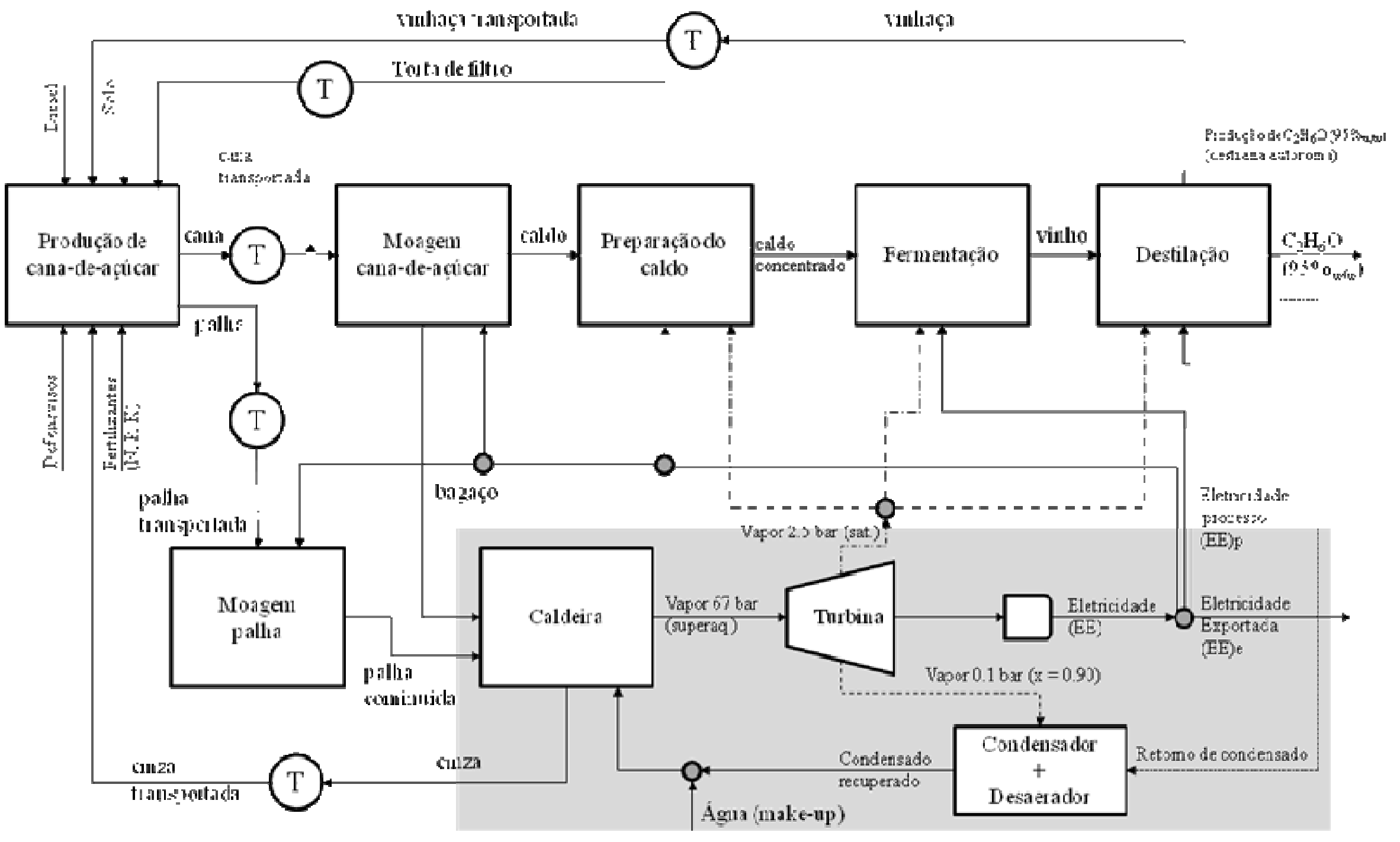


Tabela 6 - Fatores de alocação para partição de cargas ambientais entre eletricidade exportada, eletricidade consumida no processo, e vapor de alta pressão (@ 20 bar)

\begin{tabular}{|c|c|c|c|c|}
\hline \multirow{2}{*}{$\begin{array}{c}\text { Taxa de } \\
\text { adição de } \\
\text { palha } \\
(\%)\end{array}$} & \multirow{2}{*}{$\begin{array}{l}\text { Umidade da } \\
\text { palha } \\
(\%)\end{array}$} & \multicolumn{3}{|c|}{ Fator de Alocação } \\
\hline & & $\begin{array}{c}\text { Eletricidade } \\
\text { Exportada (\%) }\end{array}$ & $\begin{array}{c}\text { Eletricidade } \\
\text { Processo (\%) }\end{array}$ & $\begin{array}{c}\text { Vapor de baixa pressão } \\
(\%)\end{array}$ \\
\hline \multirow{5}{*}{10} & 10 & 18,52 & 8,32 & 73,16 \\
\hline & 15 & 18,33 & 8,36 & 73,31 \\
\hline & 25 & 17,91 & 8,44 & 73,65 \\
\hline & 35 & 17,48 & 8,53 & 73,99 \\
\hline & 50 & 16,80 & 8,71 & 74,49 \\
\hline \multirow{5}{*}{20} & 10 & 20,79 & 8,11 & 71,10 \\
\hline & 15 & 20,34 & 8,42 & 71,24 \\
\hline & 25 & 19,56 & 8,57 & 71,87 \\
\hline & 35 & 18,75 & 8,75 & 72,50 \\
\hline & 50 & 17,41 & 9,11 & 73,48 \\
\hline \multirow{5}{*}{30} & 10 & 22,81 & 8,37 & 68,82 \\
\hline & 15 & 22,26 & 8,47 & 69,27 \\
\hline & 25 & 21,15 & 8,69 & 70,16 \\
\hline & 35 & 19,95 & 8,96 & 71,09 \\
\hline & 50 & 17,99 & 9,49 & 72,52 \\
\hline \multirow{5}{*}{40} & 10 & 24,75 & 8,39 & 66,86 \\
\hline & 15 & 24,08 & 8,52 & 67,40 \\
\hline & 25 & 22,64 & 8,81 & 68,55 \\
\hline & 35 & 21,11 & 9,17 & 69,72 \\
\hline & 50 & 18,55 & 9,87 & 71,58 \\
\hline \multirow{5}{*}{50} & 10 & 26,61 & 8,41 & 64,98 \\
\hline & 15 & 25,86 & 8,56 & 65,59 \\
\hline & 25 & 24,07 & 8,93 & 67,00 \\
\hline & 35 & 22,22 & 9,36 & 68,42 \\
\hline & 50 & 19,10 & 10,24 & 70,66 \\
\hline
\end{tabular}


Tabela 7 - Fatores de alocação para partição de cargas ambientais entre eletricidade exportada, eletricidade consumida no processo, e vapor de alta pressão (@ 45 bar).

\begin{tabular}{|c|c|c|c|c|}
\hline \multirow{2}{*}{$\begin{array}{c}\text { Taxa de } \\
\text { adição de } \\
\text { palha } \\
(\%)\end{array}$} & \multirow{2}{*}{$\begin{array}{l}\text { Umidade da } \\
\text { palha } \\
(\%)\end{array}$} & \multicolumn{3}{|c|}{ Fator de Alocação } \\
\hline & & $\begin{array}{c}\text { Eletricidade } \\
\text { Exportada (\%) }\end{array}$ & $\begin{array}{l}\text { Eletricidade } \\
\text { Processo (\%) }\end{array}$ & $\begin{array}{c}\text { Vapor de baixa pressão } \\
(\%)\end{array}$ \\
\hline \multirow{5}{*}{10} & 10 & 24,23 & 7,74 & 68,03 \\
\hline & 15 & 24,04 & 7,77 & 68,19 \\
\hline & 25 & 23,61 & 7,85 & 68,54 \\
\hline & 35 & 23,18 & 7,94 & 68,88 \\
\hline & 50 & 22,48 & 8,11 & 69,41 \\
\hline \multirow{5}{*}{20} & 10 & 26,54 & 7,73 & 65,73 \\
\hline & 15 & 26,23 & 7,81 & 65,96 \\
\hline & 25 & 25,34 & 7,95 & 66,71 \\
\hline & 35 & 24,52 & 8,13 & 67,35 \\
\hline & 50 & 23,31 & 8,50 & 68,19 \\
\hline \multirow{5}{*}{30} & 10 & 28,67 & 7,73 & 63,60 \\
\hline & 15 & 28,12 & 7,83 & 64,05 \\
\hline & 25 & 26,99 & 8,05 & 64,96 \\
\hline & 35 & 25,79 & 8,31 & 65,90 \\
\hline & 50 & 23,81 & 8,82 & 67,37 \\
\hline \multirow{5}{*}{40} & 10 & 30,67 & 7,73 & 61,60 \\
\hline & 15 & 29,99 & 7,86 & 62,15 \\
\hline & 25 & 28,55 & 8,14 & 63,31 \\
\hline & 35 & 27,01 & 8,48 & 64,51 \\
\hline & 50 & 24,43 & 9,16 & 66,41 \\
\hline \multirow{5}{*}{50} & 10 & 32,57 & 7,72 & 59,71 \\
\hline & 15 & 31,75 & 7,88 & 60,37 \\
\hline & 25 & 30,03 & 8,23 & 61,74 \\
\hline & 35 & 28,17 & 8,65 & 63,18 \\
\hline & 50 & 25,05 & 9,49 & 65,46 \\
\hline
\end{tabular}


Tabela 8 - Fatores de alocação para partição de cargas ambientais entre eletricidade exportada, eletricidade consumida no processo, e vapor de alta pressão (@67 bar).

\begin{tabular}{|c|c|c|c|c|}
\hline \multirow{2}{*}{$\begin{array}{c}\text { Taxa de } \\
\text { adição de } \\
\text { palha } \\
(\%)\end{array}$} & \multirow{2}{*}{$\begin{array}{l}\text { Umidade da } \\
\text { palha } \\
(\%)\end{array}$} & \multicolumn{3}{|c|}{ Fator de Alocação } \\
\hline & & $\begin{array}{c}\text { Eletricidade } \\
\text { Exportada (\%) }\end{array}$ & $\begin{array}{l}\text { Eletricidade } \\
\text { Processo (\%) }\end{array}$ & $\begin{array}{c}\text { Vapor de baixa pressão } \\
(\%)\end{array}$ \\
\hline \multirow{5}{*}{10} & 10 & 27,52 & 7,41 & 65,07 \\
\hline & 15 & 27,32 & 7,44 & 65,24 \\
\hline & 25 & 26,89 & 7,51 & 65,60 \\
\hline & 35 & 26,45 & 7,60 & 65,95 \\
\hline & 50 & 25,76 & 7,77 & 66,47 \\
\hline \multirow{5}{*}{20} & 10 & 29,85 & 7,39 & 62,76 \\
\hline & 15 & 29,45 & 7,45 & 63,10 \\
\hline & 25 & 28,65 & 7,60 & 63,75 \\
\hline & 35 & 27,83 & 7,77 & 64,40 \\
\hline & 50 & 26,47 & 8,11 & 65,42 \\
\hline \multirow{5}{*}{30} & 10 & 32,01 & 7,37 & 60,62 \\
\hline & 15 & 31,47 & 7,47 & 61,06 \\
\hline & 25 & 30,34 & 7,68 & 61,98 \\
\hline & 35 & 29,13 & 7,93 & 62,94 \\
\hline & 50 & 27,16 & 8,43 & 64,41 \\
\hline \multirow{5}{*}{40} & 10 & 34,03 & 7,35 & 58,62 \\
\hline & 15 & 33,35 & 7,48 & 59,17 \\
\hline & 25 & 31,88 & 7,76 & 60,36 \\
\hline & 35 & 30,37 & 8,09 & 61,54 \\
\hline & 50 & 27,81 & 8,75 & 63,44 \\
\hline \multirow{5}{*}{50} & 10 & 35,93 & 7,34 & 56,73 \\
\hline & 15 & 35,12 & 7,49 & 57,39 \\
\hline & 25 & 33,41 & 7,83 & 58,76 \\
\hline & 35 & 31,56 & 8,24 & 60,20 \\
\hline & 50 & 28,45 & 9,06 & 62,49 \\
\hline
\end{tabular}


Tabela 9 - Fatores de alocação para partição de cargas ambientais entre eletricidade exportada, eletricidade consumida no processo, e vapor de alta pressão (@ 80 bar).

\begin{tabular}{|c|c|c|c|c|}
\hline \multirow{2}{*}{$\begin{array}{c}\text { Taxa de } \\
\text { adição de } \\
\text { palha } \\
(\%)\end{array}$} & \multirow{2}{*}{$\begin{array}{l}\text { Umidade da } \\
\text { palha } \\
(\%)\end{array}$} & \multicolumn{3}{|c|}{ Fator de Alocação } \\
\hline & & $\begin{array}{c}\text { Eletricidade } \\
\text { Exportada (\%) }\end{array}$ & $\begin{array}{l}\text { Eletricidade } \\
\text { Processo (\%) }\end{array}$ & $\begin{array}{c}\text { Vapor de baixa pressão } \\
(\%)\end{array}$ \\
\hline \multirow{5}{*}{10} & 10 & 28,99 & 7,25 & 63,76 \\
\hline & 15 & 28,79 & 7,29 & 63,92 \\
\hline & 25 & 28,36 & 7,36 & 64,28 \\
\hline & 35 & 27,92 & 7,45 & 64,63 \\
\hline & 50 & 27,22 & 7,62 & 65,16 \\
\hline \multirow{5}{*}{20} & 10 & 31,34 & 7,23 & 61,43 \\
\hline & 15 & 30,93 & 7,30 & 61,77 \\
\hline & 25 & 30,13 & 7,44 & 62,43 \\
\hline & 35 & 29,31 & 7,61 & 63,08 \\
\hline & 50 & 27,95 & 7,94 & 64,11 \\
\hline \multirow{5}{*}{30} & 10 & 33,50 & 7,21 & 59,29 \\
\hline & 15 & 32,96 & 7,30 & 59,74 \\
\hline & 25 & 31,83 & 7,52 & 60,65 \\
\hline & 35 & 30,62 & 7,77 & 61,61 \\
\hline & 50 & 28,65 & 8,26 & 63,09 \\
\hline \multirow{5}{*}{40} & 10 & 35,53 & 7,19 & 57,28 \\
\hline & 15 & 34,85 & 7,31 & 57,84 \\
\hline & 25 & 33,41 & 7,59 & 59,00 \\
\hline & 35 & 31,88 & 7,91 & 60,21 \\
\hline & 50 & 29,31 & 8,57 & 62,12 \\
\hline \multirow{5}{*}{50} & 10 & 37,43 & 7,17 & 55,40 \\
\hline & 15 & 36,62 & 7,32 & 56,06 \\
\hline & 25 & 34,91 & 7,65 & 57,44 \\
\hline & 35 & 33,07 & 8,06 & 58,87 \\
\hline & 50 & 29,98 & 8,86 & 61,16 \\
\hline
\end{tabular}


Tabela 10 - Fatores de alocação para partição de cargas ambientais entre eletricidade exportada, eletricidade consumida no processo, e vapor de alta pressão (@100 bar).

\begin{tabular}{|c|c|c|c|c|}
\hline \multirow{2}{*}{$\begin{array}{c}\text { Taxa de } \\
\text { adição de } \\
\text { palha } \\
(\%)\end{array}$} & \multirow{2}{*}{$\begin{array}{l}\text { Umidade da } \\
\text { palha } \\
(\%)\end{array}$} & \multicolumn{3}{|c|}{ Fator de Alocação } \\
\hline & & $\begin{array}{c}\text { Eletricidade } \\
\text { Exportada (\%) }\end{array}$ & $\begin{array}{c}\text { Eletricidade } \\
\text { Processo (\%) }\end{array}$ & $\begin{array}{c}\text { Vapor de baixa pressão } \\
(\%)\end{array}$ \\
\hline \multirow{5}{*}{10} & 10 & 30,22 & 7,13 & 62,65 \\
\hline & 15 & 30,02 & 7,16 & 62,82 \\
\hline & 25 & 29,59 & 7,24 & 63,17 \\
\hline & 35 & 29,15 & 7,32 & 63,53 \\
\hline & 50 & 28,45 & 7,49 & 64,06 \\
\hline \multirow{5}{*}{20} & 10 & 32,57 & 7,10 & 60,33 \\
\hline & 15 & 32,17 & 7,17 & 60,66 \\
\hline & 25 & 31,37 & 7,31 & 61,32 \\
\hline & 35 & 30,55 & 7,48 & 61,97 \\
\hline & 50 & 29,19 & 7,81 & 63,00 \\
\hline \multirow{5}{*}{30} & 10 & 34,75 & 7,07 & 58,18 \\
\hline & 15 & 34,20 & 7,17 & 58,63 \\
\hline & 25 & 33,07 & 7,38 & 59,55 \\
\hline & 35 & 31,87 & 7,63 & 60,50 \\
\hline & 50 & 29,90 & 8,11 & 61,99 \\
\hline \multirow{5}{*}{40} & 10 & 36,77 & 7,05 & 56,18 \\
\hline & 15 & 36,09 & 7,17 & 56,74 \\
\hline & 25 & 34,66 & 7,44 & 57,90 \\
\hline & 35 & 33,13 & 7,77 & 59,10 \\
\hline & 50 & 30,57 & 8,42 & 61,01 \\
\hline \multirow{5}{*}{50} & 10 & 38,67 & 7,02 & 54,31 \\
\hline & 15 & 37,87 & 7,17 & 54,96 \\
\hline & 25 & 36,17 & 7,51 & 56,32 \\
\hline & 35 & 34,35 & 7,90 & 57,75 \\
\hline & 50 & 31,24 & 8,70 & 60,06 \\
\hline
\end{tabular}




\subsubsection{Método de Avaliação de Impactos e Categorias de Impacto Ambiental}

A avaliação de impacto foi conduzida a partir da aplicação do método ReCiPe midpoint (H) v1.12 (GOEDKOOP et al, 2013). Para levar adiante a referida avaliação, foram selecionadas as seguintes categorias de impacto: Mudança Climática (CC), Acidificação Terrestre (TAc), Eutrofização Aquática (FEu), além da Formação de Oxidante Fotoquímica (POF) e Formação de Material Particulado (PMF). A opção por tais recortes da matéria ambiental foi decidida em função das particularidades do objeto de estudo, assim como, do caráter da análise. 


\section{RESULTADOS E DISCUSSÃO}

\subsection{Análise termodinâmica}

A análise do desempenho termodinâmico foi conduzida por meio da comparação entre os principais indicadores de desempenho de cada cenário. Tal como já foi detalhado antes, estes índices foram obtidos para distintas condições de pressão de operação da caldeira (P), taxa de adição de palha (A) e teor de umidade dessa biomassa (u).

Os totais de eletricidade excedente $\left(\mathrm{E}_{\mathrm{e}}\right)$ que foram calculadas a partir das equações $\mathrm{Eq}$ 25 a Eq 32 para variadas condições de operação do ciclo Rankine aparecem descritos a seguir na Tabela 11. O perfil de distribuição demonstrado por aqueles resultados leva a concluir que $E_{e}$ não guarda uma relação de linearidade com as variações de $\left(\mathrm{P}_{\mathrm{i}}, \mathrm{A}_{\mathrm{j}}, \mathrm{u}_{\mathrm{k}}\right)$ que foram testadas nesta análise. Isso se deve ao fato já reportado de os consumos de eletricidade ocorridos na destilaria se manterem constantes para uma produção fixa de etanol (que para o caso presente foi definida como sendo de $10 \mathrm{t}$ ), ao mesmo tempo que a energia total $\left(\mathrm{E}_{\mathrm{T}}\right)$ produzida aumenta com a adição de biomassa, mais especificamente, de palha, mesmo que está apresente teores de umidade mais elevados. O consumo de energia térmica do processo permanece também inalterado em todos os cenários, mais uma vez em virtude da fixação do volume produzido de etanol. Tal como aparece descrito na seção 4.2.1 o montante adotado para este parâmetro no caso presente foi de $400 \mathrm{~kg} / \mathrm{tc}_{\mathrm{c}}$ (ou seja, 272,0 kWh/t $\mathrm{c}$ quando expresso na forma de conteúdo energético de vapor saturado @ 2,5 bar e $\mathrm{x}=1,0)$. 
Tabela 11 - Eletricidade Excedente gerada em cada cenário de análise

\begin{tabular}{|c|c|c|c|c|c|c|c|}
\hline Cenário & Palha (\%) & $\begin{array}{l}\text { Umidade da } \\
\text { palha }(\%)\end{array}$ & $\begin{array}{c}\text { Eletricidade } \\
\text { (MWh/FR) } \\
20 \mathrm{bar}\end{array}$ & $\begin{array}{c}\text { Eletricidade } \\
\text { (MWh/FR) } \\
45 \text { bar }\end{array}$ & $\begin{array}{c}\text { Eletricidade } \\
\text { (MWh/FR) } \\
\text { 67bar }\end{array}$ & $\begin{array}{c}\text { Eletricidade } \\
\text { (MWh/FR) } \\
80 \text { bar }\end{array}$ & $\begin{array}{c}\text { Eletricidade } \\
\text { (MWh/FR) } \\
100 \mathrm{bar}\end{array}$ \\
\hline \multirow{5}{*}{ I } & \multirow{5}{*}{10} & 10 & 10,5 & 14,8 & 17,5 & 18,8 & 19,9 \\
\hline & & 15 & 10,3 & 14,6 & 17,3 & 18,6 & 19,8 \\
\hline & & 25 & 10,1 & 14,2 & 16,9 & 18,2 & 19,4 \\
\hline & & 35 & 9,8 & 13,9 & 16,6 & 17,9 & 19,0 \\
\hline & & 50 & 9,3 & 13,4 & 16,0 & 17,3 & 18,4 \\
\hline \multirow{5}{*}{ II } & \multirow{5}{*}{20} & 10 & 12,1 & 16,7 & 19,7 & 21,1 & 22,3 \\
\hline & & 15 & 11,8 & 16,4 & 19,3 & 20,7 & 21,9 \\
\hline & & 25 & 11,2 & 15,7 & 18,6 & 19,9 & 21,2 \\
\hline & & 35 & 10,7 & 15,1 & 17,9 & 19,2 & 20,4 \\
\hline & & 50 & 9,8 & 14,0 & 16,7 & 18,0 & 19,2 \\
\hline \multirow{5}{*}{ III } & \multirow{5}{*}{30} & 10 & 13,7 & 18,6 & 21,8 & 23,4 & 24,7 \\
\hline & & 15 & 13,3 & 18,2 & 21,3 & 22,8 & 24,1 \\
\hline & & 25 & 12,5 & 17,2 & 20,2 & 21,7 & 23,0 \\
\hline & & 35 & 11,6 & 16,2 & 19,1 & 20,6 & 21,8 \\
\hline & & 50 & 10,3 & 14,6 & 17,4 & 18,8 & 20,0 \\
\hline \multirow{5}{*}{ IV } & \multirow{5}{*}{40} & 10 & 15,3 & 20,6 & 24,0 & 25,6 & 27,1 \\
\hline & & 15 & 14,8 & 19,9 & 23,3 & 24,9 & 26,3 \\
\hline & & 25 & 13,7 & 18,6 & 21,9 & 23,4 & 24,8 \\
\hline & & 35 & 12,5 & 17,3 & 20,4 & 21,9 & 23,2 \\
\hline & & 50 & 10,7 & 15,2 & 18,1 & 19,5 & 20,7 \\
\hline \multirow{5}{*}{$\mathrm{V}$} & \multirow{5}{*}{50} & 10 & 16,9 & 22,6 & 26,2 & 27,9 & 29,4 \\
\hline & & 15 & 16,2 & 21,7 & 25,3 & 27,0 & 28,5 \\
\hline & & 25 & 14,9 & 20,1 & 23,5 & 25,1 & 26,5 \\
\hline & & 35 & 13,4 & 18,4 & 21,7 & 23,2 & 24,6 \\
\hline & & 50 & 11,1 & 15,8 & 18,8 & 20,3 & 21,5 \\
\hline
\end{tabular}




\subsection{Análise Ambiental - Inventários de Ciclo de Vida - ICVs}

Como não poderia deixar de ser, a análise ambiental seguiu as mesmas orientações que foram estabelecidas para a análise energética. Assim, também nesse caso foram investigados cento e vinte e cinco cenários dado que cogeração variou suas características no que se refere a correntes materiais e energéticas de entrada e saída. Para essas últimas inclusive, as oscilações ocorreram tanto em termos de fluxos elementares na forma de emissões, como de produto $\left(\mathrm{E}_{\mathrm{e}}\right)$.

Aparecem descritos nas seções que se seguem os Inventários de Ciclo de Vida (ICVs) mais relevantes para a composição dos modelos de sistema de produto que suportaram a análise de desempenho ambiental. Junto de cada conjunto estão indicadas premissas gerais e, quando coube, também considerações específicas que orientaram a elaboração do respectivo ICV.

\subsubsection{Produção de cana-de-açúcar}

O inventário da produção de cana-de-açúcar aparece representado na Tabela 12. Este foi construído a partir de uma parceria com o Laboratório Nacional de Ciência e Tecnologia do Bioetanol (CTBE). Para a elaboração deste ICV foram estabelecidas as seguintes premissas:

- Fonte dos dados: secundários;

- Cobertura Temporal: 2008 a 2011. A exceção ocorreu quando se fez uso do banco de dados, visto que este representa realidades anteriores à cobertura temporal deste ICV;

- Cobertura Geográfica: estado de São Paulo. Qualquer variação de ordem geográfica foi introduzida por conta do uso de banco de dados;

- Cobertura Tecnológica: mix das formas manual e mecanizada, tanto para plantio quanto para colheita.

No que se refere aos fertilizantes minerais, a análise baseou-se em dados obtidos junto a Seabra et al (2011). De acordo com essa fonte as demandas nutricionais médias por hectare de cana-de-açúcar cultivada durante uma safra [/(ha. ano)] que esteja instalada no estado de São Paulo são respectivamente: amônia $=8,12 \mathrm{~kg}$; ureia $=134 \mathrm{~kg}$; nitrato de amônio $=31,3$ $\mathrm{kg}$; fosfato de monoamônio $(\mathrm{MAP})=6,27 \mathrm{~kg}$; superfosfato simples $(\mathrm{SSP})=186 \mathrm{~kg}$; e cloreto de potássio $(\mathrm{KCl})=115 \mathrm{~kg}$. Os autores mencionam também que para as mesmas condições de análise, serão consumos corretivos na forma de calcário e gesso à razão 2,00 e 1,00t/(ha.ano), respectivamente. 
Tabela 12 - Aspectos ambientais associados à produção de 1,0 t de cana-de-açúcar para as condições de processamento agrícola exercitadas no Estado de São Paulo

\begin{tabular}{|c|c|c|}
\hline Entradas/saídas & Quantidade & Unidade \\
\hline \multicolumn{3}{|c|}{ Entradas } \\
\hline Transformação, de pasto em prado, extensivo & 10,6 & $\mathrm{~m}^{2}$ \\
\hline Transformação, de arável, não irrigado & 118 & $\mathrm{~m}^{2}$ \\
\hline Transformação, para arável, não irrigado & 128 & $\mathrm{~m}^{2}$ \\
\hline Ocupação, arável, não irrigado & 110 & $\mathrm{~m}^{2} \mathrm{a}$ \\
\hline $\mathrm{CO}_{2}$, do ar & 653 & $\mathrm{~kg}$ \\
\hline \multicolumn{3}{|c|}{ Emissões para o ar } \\
\hline $\mathrm{CO}_{2}$, de mudança de uso da terra & 59,4 & $\mathrm{~kg}$ \\
\hline VOC, compostos orgânicos voláteis & 442 & $\mathrm{~g}$ \\
\hline CO, biogênico & 5,81 & $\mathrm{~kg}$ \\
\hline $\mathrm{NO}_{\mathrm{x}}$ & 96,0 & $\mathrm{~kg}$ \\
\hline Particulados, < 10 um & 493 & $\mathrm{~g}$ \\
\hline Particulados, $<2.5$ um & 12,1 & $\mathrm{~kg}$ \\
\hline $\mathrm{SO}_{\mathrm{x}}$ & 25,0 & $\mathrm{~g}$ \\
\hline $\mathrm{N}_{2} \mathrm{O}$ & 40,0 & g \\
\hline $\mathrm{CH}_{4}$, biogênico & 171 & g \\
\hline $\mathrm{NH}_{3}$ & 134 & $\mathrm{~g}$ \\
\hline $\mathrm{NH}_{4}^{+}$ & 159 & $\mathrm{~g}$ \\
\hline $\mathrm{CO}_{2}$ & 9,57 & $\mathrm{~kg}$ \\
\hline $\mathrm{CH}_{4}$ & 2,95E-04 & $\mathrm{kg}$ \\
\hline $\mathrm{SO}_{2}$ & $2,40 \mathrm{E}-03$ & $\mathrm{~kg}$ \\
\hline $\mathrm{C}_{6} \mathrm{H}_{6}$ & $1,64 \mathrm{E}-02$ & $\mathrm{~kg}$ \\
\hline $\mathrm{Cd}$ & $2,30 \mathrm{E}-05$ & $\mathrm{~kg}$ \\
\hline $\mathrm{Cr}$ & $1,13 \mathrm{E}-04$ & $\mathrm{~kg}$ \\
\hline $\mathrm{Cu}$ & $3,83 \mathrm{E}-03$ & $\mathrm{~kg}$ \\
\hline $\mathrm{Ni}$ & $1,58 \mathrm{E}-04$ & $\mathrm{~kg}$ \\
\hline $\mathrm{Se}$ & $2,30 \mathrm{E}-05$ & $\mathrm{~kg}$ \\
\hline $\mathrm{Zn}$ & $2,25 \mathrm{E}-03$ & $\mathrm{~kg}$ \\
\hline Benzopireno & $6,80 \mathrm{E}-05$ & $\mathrm{~kg}$ \\
\hline $\mathrm{C}_{\mathrm{x}} \mathrm{H}_{\mathrm{y}}$ & $7,42 \mathrm{E}-03$ & $\mathrm{~kg}$ \\
\hline $\mathrm{CO}$ & $1,25 \mathrm{E}-02$ & $\mathrm{~kg}$ \\
\hline NMVOC (VOC não- metânicos) & 6,76 & $\mathrm{~kg}$ \\
\hline $\mathrm{C}_{\mathrm{x}} \mathrm{H}_{\mathrm{y}}$, não especificados & $8,90 \mathrm{E}-05$ & $\mathrm{~kg}$ \\
\hline Particulados, não especificados & $4,30 \mathrm{E}-05$ & $\mathrm{~kg}$ \\
\hline \multicolumn{3}{|c|}{ Emissões para água } \\
\hline Nitrato $\left(\mathrm{NO}_{3}^{-}\right)$ & $1,55 \mathrm{E}-01$ & $\mathrm{~kg}$ \\
\hline \multicolumn{3}{|c|}{ Emissões para o solo } \\
\hline Carbofuran & $5,40 \mathrm{E}-03$ & $\mathrm{~kg}$ \\
\hline Diuron & $1,20 \mathrm{E}-03$ & $\mathrm{~kg}$ \\
\hline Fipronil & $5,16 \mathrm{E}-04$ & $\mathrm{~kg}$ \\
\hline Glifosate & $3,00 \mathrm{E}-03$ & $\mathrm{~kg}$ \\
\hline Hexazinona & $3,66 \mathrm{E}-04$ & $\mathrm{~kg}$ \\
\hline Imazapic & $1,57 \mathrm{E}-03$ & $\mathrm{~kg}$ \\
\hline Tebutiuron & 1,29E-03 & $\mathrm{kg}$ \\
\hline Etil-trinexapac & $1,12 \mathrm{E}-03$ & $\mathrm{~kg}$ \\
\hline $\mathrm{Cd}$ & 10,4 & $\mathrm{~kg}$ \\
\hline $\mathrm{Cu}$ & 131 & $\mathrm{~kg}$ \\
\hline $\mathrm{Zn}$ & 546 & $\mathrm{~kg}$ \\
\hline $\mathrm{Pb}$ & 222 & $\mathrm{~kg}$ \\
\hline $\mathrm{Ni}$ & 120 & $\mathrm{~kg}$ \\
\hline $\mathrm{Cr}$ & 158 & $\mathrm{~kg}$ \\
\hline
\end{tabular}


Quanto aos agroquímicos, foram selecionados produtos de uso regular no controle de pragas e doenças de lavouras desenvolvidas em São Paulo. De acordo com Sugawara (2012) as dosagens destes, uma vez mais [/(ha.ano)] e em termos dos respectivos princípios ativos são: Fipronil $=200 \mathrm{~g}$; Carbofuran $=2,10 \mathrm{~kg}$; Glifosato $=1,30 \mathrm{~kg}$; Etil-trinexapaque $=250 \mathrm{~g}$; além de Diuron $=490 \mathrm{~g} ;$ Tebutiuron $=500 \mathrm{~g} ;$ Hexazinona $=140 \mathrm{~g} ;$ e Imazapique $=175 \mathrm{~g}$.

Admitiu-se neste estudo que todos os resíduos industriais gerados na etapa industrial do processamento de etanol como vinhaça, torta de filtro e cinzas, são reaproveitados no campo. A área coberta com esses resíduos depende da disponibilidade de cada material; as dosagem de aplicação, e porcentagem da área total de cada um foram estimadas por Sugawara (2012) como sendo: Torta de filtro: 5,00 t/(ha.ano) e 11,2\% da área total; Vinhaça: 100 kg/(ha.ano) e 51,8\% da área total; e Cinzas: 5,00 t/(ha.ano) e 8,4\% da área total.

Esta modelagem admite por premissa o aproveitamento integral da palha, seja este para cogeração de eletricidade, ou na proteção/cobertura do solo agricultável. Assim, quaisquer práticas envolvendo queima prévia dos canaviais foram desconsideradas. Dessa forma, cada 1,00 t cana-de-açúcar gera $140 \mathrm{~kg}$ de palha (base seca). Admitindo-se a título de exemplificação que $\mathrm{u}_{\mathrm{p}}=15 \%$ (uma das possibilidades examinadas pelo estudo) chega-se à produção de exatos $164,7 \mathrm{~kg}$ palha úmida. Se a metade desse total for reaproveitada pela cogeração (ou seja: $\mathrm{A}=50 \%$ que corresponde a outra das possibilidades verificadas pelos estudo), exatos $82,35 \mathrm{~kg}$ palha serão enfardados e transportados para a usina enquanto, logicamente, uma quantidade igual a esta permanece no campo.

Os consumos e emissões relativos à etapa agrícola de produção de cana se mantiveram constantes em todos os cenários. O mesmo ocorreu em termos de captura de $\mathrm{CO}_{2}$ do ar, que segundo Frischknecht e Jungbluth (2007), deve ser inventariada para expressar a taxa de retirada de carbono do ambiente. Como estimativa desse valor adotou-se o dado disponibilizado por CGEE (2008), de $653 \mathrm{kgCO}_{2} /$ tc. As emissões para o ar ocorreram devido a queima de diesel nos maquinários agrícolas; oxidação de fertilizantes, oxidação de calcário, oxidação de resíduos industriais e uso do solo. De acordo com Franco (2008), o conteúdo total de nitrogênio na palha deixada no campo é de $0,48 \%$ (base seca). Já a palha enfardada e transportada até a usina tem emissões variáveis em função da quantidade e do teor de umidade em está será adicionada ao sistema de cogeração. Estes valores serão apresentados mais adiante. 
As emissões para a água de compostos de $\mathrm{P}$ e $\mathrm{K}$ foram desconsideradas. Essa decisão está baseada na consideração de Sugawara (2012) de que essas perdas, quando ocorrem, são quase que desprezíveis em razão de os solos brasileiros apresentarem teor elevado de acidez $(4,0<\mathrm{pH}<5,2)$. No entanto, o mesmo autor reporta que uma perda de 5,0\% do $\mathrm{N}$ aplicado como ureia é convertido para nitrato, que acaba sendo lixiviado para águas subterrâneas. São fontes de emissões para o solo os metais pesados associados a corretivos e fertilizantes minerais, e os ingredientes ativos dos pesticidas. De acordo com Jungbluth (2007), não há acumulo de qualquer ingrediente ativo de agroquímico na cana e, portanto, as quantidades integrais dessas dosagens serão emitidas para o solo.

\subsubsection{Tratamentos preliminares e transporte de cana-de-açúcar e palha}

Nesse trabalho, adotou-se como procedimentos de tratamento e transporte de cana e palha a rota proposta por Hassuani (2005). Nesse caso, a cana é picada e transportada durante a colheita, ao passo que a palha a ser usada na cogeração será enfardamento no campo, e transporte nessas condições, para apenas depois, já na destilaria, ser moída antes de se misturar ao bagaço. Outro desdobramento desse arranjo é o fato de que cana e palha são transportados separadamente. Em termos de distância de deslocamento, admitiu-se um trajeto de 32,3 km entre o campo e a destilaria. Esse dado foi determinado por Sugawara (2012) e refere-se à média de tais distâncias para os principais municípios produtores de cana-deaçúcar em São Paulo. Por fim, as emissões associadas a essa etapa foram contabilizadas utilizando o banco de dados do Ecoinvent, 'Transport, lorry 16-32t, EURO4/RER U' (JUNGBLUTH, 2007).

\subsubsection{Tratamento e moagem de cana-de-açúcar}

Ao chegar à planta industrial a cana é descarregada sobre mesas alimentadoras após o que será desfibrada para facilitar a extração do caldo. Durante a moagem, a cana passa por um conjunto de rolos de esmagamento, denominados ternos, cuja ação separa o caldo primário (que segue para produção de etanol) do bagaço (encaminhado para a caldeira). Esse processo é facilitado pela adição de água de imbibição. No modelo elaborado para representar a moagem da cana, admitiu-se uma taxa de água de imbibição de $300 \mathrm{~kg} / \mathrm{t}_{\mathrm{c}}$. Este desempenho foi determinado tendo em vista os resultados descritos em Pistore (2004) e Elia Neto (2009). 
Procedimento semelhante foi adotado na quantificação do consumo de eletricidade. No entanto, neste caso as informações disponíveis na literatura (PISTORE, 2004; CORTEZ, 2010; e DIAS et al 2011) induziram a adoção de um dado agregado para representar este parâmetro. Nesses termos, estabeleceu-se em $17 \mathrm{kWh} / \mathrm{t}_{\mathrm{c}} \mathrm{o}$ valor da demanda elétrica total das atividades de recebimento e preparo da cana (incluindo-se a moagem) para obtenção de caldo e bagaço. Deve-se ainda ressaltar que esta necessidade é suprida pelo sistema de cogeração.

Por fim, a moagem da cana é um processo multifuncional. A situação foi tratada por meio do procedimento de alocação por critério físico (massa). Em virtude dessa decisão, coube ao caldo o equivalente a 78,5\% das cargas ambientais pregressas e geradas na referida etapa; a parcela remanescente foi atribuída ao bagaço. A referida partição admitiu que todo bagaço gerado na moagem seria consumido pela cogeração da planta.

\subsubsection{Produção de etanol hidratado}

Assim como ocorreu com o subsistema da produção de cana-de-açúcar, também o ICV de produção de etanol anidro foi construído a partir de dados secundários. Além disso, o estudo considerou apenas a produção de etanol de $1^{a}$ geração $(1 \mathrm{G})$, obtido a partir dos colmos da cana. A fim de proporcionar uniformidade aos dados, a Cobertura Geográfica compreendeu também o estado de São Paulo. Já a Cobertura Temporal levou em conta dados médios de produção do período 2004 - 2010, enquanto a Cobertura Tecnológica dispôs sobre rotas processuais típicas de destilarias autônomas. Os dois subprodutos vinhaça e torta de filtro não saem da fronteira do sistema sendo utilizados na etapa de produção de cana.

Pistore (2004), Dias et al (2009 e 2011) estimam em $13 \mathrm{kWh} / \mathrm{t}_{\mathrm{c}}$ o consumo agregado de eletricidade dessa etapa do processo. Sob esse total figuras demandas associadas à fermentação, destilação e retificação de etanol, bem como aqueles que ocorrem no ciclo de cogeração. Além disso, foram incorporadas ao ICV emissões de $\mathrm{CO}_{2}$ biogênico provenientes da fermentação.

Se analisado de maneira agregada como ocorreu para efeito de elaborado do modelo, o conjunto de operação que compreende a conversão de caldo em etanol se transforma também em um subsistema multifuncional. Assim como já fora apontado na seção 4.3.3 esta também foi tratada por alocação mássica, por conta do que foram atribuídas as seguintes participações 
aos produtos dela emanados: etanol: 4,86\%; condensado de retorno: $26,5 \%$; vinhaça $66,7 \%$; e torta de filtro $1,92 \%$.

A Tabela 13 apresenta o ICV consolidado da produção de 1,0 t de etanol hidratado.

Tabela 13 - Inventário produção de 1,0 t de etanol $(99,5 \%$ v/v $)$

\begin{tabular}{|c|c|c|}
\hline Entradas/saídas & Quantidades & Unidades \\
\hline \multicolumn{3}{|c|}{ Entradas } \\
\hline Caldo de cana & 1,03 & $\mathrm{t}$ \\
\hline $\mathrm{H}_{2} \mathrm{SO}_{4,(1)}$ & 501 & $\mathrm{~kg}$ \\
\hline Calcário hidratado & 825 & $\mathrm{~g}$ \\
\hline Óleo lubrificante & 14,0 & $\mathrm{~g}$ \\
\hline Ciclohexano & 70,3 & $\mathrm{~g}$ \\
\hline Compostos químicos inorgânicos & 7,96 & $\mathrm{~kg}$ \\
\hline Água industrial & 38,4 & $\mathrm{~kg}$ \\
\hline \multicolumn{3}{|c|}{ Saídas } \\
\hline $\mathrm{C}_{2} \mathrm{H}_{6} \mathrm{O}\left(99,5 \%_{\mathrm{v} / \mathrm{v}}\right)$ & 66,0 & $\mathrm{~kg}$ \\
\hline Torta de filtro & 26,1 & $\mathrm{~kg}$ \\
\hline Vinhaça & 906 & $\mathrm{~kg}$ \\
\hline Condensado & 360 & $\mathrm{~kg}$ \\
\hline \multicolumn{3}{|c|}{ Emissão para o ar } \\
\hline $\mathrm{CO}_{2}$, biogênico & 1,02 & $\mathrm{~kg}$ \\
\hline $\mathrm{C}_{2} \mathrm{H}_{6} \mathrm{O}$ & 2,01 & $\mathrm{~g}$ \\
\hline
\end{tabular}

\subsubsection{Enfardamento da Palha}

Hassuani (2005) testou diferentes estratégias de acondicionamento e transporte da palha e concluiu ser possível recuperá-la para uso como fonte de energia caso o enfardamento seja realizado com equipamentos adequados. Nesse caso o autor estima haver um consumo médio de $1,90 \mathrm{~L}$ diesel por tonelada de palha $\left(\mathrm{t}_{\mathrm{p}}\right)$ enfardada $\left(\mathrm{u}_{\mathrm{p}}=15 \%\right)$.

A indisponibilidade de dados mais precisos sobre emissões atmosféricas geradas em decorrência dessa operação fez com que os fatores de emissão para a queima de diesel em 
máquinas agrícolas, obtidos de Nemecek e Käji (2007) e Sugawara (2012) fossem também adotados nesse caso. Esses valores são apresentados mais adiante na Tabela 14.

\subsubsection{Transporte da palha}

Assim como já havia sido comentado na seção 5.2.2, cana e palha são transportadas das mesmas origens (zona rural) aos mesmos destinos (planta industrial). Por conta disso, todas as premissas estabelecidas para modelagem do deslocamento da cana, são válidas também para o caso presente; quais sejam: (i) a distância percorrida $\mathrm{L}=32,3 \mathrm{~km}$; (ii) as emissões atmosféricas são representadas por dados secundários coletados do banco de dados do Ecoinvent para o modal de transporte 'Transport, lorry 16-32t, EURO4/RER U' (JUNGBLUTH, 2007).

Tabela 14 - Fatores de emissão para a queima de óleo diesel em maquinários agrícolas.

\begin{tabular}{|c|c|}
\hline Emissão para o ar & $\begin{array}{c}\text { Quantidade } \\
\text { (g/kg de diesel) }\end{array}$ \\
\hline $\mathrm{CO}_{2}$, fóssil & $3,12 \mathrm{E} 03$ \\
\hline $\mathrm{CH}_{4}$, fóssil & $1,29 \mathrm{E}-01$ \\
\hline $\mathrm{N}_{2} \mathrm{O}$ & $1,20 \mathrm{E}-01$ \\
\hline $\mathrm{NH}_{3}$ & $2,00 \mathrm{E}-02$ \\
\hline $\mathrm{SO}_{2}$ & 1,01 \\
\hline $\mathrm{C}_{6} \mathrm{H}_{6}$ & $7,30 \mathrm{E}-03$ \\
\hline $\mathrm{Cd}$ & $1,00 \mathrm{E}-05$ \\
\hline $\mathrm{Cr}$ & $5,00 \mathrm{E}-05$ \\
\hline $\mathrm{Cu}$ & $1,70 \mathrm{E}-03$ \\
\hline $\mathrm{Ni}$ & $7,00 \mathrm{E}-05$ \\
\hline $\mathrm{Se}$ & $1,00 \mathrm{E}-05$ \\
\hline $\mathrm{Zn}$ & $1,00 \mathrm{E}-03$ \\
\hline Benzopireno & $3,00 \mathrm{E}-05$ \\
\hline PAH, Hidrocarbonetos aromáticos policíclicos & 3,29E-03 \\
\hline $\mathrm{C}_{\mathrm{x}} \mathrm{H}_{\mathrm{y}}$, não especificado & 3,00 \\
\hline $\mathrm{CO}$, fóssil & 5,40 \\
\hline $\mathrm{NO}_{\mathrm{x}}$ & 42,5 \\
\hline
\end{tabular}

Fonte: Nemecek e Käji (2007); Sugawara (2012) 


\subsubsection{Moagem da palha}

A palha que chega a destilaria deve ser picada antes de ser alimentada à fornalha da caldeira (Hassuani, 2005). A ausência de dados mais precisos sobre o consumo de eletricidade que é dispensado nessa operação fez com que uma conduta conservadora fosse adotada nesta situação. Assim, assumiu-se que a potência consumida na moagem equivale a potência nominal do equipamento de $68,3 \mathrm{kWh} / \mathrm{t}_{\mathrm{p}}$ (ou 5,60 kWh/t $\mathrm{t}_{\mathrm{c}}$ ) (GUERRA, 2014). Ressalte-se que a demanda elétrica do moinho será também fornecida pela cogeração.

\subsubsection{Cogeração}

A cogeração também é multifuncional. Dela emanam quatro produtos: (i) eletricidade excedente disponível para exportação; (ii) eletricidade utilizado processo; (iii) vapor saturado (@ 2,5 bar e $x=1,0$ ), também empregado como fonte energética (térmica) na produção de etanol; e (iv) cinzas, que retornam ao campo para complementação de teores de metais no solo. Assim, tal como já havia ocorrido em outras situações, optou-se pela alocação para repartição das cargas ambientais. A indisponibilidade de dados econômicos remeteu a escolha do critério a propriedades físicas. No entanto, dadas as diferentes características desses produtos, não se encontrou uma solução que pudesse contemplar a todos. Diante dessa constatação aplicou-se o critério de conteúdo energético para a distribuição de cargas e assim, as cinzas acabaram sendo automaticamente isentadas de quaisquer consumos e emissões. Muito embora a decisão resultasse em uma exclusão, os produtos que de fato detêm contribuições efetivas em termos de desempenho ambiental acabaram por ser contemplados a partir da escolha.

Nunca é demais ressaltar que cada cenário avaliado possui um potencial específico de geração dos produtos e consumo de água. Esses dados foram estimados via análise energética para cada condição $\left(\mathrm{P}_{\mathrm{i}} ; \mathrm{A}_{\mathrm{j}} ; \mathrm{u}_{\mathrm{k}}\right)$. Os resultados obtidos incorporados ao modelo que verificou o desempenho impacto ambientais.

As emissões atmosféricas da queima do bagaço na caldeira foram estimadas a partir dos fatores de emissão obtidos de Greet (2010). Os valores adotados nesse caso (/kg bagaço) foram: $\mathrm{CO}=560 \mathrm{mg} ; \mathrm{NO}_{\mathrm{x}}=540 \mathrm{mg} ; \mathrm{N}_{2} \mathrm{O}=30,0 \mathrm{mg} ; \mathrm{SO}_{\mathrm{x}}=29,0 \mathrm{mg} ; \mathrm{CH}_{4}=25,0 \mathrm{mg}$; VOC $=38,0 \mathrm{mg} ;$ Particulados $\left(\varphi_{\mathrm{ap}}<10 \mu \mathrm{m}\right)=62,0 \mathrm{mg}$; e Particulados $\left(\varphi_{\mathrm{ap}}<2,5 \mu \mathrm{m}\right)=31,0 \mathrm{mg}$. 
Para as emissões decorrentes de queima de palha foram considerados os mesmos fatores de emissão do bagaço. No entanto, estes foram corrigidos em função das variações de $\left(u_{k}\right)$. A Tabela 15 traz um exemplo de ICV da cogeração para o caso em que $(P=20$ bar; $A=$ $10 \%$; e u $=10 \%$ ).

Tabela 15 - Inventário do sistema de cogeração para: $\mathrm{P}=20$ bar, $\mathrm{a}=10 \%$ palha, $\mathrm{u}=10 \%$

\begin{tabular}{|c|c|c|}
\hline Entradas/saídas & Quantidade & Unidade \\
\hline \multicolumn{3}{|c|}{ Entradas } \\
\hline Bagaço & 280 & $\mathrm{~kg}$ \\
\hline Palha & 15,5 & $\mathrm{~kg}$ \\
\hline Água deionizada & 19,5 & $\mathrm{~kg}$ \\
\hline Água industrial & 550 & $\mathrm{~kg}$ \\
\hline Condensado (procedente da destilaria) & 360 & $\mathrm{~kg}$ \\
\hline \multicolumn{3}{|c|}{ Emissão para o ar } \\
\hline $\mathrm{CO}_{2}$, biogênico & 251 & $\mathrm{~kg}$ \\
\hline $\mathrm{CO}$ & $7,87 \mathrm{E}-02$ & $\mathrm{~kg}$ \\
\hline $\mathrm{NO}_{\mathrm{x}}$ & $8,39 \mathrm{E}-02$ & $\mathrm{~kg}$ \\
\hline $\mathrm{N}_{2} \mathrm{O}$ & $5,30 \mathrm{E}-04$ & $\mathrm{~kg}$ \\
\hline $\mathrm{SO}_{\mathrm{x}}$ & $4,20 \mathrm{E}-03$ & $\mathrm{~kg}$ \\
\hline $\mathrm{CH}_{4}$, biogênico & $3,24 \mathrm{E}-02$ & $\mathrm{~kg}$ \\
\hline VOC, compostos orgânicos voláteis & $5,48 \mathrm{E}-03$ & $\mathrm{~kg}$ \\
\hline Particulados, $<10$ um & $8,88 \mathrm{E}-02$ & $\mathrm{~kg}$ \\
\hline Particulados, $<2.5$ um & $4,44 \mathrm{E}-02$ & $\mathrm{~kg}$ \\
\hline \multicolumn{3}{|c|}{ Emissão para o solo } \\
\hline $\mathrm{C}$ (proveniente da combustão do bagaço) & $1,75 \mathrm{E}-01$ & $\mathrm{~kg}$ \\
\hline $\mathrm{C}$ (proveniente da combustão da palha) & $2,73 \mathrm{E}-02$ & $\mathrm{~kg}$ \\
\hline
\end{tabular}




\subsection{Avaliação de Impactos}

A avaliação de impactos corresponde em termos efetivos, a verificação do desempenho ambiental da cogeração de eletricidade a partir de sucessivas adições de palha em uma destilaria autônoma de etanol. Tal como aparece descrito na seção 4.3.4 esta etapa metodológica da ACV foi cumprida utilizando-se o método ReCiPe Midpoint $(\mathrm{H})$ - versão 1.12 (GOEDKOOP et al, 2013), para as categorias de impacto de Acidificação Terrestre, Eutrofização Aquática, Formação de Oxidante Fotoquímica e de Material Particulado, e Mudança Climática.

O principal objetivo dessa investigação foi conhecer quais as tendências em termos de comportamento de um determinado Impacto Ambiental $\left(\mathrm{IA}_{n}\right)$, diante de diferentes situações de operação do ciclo Rankine, a serem definidas em função de mudanças na (i) pressão do vapor de saída da caldeira, (ii) taxa de adição de palha e (iii) grau de umidade da palha. Em termos algébricos, esse propósito pode ser sintetizado pela equação (Eq 33)

$$
\Delta \mathrm{IA} A_{\mathrm{n}}=\mathrm{f}\left(\mathrm{P}_{\mathrm{i}} ; \mathrm{A}_{\mathrm{j}} ; \mathrm{u}_{\mathrm{k}}\right)
$$

Os resultados são discutidos em relação a quantidade de eletricidade excedente $\left(E_{e}\right)$. No entanto, diante da variabilidade apresentada pelo sistema em termos de quantidade de energia gerada $\left(\mathrm{E}_{\mathrm{T}}\right)$ (ver resultados da Tabela 11), optou-se por realizar a verificação dos impactos com relação a esse parâmetro em termos específicos $\left[/\left(\mathrm{MWh}_{\text {exportado }}\right)=/\left(\mathrm{MWh}_{\mathrm{e}}\right)\right]$.

Os resultados obtidos estão descritos na forma das superfícies que compõem os Gráficos de 5 a 14. A análise foi realizada em dois níveis. O primeiro deles remete a abordagem descrita em Eq 33, em que os eixos são ocupados pelos parâmetros que impõem variações a cogeração $\left(\mathrm{P}_{\mathrm{i}} ; \mathrm{A}_{\mathrm{j}} ; \mathrm{u}_{\mathrm{k}}\right)$ e as tendências de impacto se desenvolvem na forma do código de cores que distingue cada plano. O segundo nível altera aquela lógica ao colocar $\Delta \mathrm{IA}_{\mathrm{n}}$ em um dos eixos, e deslocar $\mathrm{P}_{\mathrm{i}}$ para cada um dos planos. Com tal estratégia esperava-se poder proporcionar ao leitor do estudo recortes distintos em termos de tendências de integração estabelecida entre impactos ambientais e parâmetros de processo.

\subsubsection{Acidificação Terrestre (TAc)}

Os resultados indicados no Gráfico 5 confirmam uma expectativa que, de certa forma, já poderia ser esperada. Os menores impactos ambientais de $365 \mathrm{~kg} \mathrm{SO} \mathrm{Seq}_{2 \mathrm{CWh}} /\left(\mathrm{MW}_{\mathrm{e}}\right)$ foram registrados para as condições mais favoráveis de operação do sistema: $\mathrm{P}_{\mathrm{i}}=\mathrm{P}_{\text {máx }}=100$ bar; 
$A_{j}=A_{\text {máx }}=50 \% ; u_{k}=u_{\text {mín }}=10 \%$. Para essa condição registram-se os impactos mais elevados de TAc em termos absolutos.

Por outro lado, nas mesmas condições a quantidade de energia exportada $E_{e}=E_{e, \text { máx }}$ amortecendo os efeitos adversos quando esses são mensurados em termos específicos. Tal inter-relação fica ainda mais evidente para o caso oposto, em que o sistema opera com $\left(\mathrm{P}_{\mathrm{i}}=\right.$ $\mathrm{P}_{\text {mín }}=20$ bar; $A_{j}=A_{\text {mín }}=10 \% ; u_{k}=u_{m a ́ x}=50 \%$ ). Nessa situação $E_{e}=E_{e, m i ́ n}$, no entanto, não se observa um decréscimo de impacto equivalente a essa produção. Assim, os valores de TAc alcançam $599 \mathrm{~kg} \mathrm{SO} 2 \mathrm{eq} /\left(\mathrm{MWh}_{\mathrm{e}}\right)$ muito próximo ao limite superior da escala.

\section{Gráfico 5 - Pressão vs. Adição de palha vs. Umidade da palha para TAc}
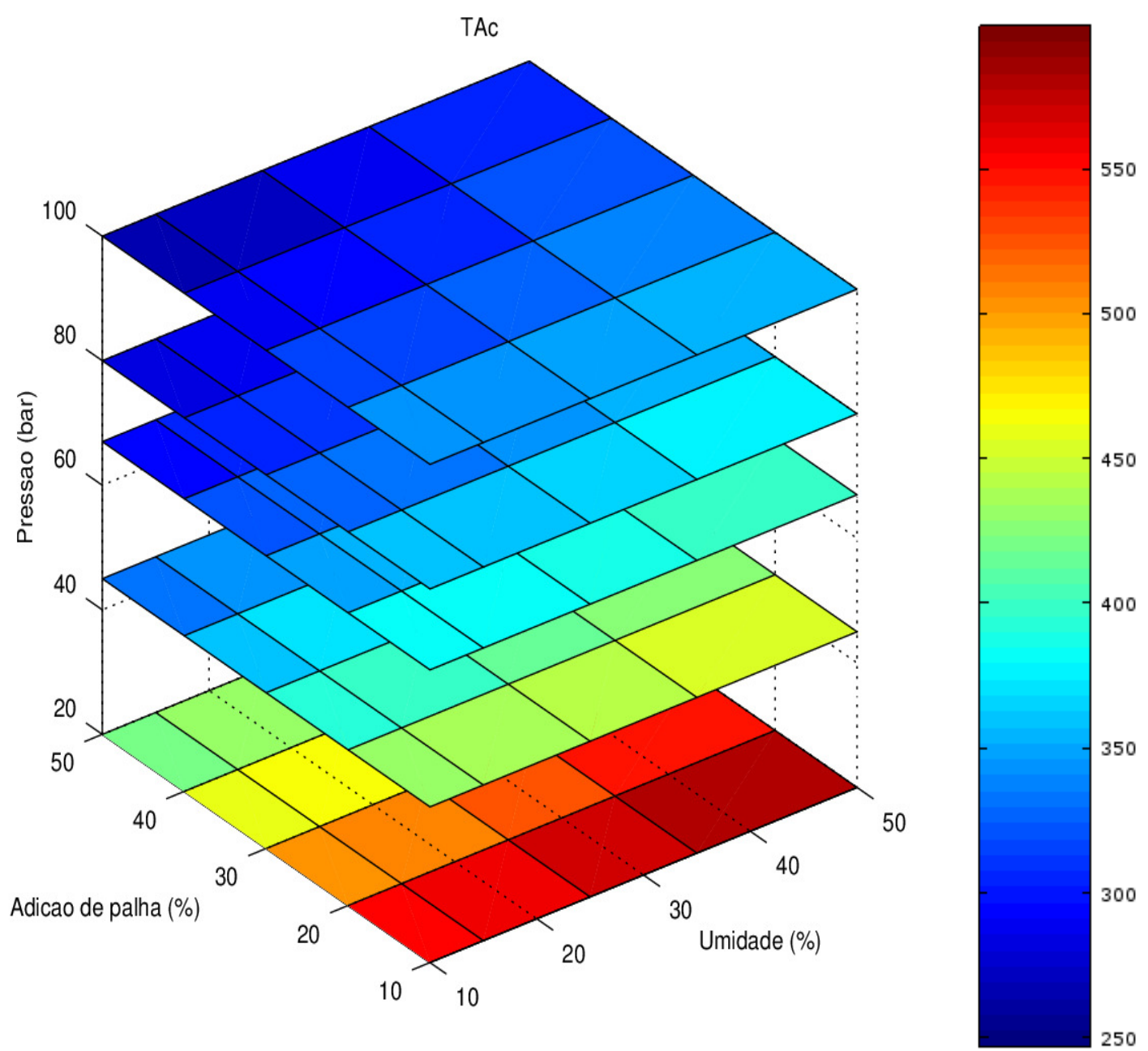

Outra constatação importante é a de que os valores de TAc são muito mais sensíveis a variações de $A_{j}$ e $u_{k}$ quando $P_{1}=20$ bar. Esse fenômeno mostra-se mais atenuado nos patamares seguintes (na faixa que compreende $\mathrm{P}_{2}=45$ bar e $\mathrm{P}_{3}=67$ bar). Já para pressões 
elevadas, a partir de $\mathrm{P}_{4}=80$ bar, os impactos como TAc mostram uma tendência de convergência.

Nesse caso, o efeito da pressão se faz notar apenas nas situações mais extremas quanto à adição de palha $\left(\mathrm{A}_{1}=10 \%\right)$ e teor de umidade $\left(\mathrm{u}_{5}=50 \%\right)$. Essa leitura fica mais clara quando o desempenho do sistema de produto é observado segundo o arranjo descrito no Gráfico 6.

Gráfico 6 - TAc vs. Adição de palha vs. Umidade da palha para diferentes pressões

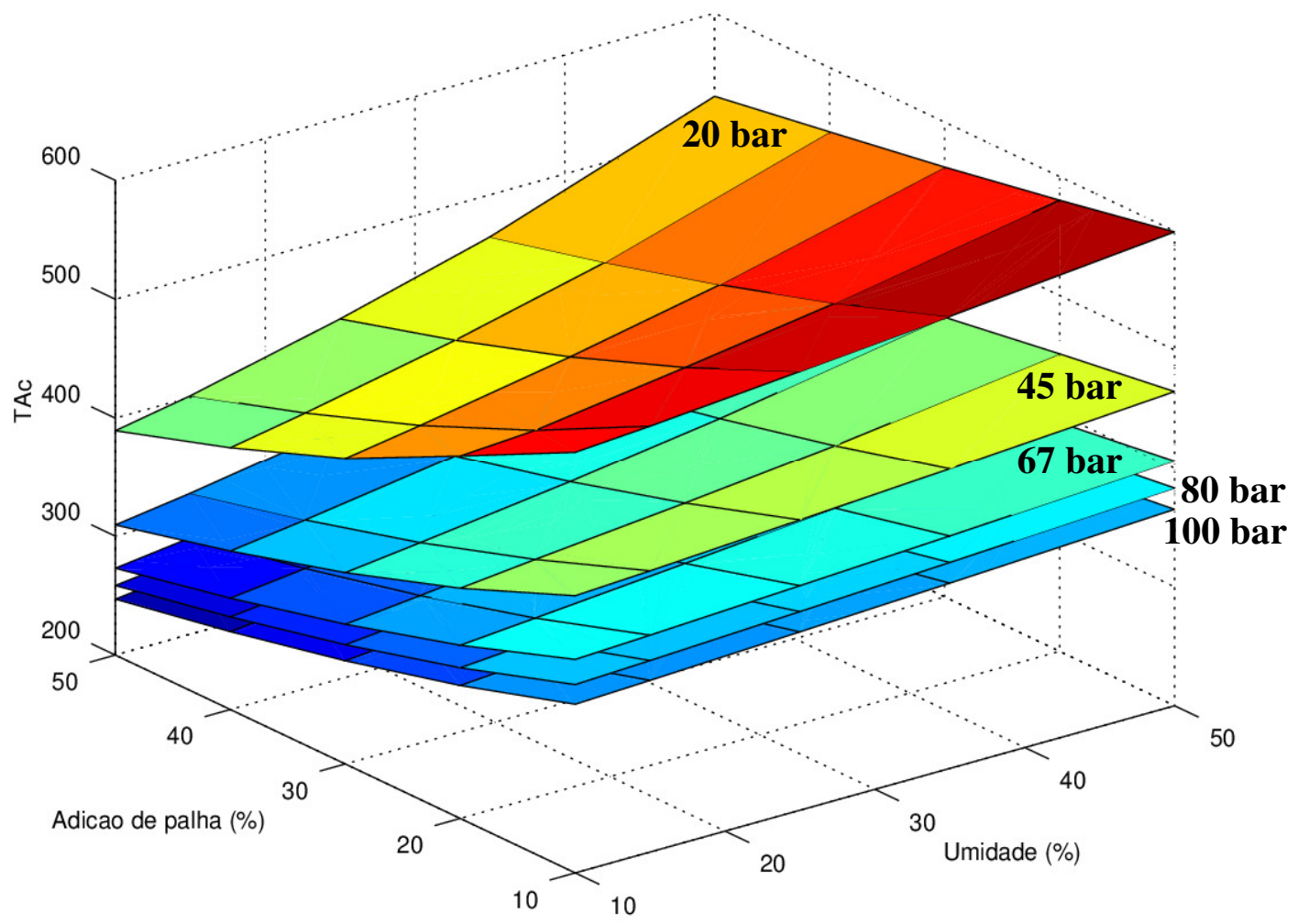

No caso de baixas pressões de operação do sistema os impactos decorrentes da etapa agrícola passam a se fazer notar de maneira mais expressiva. Para condições de operação da cogeração nas quais $20<\mathrm{P}_{\mathrm{i}}$ (bar) $<45$ predominam as contribuições decorrentes de emissões atmosféricas de NOx as quais são originárias da decomposição de adubos nitrogenados no solo durante o cultivo da cana-de-açúcar.

Como a quantidade de etanol se manteve constante ao longo de toda a análise, quaisquer contribuições advindas da etapa agrícola se mantiveram igualmente inalteradas. No entanto, seus aportes ao total de impactos de TAc são mais evidentes a baixas pressões 
justamente em virtude de ali se registrarem os menores valores de $E_{e}$ que o sistema pode alcançar.

\subsubsection{Eutrofização Aquática (FEu)}

Os Gráficos 7 e 8 descrevem o comportamento de FEu em função de variações de $\mathrm{P}_{\mathrm{i}}$, $A_{j}$ e $u_{k}$. Também neste caso o desempenho ambiental é bastante influenciado pela pressão do vapor de alta pressão que deixa a caldeira sobretudo quando $\mathrm{P}_{\mathrm{i}} \rightarrow \mathrm{P}_{\text {mín }}$ (que nesta análise refere-se a $\mathrm{P}_{1}=20$ bar).

Tal como já ocorrera com TAc, a maior intensidade de impacto provocado pelo sistema com relação a $\mathrm{FEu}$ foi de $151 \mathrm{~g} \mathrm{P}$ eq $/ \mathrm{MWh}_{\mathrm{e}}$. Este patamar foi alcançado exatamente na situação em que o sistema operava em $\left(\mathrm{P}_{1}=20\right.$ bar; $\left.\mathrm{A}_{1}=10 \% ; \mathrm{u}_{5}=50 \%\right)$, atingindo o nível mais discreto em termos de exportação de eletricidade $\mathrm{E}_{\mathrm{e}}=9,3 \mathrm{MWh}_{\mathrm{e}}($ Tabela 11).

Gráfico 7 - Pressão vs. Adição de palha vs. Umidade da palha para FEu

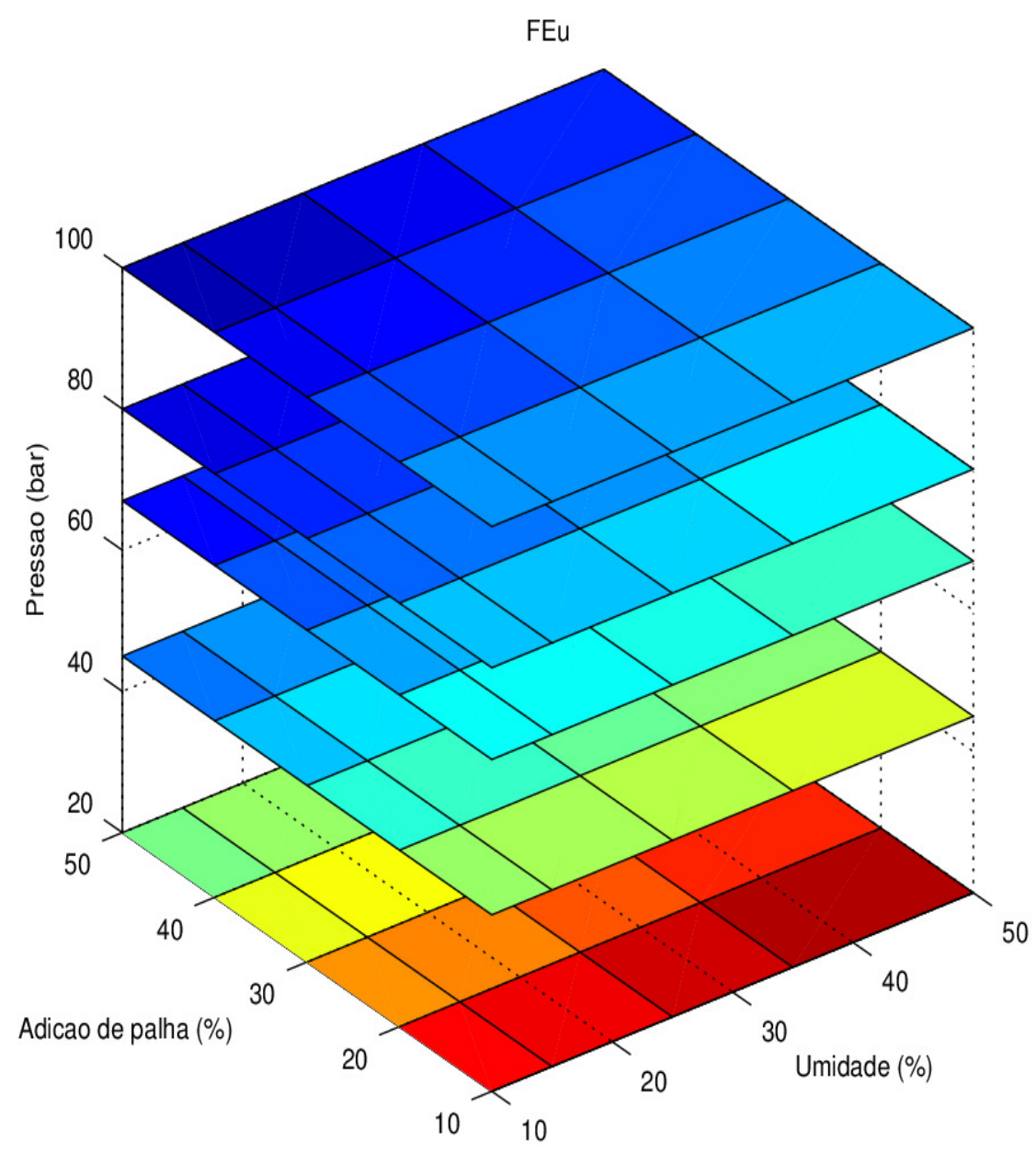


Observando o fenômeno no que se refere a tendências é possível perceber que a relação $\mathrm{FEu}=\mathrm{f}(\mathrm{Pi})$ guarda grande semelhança com àquele apresentado por TAc. Conforme a pressão do sistema se eleva o impacto totalizado converge para uma faixa restrita. Ao ser atingido limite de $\mathrm{P}_{\text {máx }}\left(\mathrm{P}_{5}=100\right.$ bar $)$ estes se distribuem entre $81<\mathrm{FEu}\left(\mathrm{g} \mathrm{P}\right.$ eq $\left./ \mathrm{MWh}_{\mathrm{e}}\right)<92$, ou seja, com uma variação de apenas $13 \%$ entre as condições extremas do par $\left(\mathrm{A}_{j} ; \mathrm{u}_{\mathrm{k}}\right)$ que são $\left(\mathrm{A}_{1} ; \mathrm{u}_{5}\right)$ e $\left(\mathrm{A}_{5} ; \mathrm{u}_{1}\right)$.

A etapa industrial, da qual a cogeração é parte integrante, não emite qualquer precursor de $\mathrm{FEu}$ para o meio ambiente. Portanto, as contribuições para essa categoria procedem em sua totalidade da etapa agrícola, ou da produção de ativos que por ela são utilizados. Os efeitos na forma de FEu que o sistema de produto aporta decorrem de lançamentos de fosfatos $\left(\mathrm{PO}_{4}{ }^{3-}\right)$ para a água. Estes são introduzidos no processamento agrícola da cana por meio de dosagens de SSP e MAP para suprir as necessidades de fósforo da cultura.

As perdas de $\mathrm{PO}_{4}{ }^{3-}$ representam $99 \%$ da contribuição para esta categoria; no entanto, em termos absolutos, estas se mantêm inalteradas para quaisquer dos casos analisados já que a produção de etanol é constante por premissa. Disso conclui-se que a variação de impacto antes observada, cuja medida é feita em termos relativos, está ligada em verdade à oscilação de $\mathrm{E}_{\mathrm{e}}$, esta sim, intimamente vinculada à pressão de operação do ciclo Rankine.

Gráfico 8 - FEu vs. Adição de palha vs. Umidade da palha para diferentes pressões

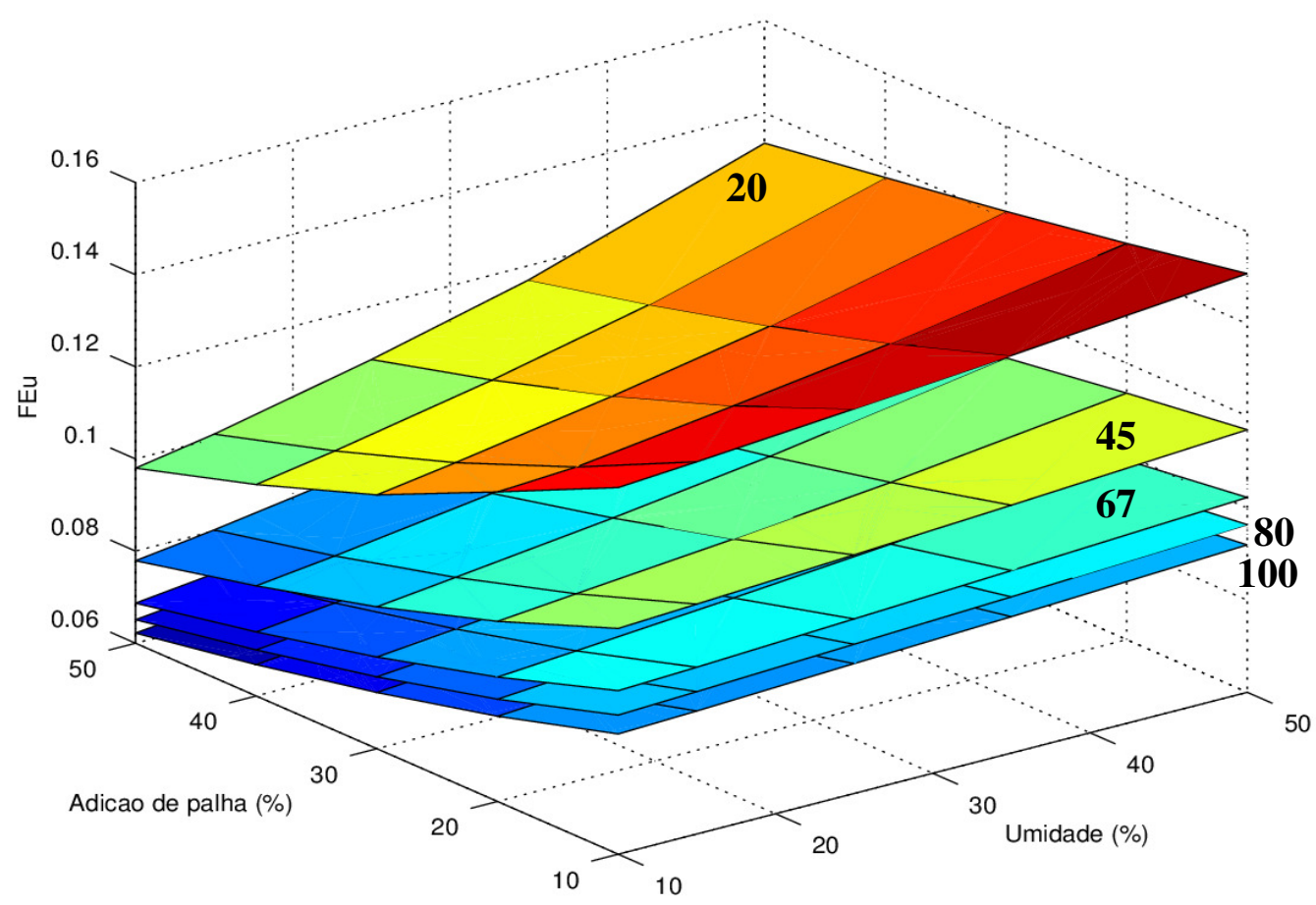




\subsubsection{Formação de Oxidante Fotoquímico (POF)}

Os Gráficos 9 e 10 descrevem o perfil de variação de POF em função de modificações na quantidade de energia elétrica exportada. Para este caso percebe-se mais uma replicação dos comportamentos antes demonstrados por TAc e FEu quando alterações de pressão $\left(\Delta \mathrm{P}_{\mathrm{i}}\right)$ exercem maior influência sobre o desempenho específico do sistema do que podem causar $\Delta \mathrm{A}_{\mathrm{j}} \mathrm{e} \Delta \mathrm{u}_{\mathrm{k}}$

Gráfico 9 - Pressão vs. Adição de palha vs. Umidade da palha para POF
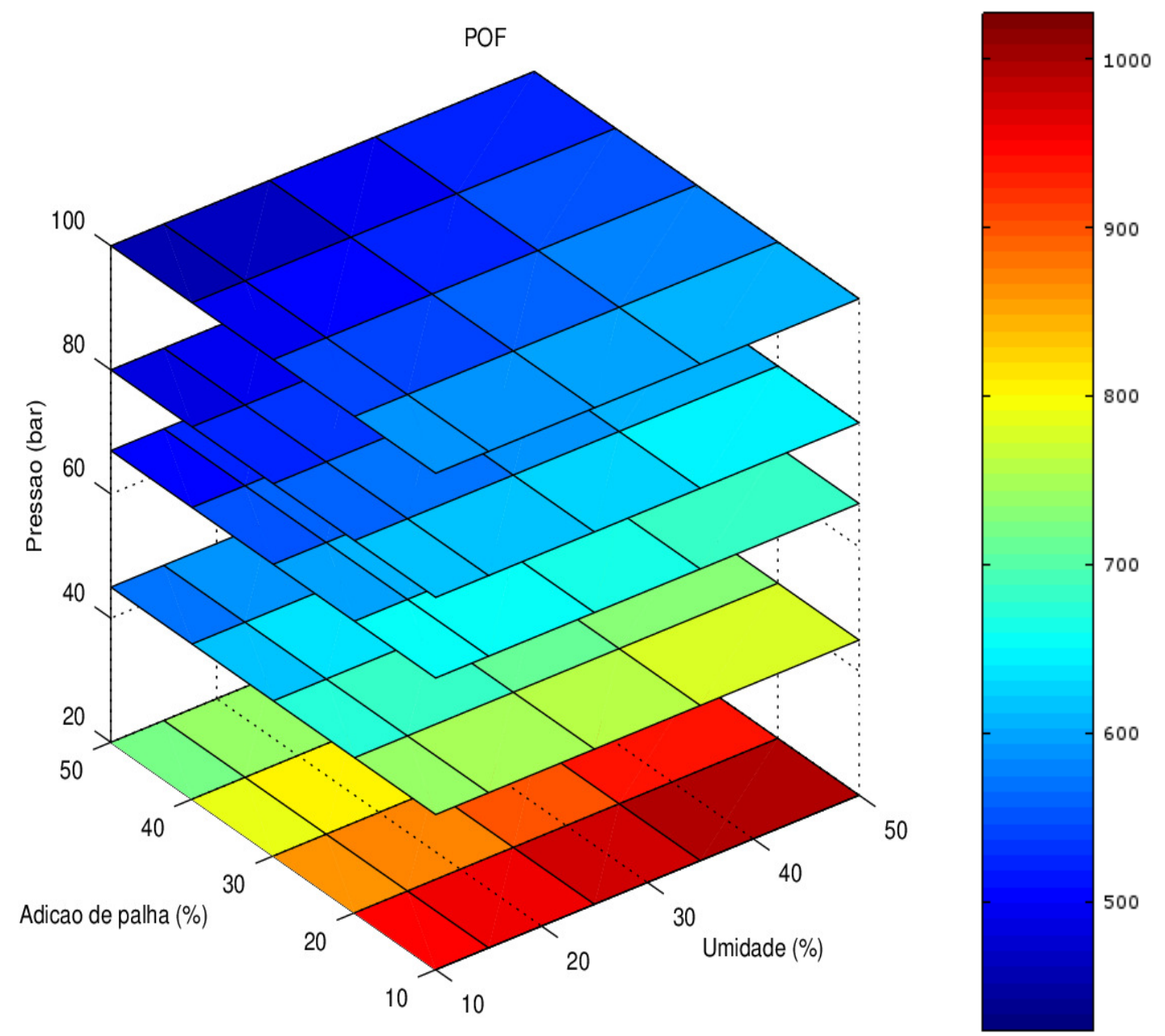

$\mathrm{O}$ melhor desempenho do sistema, de $508 \mathrm{~kg}$ NMVOC/MWh $\mathrm{e}$ foi registrado exatamente em $\left(\mathrm{P}_{5}=100\right.$ bar; $\left.\mathrm{A}_{5}=50 \% ; \mathrm{u}_{1}=10 \%\right)$ quando $\mathrm{E}_{\mathrm{e}}=\mathrm{E}_{\mathrm{e} \text {,máx }}=29,4 \mathrm{MWh}_{\mathrm{e}}$, ao passo que a maior intensidade de efeitos adversos nesta categoria, 1,03 t $\mathrm{NMVOC}_{\mathrm{kWh}}$ se dá, como não poderia deixar de ser, na condição oposta, de $E_{e}=E_{e, m i ́ n}$ A variação entre ambos os limites nesse caso foi expressiva, atingindo pouco mais de $102 \%$. 
Gráfico 10 - POF vs. Adição de palha vs. Umidade da palha para diferentes pressões

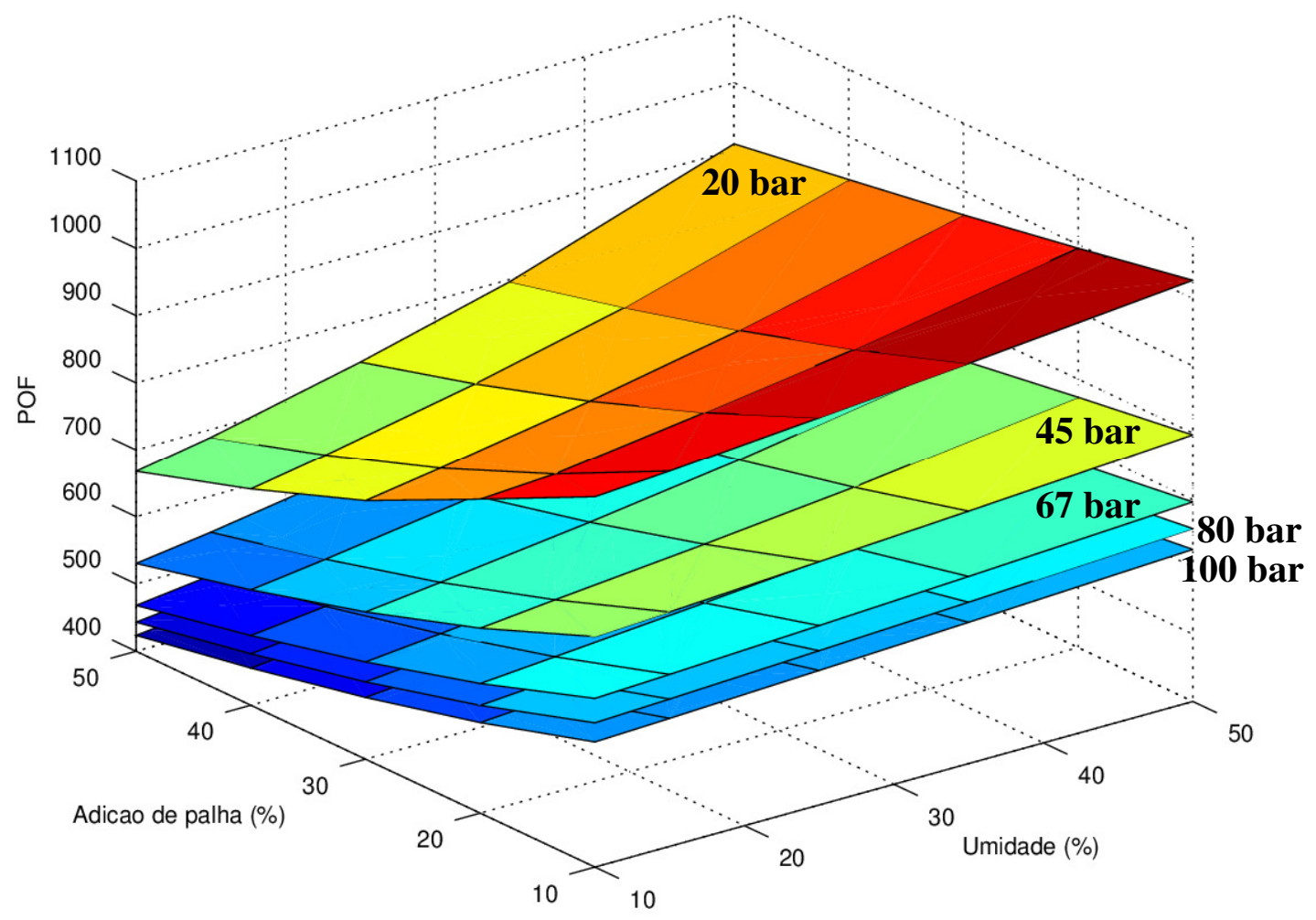

Uma análise mais detida da questão expõe certas peculiaridades da conduta do sistema no que se refere à relação $\mathrm{POF}=\mathrm{g}\left(\mathrm{P}_{\mathrm{i}}\right)$. Realizou-se uma análise comparada, na qual a pressão do sistema oscilou, mas foram mantidas constantes e nos níveis mais desfavoráveis, as condições de dosagem de palha e umidade (ou seja: $\mathrm{P}_{\mathrm{i}} ; \mathrm{A}_{1} ; \mathrm{u}_{5}$ ). Os impactos totais para POF estão indicados na Tabela 16, assim como as variações relativas entre aqueles resultados.

Tabela 16 - Análise da influência da pressão de operação do sistema sobre POF

\begin{tabular}{ccc} 
Pressão $\left(\mathrm{P}_{\mathrm{i}}\right.$, bar $)$ & $\mathrm{POF}\left(\mathrm{kg} \mathrm{NMVOC} / \mathrm{kWh}_{\mathrm{e}}\right)$ & $\Delta(\%)$ \\
\hline 20 & 1027 & - \\
45 & 797 & $(-) 22,4$ \\
67 & 696 & $(-) 12,7$ \\
80 & 657 & $(-) 5,60$ \\
100 & 626 & $(-) 4,72$ \\
\hline
\end{tabular}


A análise de convergência cujos resultados constam da Tabela 16 indica não apenas a inexistência de linearidade na relação $\mathrm{POF}=\mathrm{g}\left(\mathrm{P}_{\mathrm{i}}\right)$, mas que, a partir de $\mathrm{P}_{3}=67$ bar as variações de impacto podem ser consideradas discretas o suficiente para inclusive sugerir uma tendência de constância, sobretudo se nessa digressão fossem levadas em conta incertezas associadas aos dados, à modelagem, e até à forma de aplicação da metodologia - em particular, na abordagem dos processos multifuncionais - que cercam o estudo. Como um desdobramento imediato disso, pode-se concluir que para a operação do ciclo Rankine em níveis de pressão tais que $\mathrm{P}_{\mathrm{i}} \geq \mathrm{P}_{3}$, considerados de porte médio para as escalas em que o sistema tem potencial para operar, têm-se que POF $\rightarrow \mathrm{k}$ (constante).

Tal como já havia ocorrido com TAc as emissões atmosféricas de $\mathrm{NO}_{\mathrm{x}}$ representam a principal fonte de impacto para POF. Para quaisquer pressões analisadas a contribuição dessa carga ambiental esteve em torno de 93\%. Essa constância em termos relativos está justificada devido as perdas de NOx se concentrarem quase que integralmente no processamento agrícola, em decorrência de degradação de fertilizantes nitrogenados no solo. Uma contribuição residual, mas existente e variável, ocorre na caldeira, quando uma fração dos Ncompostos incorporados à biomassa é oxidada durante a combustão e no caso em que o $\mathrm{N}_{2}$ (g) do ar segue pelo mesmo caminho.

\subsubsection{Formação de Material Particulado (PMF)}

O perfil de impactos do sistema quanto a PMF é bastante semelhante ao demonstrado para POF, como pode ser constatado pelos resultados dos Gráficos 11 e 12. Isso se deve ao fato de ambos os impactos se originarem essencialmente dos mesmos precursores: compostos gasosos de enxofre e nitrogênio em estado gasoso $\left(\mathrm{SO}_{2}, \mathrm{SO}_{\mathrm{x}}\right.$ e $\left.\mathrm{NO}_{\mathrm{x}}\right)$. A exceção reside no fato de que PMF incorpora a sua lista de aspectos ambientais os materiais particulados de granulometria variada $\left(\varphi_{\mathrm{ap}}<2,5 \mu \mathrm{m} ; 2,5<\varphi_{\mathrm{ap}}(\mu \mathrm{m})<10\right.$; e $\left.\varphi_{\mathrm{ap}}>10 \mu \mathrm{m}\right)$.

Como a análise transcorre por premissa em uma situação na qual (i) as queimadas, que seriam a fonte maior de emissão de partículas do sistema de produto, foram desconsideradas e, em contrapartida, (ii) emissões de $\mathrm{NO}_{\mathrm{x}}$ se destacam em todos os cenários analisados, constata-se uma convergência de perfis de tendência entre PMF e POF. 
Gráfico 11 - Pressão vs. Adição de palha vs. Umidade da palha para PMF
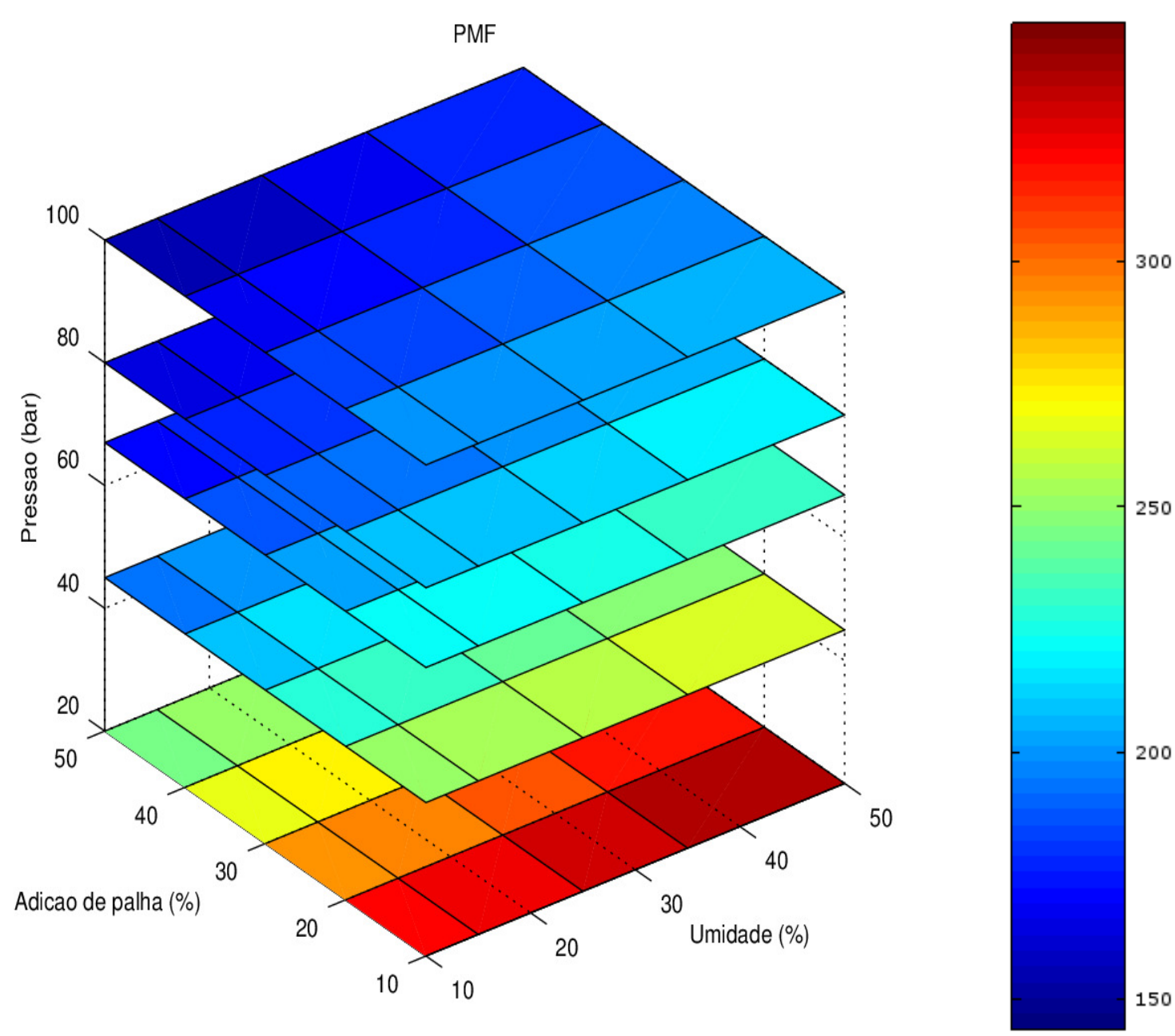

O menor nível de impacto nesse caso (163 kg $\left.\mathrm{PM}_{10 \mathrm{eq}} / \mathrm{MWh}_{\mathrm{e}}\right)$ foi, mais uma vez, obtido com $\left(\mathrm{P}_{5} ; \mathrm{A}_{5} ; \mathrm{u}_{1}\right)$ enquanto o pior desempenho (348 kg PM $\mathrm{PMeq}_{10 \mathrm{MWh}} / \mathrm{Mh}_{\mathrm{e}}$ ocorreuem $\left(\mathrm{P}_{1}\right.$; $\mathrm{A}_{1} ; \mathrm{u}_{5}$ ), projetando uma variação de $113 \%$ entre estes limites. A pressão de operação do sistema segue detendo a maior influencia sobre o impacto acumulado. Na comparação entre taxa de adição de palha e umidade, $\mathrm{u}_{\mathrm{k}}$ predomina sobre $\mathrm{A}_{\mathrm{j}}$, em termos de potencial de intervenção no desempenho ambiental. Essa característica se havia manifestado inclusive para os outros impacto analisados.

Uma análise de convergência foi também realizada para PMF. Esta investigação ocorreu nos mesmos termos que aquela que fora conduzida para POF; ou seja, tomando por referência condições de operação do tipo $\left(\mathrm{P}_{\mathrm{i}} ; \mathrm{A}_{1} ; \mathrm{u}_{5}\right)$. Os resultados obtidos estão descritos na Tabela 17, tanto em termos de impactos específicos, como de variação relativa. 
Gráfico 12 - PMF vs. Adição de palha vs. Umidade da palha para diferentes pressões

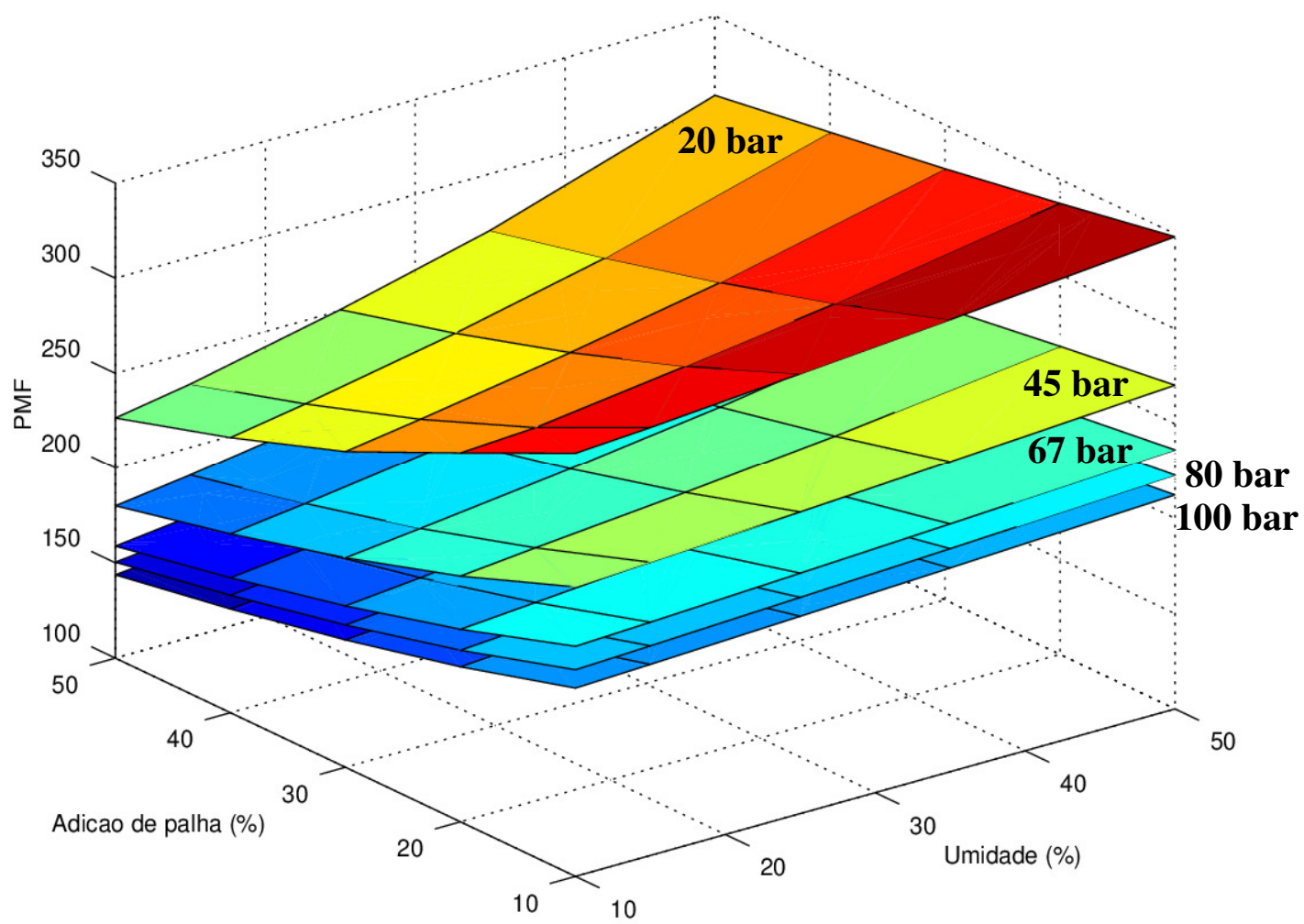

Os valores indicados na Tabela 17 reforçam a similaridade de perfil entre PMF e POF e assim, ratificam a conclusão obtida da análise anterior, de que a partir de níveis intermediários de pressão de operação na unidade de cogeração $\left(\mathrm{P}_{\mathrm{i}} \geq \mathrm{P}_{3}\right)$, há uma tendência de $\mathrm{PMF} \rightarrow \mathrm{k}_{1}$.

Tabela 17 - Análise da influência da pressão de operação do sistema sobre PMF

\begin{tabular}{ccc} 
Pressão ( $\mathrm{P}_{\mathrm{i}}$, bar $)$ & $\mathrm{PMF}_{\left(\mathrm{kg} \mathrm{PM}_{10 \mathrm{eq}} / \mathrm{kWh}_{\mathrm{e}}\right)}$ & $\Delta(\%)$ \\
\hline 20 & 348 & - \\
45 & 270 & $(-) 22,4$ \\
67 & 236 & $(-) 12,6$ \\
80 & 223 & $(-) 5,51$ \\
100 & 212 & $(-) 4,93$ \\
\hline
\end{tabular}

Para esta situação as emissões de $\mathrm{NO}_{\mathrm{x}}$ da decomposição de adubos nitrogenados no solo contribuem em cerca de $60 \%$ para o acumulado de impactos. Por fim, as emissões de 
material particulado com dimensões $\varphi_{\mathrm{ap}}<2,5 \mu \mathrm{m}$ e $\varphi_{\mathrm{ap}}>10 \mu \mathrm{m}$ que ocorrem na caldeira geraram aportes muito discretos à performance do sistema, para a categoria em referência

\subsubsection{Mudanças Climáticas (CC)}

O desempenho ambiental do sistema em termos de CC manteve o mesmo diapasão do que ocorreu antes com os demais efeitos analisados. Também nesse caso a ordem de influência dos parâmetros em verificação manteve-se inalterada, com $\mathrm{P}_{\mathrm{i}}$ sendo dominante sobre $u_{k}$ e este, sobre $A_{j}$. Essa comprovação destaca mais uma vez o efeito de $E_{e}$ sobre o desempenho específico do sistema.

Os impactos variaram de $106 \%$ entre extremos, desde $799 \mathrm{~kg} \mathrm{CO} 2 \mathrm{eq} / \mathrm{MWh}_{\mathrm{e}}$ obtidos em $\left(\mathrm{P}_{5} ; \mathrm{A}_{5} ; \mathrm{u}_{1}\right)$, até 1,64 t $\mathrm{CO}_{2 \mathrm{eq}} / \mathrm{MWh}_{\mathrm{e}}$ registrados para $\left(\mathrm{P}_{1} ; \mathrm{A}_{1} ; \mathrm{u}_{5}\right)$ (Gráficos 13 e 14). A análise de convergência também revelou tendências semelhantes às das dos outros impactos, em termos de variações relativas para os arranjos do tipo $\left(\mathrm{P}_{\mathrm{i}} ; \mathrm{A}_{1} ; \mathrm{u}_{5}\right)$. Esses resultados podem ser vistos na Tabela 18.

Gráfico 13 - Pressão vs. Adição de palha vs. Umidade da palha para CC
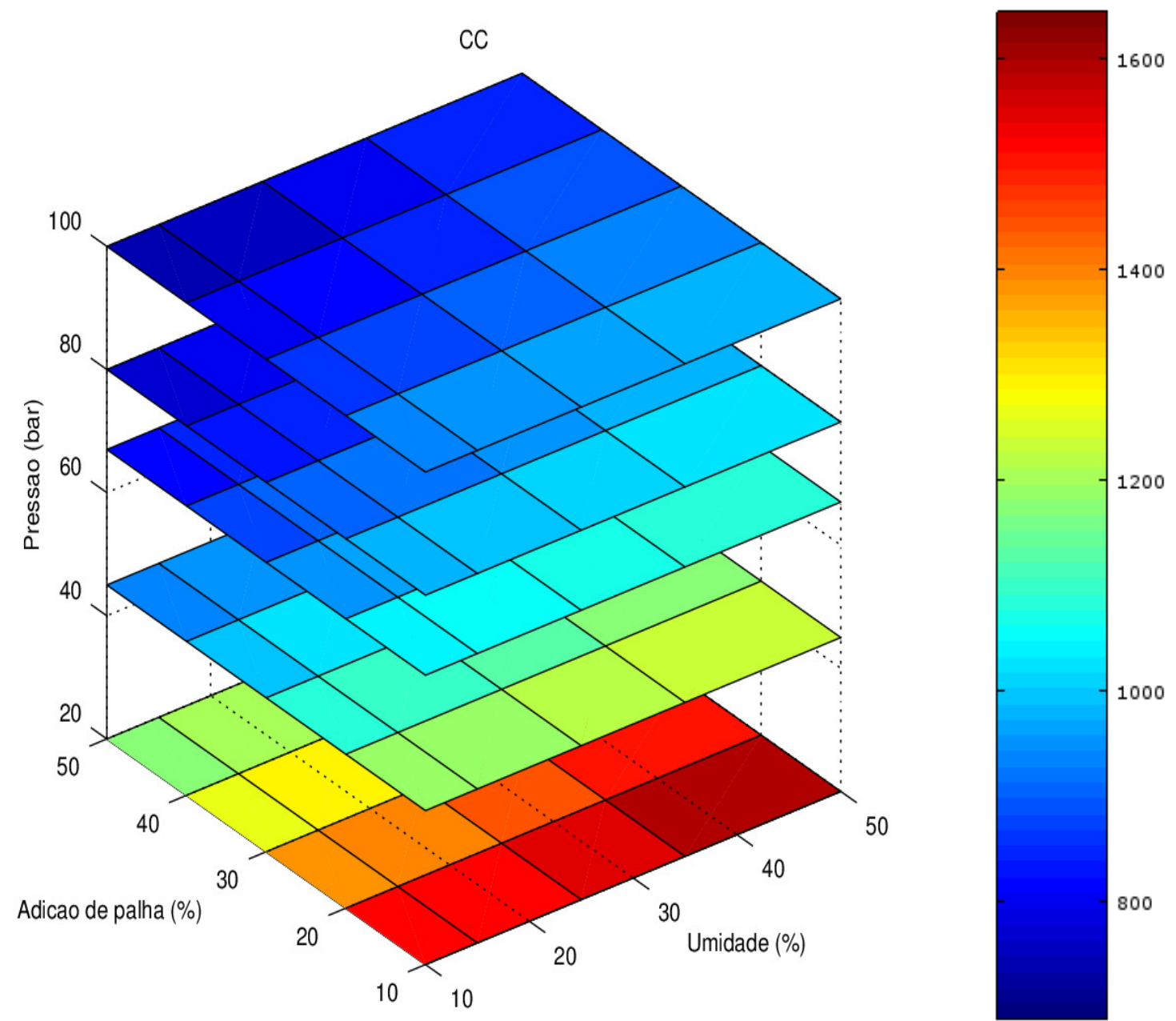
Tabela 18 - Análise da influência da pressão de operação do sistema sobre CC

\begin{tabular}{ccc} 
Pressão $\left(\mathrm{P}_{\mathrm{i}}\right.$, bar $)$ & PMF $\left(\mathrm{kg} \mathrm{PM} \mathrm{PMeq}_{10 \mathrm{eq}} / \mathrm{kWh}_{\mathrm{e}}\right)$ & $\Delta(\%)$ \\
\hline 20 & 1645 & $(-) 22,4$ \\
45 & 1276 & $(-) 12,5$ \\
67 & 1116 & $(-) 5,82$ \\
80 & 1051 & $(-) 4,66$ \\
100 & 1002 & $(-), 5$ \\
\hline
\end{tabular}

Destaca-se a proximidade dos desempenhos alcançados para $\mathrm{P}_{4}=80$ bar e $\mathrm{P}_{5}=100$ bar, cujo valor de $\Delta=4,66 \%$ foi o menor registrado em toda a análise. Esse resultado descreve o grau de constância de impactos como CC quando $\mathrm{P}_{\mathrm{i}} \geq \mathrm{P}_{4}$. No entanto, não se pode desprezar também o resultado que envolve a faixa anterior de medição (entre $\mathrm{P}_{3}$ e $\mathrm{P}_{4}$ ), na qual $\Delta=5,82 \%$. Ao ser considerado aceitável, mesmo sendo ligeiramente superior aos obtidos para POF e PMF, esse resultado amplia a faixa de operação do sistema até pressões intermediárias em torno de 67 bar.

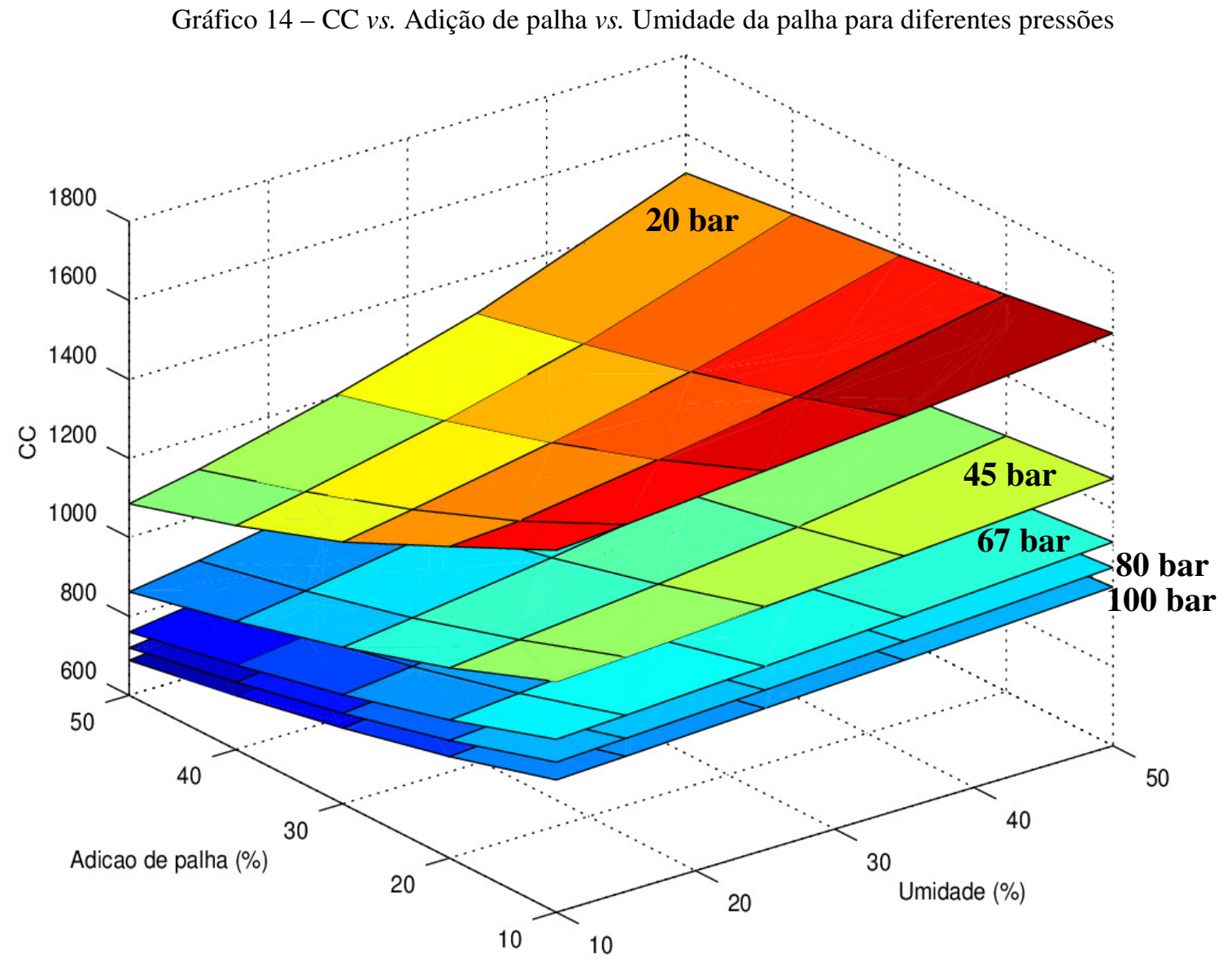


As principais contribuições para a categoria originam-se de emissões de $\mathrm{CO}_{2}$ de origem fóssil $\left(\mathrm{CO}_{2, \mathrm{f}}\right)$ advindas da queima do combustível em máquinas agrícolas usadas no preparo do solo, tratos culturais e principalmente, para a colheita que no caso presente se dá integralmente pela via mecanizada. Registram-se também, mesmo que em menor, emissões de $\mathrm{CO}_{2, \mathrm{f}}$ derivadas de transportes, tanto de cana e palha para a unidade industrial, como de vinhaça, torta de filtro e cinzas para o campo.

Ao serem somadas as emissões de $\mathrm{CO}_{2, \mathrm{f}}$ respondem por aproximadamente $44 \%$ do impacto total a despeito das condições analisadas. Isso ocorre pois, como já indicado em outras situações, esse efeito se manifesta em uma etapa do ciclo de vida em análise que não sofre intervenção direta da cogeração. Completam a relação de precursores de CC as perdas para o ar de $\mathrm{N}_{2} \mathrm{O}$ procedentes de mudanças de uso do solo, e emissões de $\mathrm{CH}_{4}$ de queima incompleta de diesel também em máquinas e caminhões.

Por fim, deve-se destacar um aspecto conceitual deveras importante. O modelo usado para contabilização de impactos ambientais disponível no método ReCiPe segue as orientações estabelecidas pelo Intergovernmental Panel on Climate Change (IPPC), as quais assumem por premissa a condição de balanço nulo em termos de captação de carbono do ar, e de emissão de carbono biogênico $\left(\mathrm{CO}_{2, \mathrm{~b}}\right)$. Por essa leitura, o benefício que poderia ser atribuído ao processo devido a elevada taxa de sequestro de carbono ar que a cana apresenta $\left(653 \mathrm{CO}_{2} \mathrm{~kg} / \mathrm{t}_{\mathrm{c}}\right.$ ) deixaram de ser considerados, assim os lançamentos de $\mathrm{CO}_{2, \mathrm{~b}}$ que ocorrem na caldeira devido a queima de biomassa. No caso da palha essa taxa será crescente conforma $\mathrm{A}_{\mathrm{j}}$ aumenta.

A decisão de usar o referido método de AICV para verificar o desempenho de CC foi baseada no conceito que essa leitura apresenta junto á comunidade científica. No entanto, para trabalhos futuros derivados do desenvolvimento do tema é recomendável realizar uma análise baseada em compensação de carbono para investigar que efeitos essa abordagem produziria nos resultados finais para a categoria. 


\section{CONCLUSÕES}

Este estudo tratou de verificar o efeito de variações em termos de desempenho ambiental na condição operacional (pressão $P_{i}$ da caldeira), adição de palha $(A j)$, e taxa de umidade $\left(\mathrm{u}_{\mathrm{k}}\right)$ dessa biomassa, as quais seriam provocadas no ciclo de cogeração de uma destilaria autônoma de etanol com vistas a produzir energia elétrica em quantidade suficiente para sua exportação.

A verificação ocorreu por meio da aplicação da técnica de ACV do tipo atribucional e com enfoque do 'berço-ao-portão' para cinco categorias de impacto: Acidificação Terrestre (TAc), Eutrofização Aquática (FEu), Formação de Oxidante Fotoquímico (POF), Formação de Material Particulado (PMF) e Mudança Climática (CC). Foram estabelecidos cinco níveis de intensidade para $\left(\mathrm{P}_{\mathrm{i}} ; \mathrm{A}_{\mathrm{j}} ; \mathrm{u}_{\mathrm{k}}\right)$, que depois de serem arranjados perfizeram cento e vinte cinco cenários de análise. Cada condição cenário foi modelado a partir de análises termodinâmicas de $1^{\mathrm{a}}$ e $2^{\mathrm{a}}$ leis. Além disso, as medições foram realizadas em termos específicos $\left(/ \mathrm{MWh} \mathrm{h}_{\mathrm{e}}\right)$.

Os resultados obtidos revelaram comportamentos uniformes para todos os impactos analisados. Como já se poderia intuir, os melhores desempenhos ocorreram para condições de $\mathrm{P}_{\text {máx }}=100$ bar, $\mathrm{A}_{\text {máx }}=50 \%$ e $\mathrm{u}_{\text {mín }}=10 \%$, ao passo que aqueles que mais comprometeram a performance do sistema ocorreram para $\mathrm{P}_{\text {mín }}=20$ bar, $\mathrm{A}_{\operatorname{mín}}=10 \%$ e $\mathrm{u}_{\text {máx }}=50 \%$. Verificando esses resultados em termos de tendências, percebeu-se que $\mathrm{P}_{\mathrm{i}}$ prevalece sobre os outros fatores, e $u_{k}$ domina $A_{j}$. Isso ocorre pois $P_{i}$ incide diretamente sobre a quantidade e energia exportada $\left(\mathrm{E}_{\mathrm{e}}\right)$.

A partir de níveis de pressão intermediários (que para o estudo, são aqueles que superam 67 bar) ocorre um amortecimento significativo de impactos ambientais. Essa condição define, portanto, o limite mínimo aceitável para esta variável.

Os desempenhos do sistema em termos de TAc, POF e PMF foram muito semelhantes pelo fato de serem impostos pelo mesmo precursor: decomposição de adubos nitrogenados no solo durante o cultivo da cana-de-açúcar. No caso de $\mathrm{FEu}$, a função foi ocupada majoritariamente por perdas de fosfatos, também ocorridas na etapa agrícola, mas nesse caso, devido a dosagens de SSP e MAP.

Por fim, o desempenho ambiental para CC se apoia em emissões de $\mathrm{CO}_{2, \mathrm{f}}$ advindas da queima do combustível em máquinas agrícolas usadas sobretudo na colheita, e em atividades de transporte. A forma como foram quantificados parte do conceito de carbono neutro. Assim, 
os benefícios proporcionados pela elevada taxa de captação de $\mathrm{CO}_{2}$ ar, bem como, da não emissão de $\mathrm{CO}_{2, \mathrm{~b}}$ não forma considerados. Este é um tema recomendável para estudos futuros. 


\section{REFERÊNCIAS BIBLIOGRÁFICAS}

ABNT - Associação Brasileira De Normas Técnicas. NBR ABNT NBR ISO 14040. Gestão Ambiental, Avaliação do Ciclo de Vida: definição de objetivo e escopo e Analise de Inventario. São Paulo: ABNT, 2009a.

NBR ABNT NBR ISO 14044. Gestão Ambiental, Avaliação do Ciclo de Vida: Princípios e estrutura. São Paulo: ABNT, 2009b.

ANON. Causticization of liquor: tendencies of modern technologies and equipment. Tsellyul. Bum. Karton. 3. p. 56-59, 2005.

ANP - Agência Nacional de Petróleo, Gás e Biocombustíveis. Anuário Estatístico Brasileiro do Petróleo, Gás Natural e Biocombustíveis - 2013; 2014 e 2015. Agência Nacional de Petróleo, Gás Natural e Biocombustíveis - Rio de Janeiro: ANP.

ANTON, L.; NOGUEIRA, A.R.; KULAY, L. Environmental performance analysis of cogeneration of electricity from successive additions of biomass in autonomous distiller.In:Proceedings of V CILCA Conferencia Latinoamericana de Ciclo de Vida.Lima.p. 218-223, 2015.

BATISTA, F. Produção de bioeletricidade subiu 34\% no $1^{\circ}$ tri. Valor Econômico, 17 de abril de 2015. Disponível em: <http://www.valor.com.br>. Acessoem: 22 abr. 2015.

BEEHARRY, R.P. Extended sugarcane biomass utilization for exportable electricity production in Mauritius. Biomass Bioenergy. 11(6), p. 441-449, 2006.

BEEHARRY,R.P.Strategies for augmenting sugarcane biomass availability for power production in Mauritius.Biomass Bioenergy.20, p. 421-429, 2001.

BNDES - BANCO NACIONAL DE DESENVOVIMENTO ECONÔMICO E SOCIAL; CGEE CENTRO DE GESTÃO E ESTUDOS ESTRATÉGICOS. Bioetanol combustível: uma oportunidade para o Brasil. Brasília: Centro de Gestão e Estudos Estratégicos, 2009.

.Bioetanol de cana-de-açúcar: energia para o desenvolvimento sustentável / organização BNDES e CGEE. - Rio de Janeiro: BNDES, 2008.

BONOMI A, CAVALETT O, PEREIRA DA CUNHA M, LIMA MAP. Virtual biorefinery: an optimization strategy for renewable carbon valorization. Springer International Publishing. 2016. $285 \mathrm{p}$.

BOTHA, F.C. Energy yield and cost in a sugarcane biomass system. Proc Aust Soc Sugar Cane Technol. 31, p. 1-9, 2009.

BRÄSCHER, F.Simulação numérica de centrais termelétricas. Dissertação (Mestrado) - Universidade Federal de Santa Catarina, Florianópolis, 1991.

CALDEIRA-PIRES, A., et al.Sustainability of the Biorefinery Industry for Fuel Production. Energies. 6, p.329-350, 2013.

CARDOSO, T. F., et al. ATechnical and economic assessment of trash recovery in the sugarcane bioenergy production system. Scientia Agricolca. 70(5), p. 353-360, September/October, 2013.

CAVALETT et al.Environmental and economic assessment of sugarcane first generation biorefineries in Brazil.Clean Technologies and Environmental Policy. 14, p. 399-410, 2012. 
CAVALETT O, CHAGAS MF, SEABRA JEA, BONOMI A. Comparative LCA of ethanol versus gasoline in Brazil using different LCIA methods. Int J Life Cycle Assess 18, p. 647-658,2013. doi: 10.1007/s11367-012-0465-0

CCEE - CÂMARA DE COMERCIALIZAÇÃO DE ENERGIA ELÉTRICA. Disponível em: $<$ http://ccee.org.br> Acesso em: 17 ago 2016.

CGEE - CENTRO DE GESTÃO E ESTUDOS ESTRATÉGICOS. Bioetanol combustível: uma oportunidade para o Brasil. Brasília: Centro de Gestão e Estudos Estratégicos, 2009.

CONAB - Companhia Nacional de Abastecimento. Acompanhamento da safra brasileira de cana-deaçúcar. - v. 1 safra 2014/2015 - Brasília : CONAB, 2014. Disponível em: <http://www.conab.gov.br. Acesso em: 02 abr. 2015.

CONAB - Companhia Nacional de Abastecimento. Acompanhamento da safra brasileira de cana-deaçúcar. - v. 3 safra 2016/2017 - Brasília : CONAB, 2016. Disponível em: <http://www.conab.gov.br. Acesso em: 17dez. 2016.

CORTEZ, L. A. B. Bioetanol de cana-de-açúcar: P\&D para a produtividade e sustentabilidade. São Paulo: Blücher, 2010. 954 p.

CORTINOVIS, G. F. Modelagem e otimização de um sistema de água de resfriamento e validação experimental. 159p. Dissertação (Mestrado) - Departamento de Engenharia Química, Escola Politécnica da Universidade de São Paulo, 2004.

CTC - CENTRO DE TECNOLOGIA CANAVIEIRA, Composição da palha de cana na usina.Disponívelem: <http://www.ctcanavieira.com.br> Acesso em: 04 set. 2014.

CURRAN, M.A. (Ed). Life Cycle Assessment Handbook: A Guide for Environmentally Sustainable Products. $1^{\text {st }}$ Ed. Wiley. 2012. 640p.

DANTAS, D.N.Uso da Biomassa da cana-de-açúcar para geração de energia elétrica: análise energética, exergética e ambiental de sistemas de cogeração em sucroetanoleiras do interior paulista.Dissertação (Mestrado) - Universidade Federal de São Carlos, São Carlos/SP, 2010.

DE BEER A.G., HUDSON,C. MEYER,E., SEIGMUND,B. Green cane harvesting and trash management.International Society Sugar Cane Technologists (ISSCT); 1996; 133-141p.

DIAS, M. O. S et al. Production of bioethanol and other bio-based materials from sugarcane bagasse: Integration to conventional bioethanol production process. Chemical Engineering Research and Design. 87(9), p. 1206-1216, 2009.

DIAS, M. O. S., CUNHA, M. P., JESUS, C. D., SCANDIFFIO, M., ROSELLA, C.E., MACIEL FILHO, R., BONOMI, A. Simulation of ethanol production from sugarcane in Brazil: economic study of an autonomous distillery. 20th European Symposium on Computer Aided Process Engineering, Elsevier, 2010.

DIAS, M.O.S. et al. Second generation ethanol in Brazil: can it compete with electricity production? Bioresource Technology. 102, p. 8964-8971, 2011.

DUFT, D. O que é cana bisada? Disponível em:<http://inteliagro.com.br/o-que-e-cana-bisada $>$ Acesso em 23 ago 2016. 
DUKU,M.H.,GU, S., HAGAN, E.B. A comprehensive review of biomass resources and biofuels potential in Ghana. Renew Sustain Energy Rev. 15, p.404-415, 2011.

EES - ENGINEERING EQUATION SOLVER. EES ${ }^{\circledR}$ Manual. Disponível em: $<$ https://www.fchart.com/assets/downloads/ees_manual.pdf > Acesso em 15 mar 2016

ELIA NETO, A. Manual de conservação e reuso de água na indústria sucroenergética. Agência Nacional de Águas; Federação das Indústrias do Estado de São Paulo; União da Indústria da cana-deaçúcar; Centro de Tecnologia Canavieira. Brasília, 2009.

EMBRAPA - Empresa Brasileira de Pesquisa Agropecuária. Bioeletricidade no Setor Sucroalcooleiro Paulista: participação no mercado de carbono, perspectivas e sustentabilidade, 2009. Disponível em: $<$ http://www.infoteca.cnptia.embrapa.br/bitstream/doc/83097/1/documentos78.pdf>

Empresa Brasileira de Pesquisa Agropecuária. Complexo Agroindustrial de Biodiesel no Brasil: Competitividade das Cadeias Produtivas de Matérias-Primas.Brasília: Embrapa Agroenergia, 2014. $712 \mathrm{p}$.

ENSINAS, A. V. Integração térmica e otimização termo-ecônomica aplicadas ao processo industrial de produção de açúcar e etanol a partir da cana-de-açúcar. Tese (Doutorado), Universidade Estadual de Campinas, Campinas, 2008.

EVANS, A.; STREZOV, V.; EVANS, T.J. Sustainability considerations for electricity generation from biomass. Renewable and Sustainable Energy Reviews. 14, p. 1419-1427, 2010.

FILHO, P.A., BADR, O. Biomass resources for energy in North-Eastern Brazil. Applied Energy. 77(1), p. 51-67, 2004.

FLORIO, D. N., OLIVEIRA Jr, S (2014). Thermoeconomic analysis of combined production of electricity and second generation ethanol based on the dilute acid hydrolisis of sugarcane bagasse. International Journal of Applied Thermodynamics. 17, p. 161-171, 2014.

FRANCO, H.C.J. Eficiência agronômica da adubação nitrogenada de cana planta. Tese (Doutorado). Escola Superior de Agricultura Luiz de Queiros. Universidade de São Paulo. Piracicaba, 2008.

FRISCHKNECHT, R.; JUNGBLUTH, N. (Ed). Overview and Methodology. Ecoinvent Report No.1. Dübendorf: 2007.

GAUDREAULT, C.; SANSSON, R.; STUART, P. Energy decision making in a pulp and paper mill: selection of LCA system boundary.Int J Life Cycle Assess. 15,p. 198- 211, 2010.

GIL, M.P.; MOYA, A.M.C.M.; DOMÍNGUEZ, E.R. Life cycle assessment of the cogeneration processes in the Cuban sugar industry. Journal of Cleaner Production. 41, p. 222-231, 2013.

GOEDKOOP, M., et al.Description of the ReCiPe Methodology for Life Assessment Impact Assessment. ReCiPe Main Report. Revised July 13 ${ }^{\text {th }}$, 2013. Disponível: <http://www.lciarecipe.net> Acesso: em 10 fev 2015.

GUERRA, J. P.; COLETA Jr., J.; ARRUDA, L.; SILVA, G.; KULAY, L. Comparative analysis of electricity cogeneration scenarios in sugarcane production by LCA. Int J Life Cycle Assess, 19, p. 814-825, 2014. 
GUERRA, J.P.M. Avaliação de desempenhotermodinâmico e ambiental de cenários de cogeração elétrica em usinas autônomas. 2014. 353 p. Dissertação (Mestrado) - Universidade de São Paulo, São Paulo, 2014.

GUNADY M. G. A. et al. Evaluating The Global Warming Potential Of The Fresh Produce Supply Chain For Strawberries, Romaine/Cos Lettuces (Lactuca Sativa), And Button Mushrooms (In Print Agaricus Bisporus) In Western Australia Using Life Cycle Assessment (LCA). Journal of Cleaner Production. 28, p. 81-87, 2012.

HAMMERSCHLAG, R. Ethanol's Energy Return on Investment: A Survey of the Literature 1990Present. Environ. Sci. Technol. 40, p. 1744-1750, 2006.

HASSUANI, S; REGIS, M.; CARVALHO, I. Biomass power generation: sugar cane bagasse and trash.Piracicaba: PNUD-CTC, 2005. 217p.

HUGOT, E. Manual de Engenharia Açucareira. V.1. São Paulo: Mestre Jou, 1977.

JRC - European Commission - Joint Research Centre - Institute for Environment and Sustainability: International Reference Life Cycle Data System (ILCD) Handbook - General guide for Life Cycle Assessment - Detailed guidance. $1^{\text {st }}$ Ed. (2010). EUR 24708 EN. Luxembourg. Publications Office of the European Union. 2010. 417p.

IBICT - Instituto Brasileiro de Informação em Ciência e Tecnologia. Desenvolvimento sustentável e avaliação do ciclo de vida. Brasilia: IBICT: CNI, 2014. 33p.

JUNGBLUTH, N. (Ed). Life Cycle Inventories of Bioenergy. Ecoinvent Report n. 17. Uster: 2007.

KHATIWADA, D.; SEABRA, J.; SILVEIRA, S; WALTER, A. Power generation from sugarcane biomass - a complementary option to hydroelectricity in Nepal and Brazil.Energy. 28, p. 241-254, 2012.

KIATKITTIPONG, W.; WONGSUCHOTO, P.; PAVASANT, P. Life cycle assessment of bagasse waste management options.Waste management (New York, N.Y.). 29(5), p. 1628-1633. 2009.

LEAL, M.R.L.V. et al. Sugarcane straw availability, quality, recovery and energy use: a literature review.Biomass and Bioenergy. 53, p.11-19, 2013.

LI, Y., CALISAL, S.M. Estimating power output from a tidal current turbine farm with first order approximation of hydrodynamic interaction between devices.Int. J. Green Energy. 7, p. 153-163, 2010.

LINERO, F.A.B. Biomassa adicional para aumento da geração de eletricidade. Em: Curso de Caldeiras, Vapor e Geração de Energias Renováveis. Centro de Tecnologia Canavieira, CTC. Ribeirão Preto, SP, 2012.

LORA, E.E.S., TEIXEIRA, F. N. Energia e Meio Ambiente. In: Milton Marques; Jamil Haddad; André Ramon Silva Martins. (Org). Conservação da Energia: Eficiência Energética de Instalações e Equipamentos, v.1, p. 30-93, Itajubá: UNIFEI, 2001.

LUO, L., VOET, E.V., HUPPES, G. Life cycle assessment and life cycle costing of bioethanol from sugarcane in Brazil. Renewable and Sustainable Energy Reviews.13, p. 1613-1619, 2009. 
MACEDO I.C., SEABRA J.E.A., SILVA J.E.A.R. Greenhouse gases emissions in the production and use of ethanol from sugarcane in Brazil: The 2005/2006 averages and a prediction for 2020. Biomass and Bioenergy. 32, p. 582-595,2008. doi:10.1016/j.biombioe.2007.12.006

MALÇA, J., FREIRE, F. Renewability and life-cycle energy efficiency of bioethanol and bio-ethyl tertiary butyl ether (bioETBE): Assessing the implications of allocation.Energy. 31(15), p. 3362-3380, 2006.

MAPA - Ministério da Agricultura Pecuária e Abastecimento.Cana-de-açúcar. Brasília, 2015.Disponível em:<http://www.agricultura.gov.br/vegetal/culturas/cana-de-acucar $>$ Acesso em 19 abr. 2015.

MARTINHO, H. M. Avaliação da efetividade de arranjos tecnológicos e processuais na elhoria do desempenho ambiental da produção de fosfato bicálcico. Dissertação (Mestrado). Escola Politécnica da Universidade de São Paulo. USP, São Paulo, 156p. 2014.

MAULBETSCH, J. S., DI FILIPPO, M. N. Cost and Value of Water Use at Combined-Cycle Power Plants. California Energy Commission, PIER Energy-Related Environmental Research. CEC-5002006-034. 2006.

MILANEZ, A.Y. et al. A produção de etanol pela integração do milho- safrinha às usinas de cana-deaçúcar: avaliação ambiental, econômica e sugestões de política. Revista do BNDES. 41, p. 147-208, 2014.

MINISTÉRIO DE MINAS E ENERGIA. Balanço energético Nacional 2009 - Ano Base 2008:

Resultados Preliminares. Empresa de Pesquisa Energética (EPE). Rio de Janeiro: MME/EPE, 2009.

MME - Ministério de Minas e Energia. (2015) Boletim Mensal de Acompanhamento da Indústria de Gás Natural - n. 106. Dezembro 2015. Secretária de Petróleo, Gás Natural e Combustíveis

Renováveis. Brasília. Disponível em: http://www.mme.gov.br

MORAN, M.J., SHAPIRO, H.N. Princípios de Termodinâmica para Engenharia. $4^{\mathrm{a}}$ Ed. Rio de Janeiro: LTC Editora. 2008.

MOTA, J.C. et al. Impactos e Benefícios Ambientais, Econômicos e Sociais dos Biocombustíveis: uma visão global. Engenharia Ambiental - Espírito Santo do Pinhal. 6 (3), p. 220-242, 2009.

MUNIZ, V. C. F. Análise da fundamentação da avaliação do ciclo de vida consequencial. Dissertação (Mestrado) - Escola Politécnica, Universidade de São Paulo, São Paulo, 73 p. 2012.

NEMECEK, T., KÄGI, T.Life Cycle Inventories of Agricultural Production Systems.Ecoinvent Report n. 15. Zürich e Dübendorf: Ecoinvent. 2007.

NORRIS, C. Trash Separation. Disponível em:

$<$ http://www.norrisect.com/index.php?option=com_content\&view $=$ article\&id=74\&Itemid=10> Acesso em: 28 jul 2011.

NOVACANA. Disponível em:<http://www.novacana.com> Acesso em: 18 abr. 2015.

OLIVEIRA JR., S. Exergy: Production, Cost and Renewability.Londres: Springer-Verlag London. ISBN 978-1-4471-4165-5. 2012. 338p.

OLIVÉRIO, J.L.; FERREIRA, F. M. Cogeneration - a new source of income for sugar and ethanol Mills or bioeletricity - a new business. Proc. Int. Soc. Sugar Cane Technol. 27. 2010. 
PELLEGRINI, L. F.; OLIVEIRA, J. S; BURBANO, J. C. Supercritical steam cycles and biomass integrated gasification combined cycles for sugarcane mills.Energy. 35 (2), p. 1172-1180, 2010.

PELLEGRINI, 1.F.; OLIVEIRA JR, S. Combined prodution of sugar, ethanol and electricity: Thermoeconomic and environmental analysis and optimization.Energy. 36, p. 3704 - 3715, 2011.

PISTORE, T.T.Avaliação Técnico - Econômica e Ambiental da Eletrificação das Moendas na Indústria Sucroalcooleira. Dissertação (Mestrado) - Universidade Federal de Itajubá. 2004.

PRABHAKAR, N., RAJU, D.V.L.N.; SAGAR, R.V. Cana Trash as Fuel. Proc. Int. Soc. Sugar Cane Technol. 27, 2010.

RFA - Renewable Fossil Association. Fueling a High Octane Future. 2016 Ethanol Industry Outlook. Washington DC. 2016. 40p. Disponível em: <http://www.ethanolrfa.org/wpcontent/uploads/2016/02/Ethanol-Industry-Outlook-2016.pdf> Acesso: 18 nov. 2016.

RIPOLI, T. C. C. e RIPOLI, M. L. C. Biomassa de cana-de-açúcar: colheita, energia e ambiente. $2^{\circ}$ Ed. Piracicaba: T.C.C. Ripoli, 2009. 302p.

ROJAS, S. P. Contribuição do Enfoque de Ciclo de Vida da Ecologia Industrial na Economia do Meio Ambiente. Doutorado em Economia. Tese(Doutorado) - Universidade de Brasília. 2012.

SALISBURY, J.K. Steam Turbines and Their Cycles $2^{\text {nd }}$ Edition. Krieger Pub Co. 1974. 670p.

SÃO PAULO. Protocolo de Cooperação:Governo do Estado de São Paulo e a União da Agroindústria Canavieira de São Paulo para consolidaçãodo desenvolvimento sustentável da indústria da cana-de-açúcar no Estado de São Paulo. São Paulo, 04 de junho de 2007. Disponível em: <http://www.cetesb.sp.gov.br/noticentro/2007/06/04_protocolo.pdf>.Acesso em: 25 nov. 2014.

SARTORI, M.M.P.; FLORENTINO, H. O. Energy balance optimization of sugarcane crop residual biomass. Energy.32, p. 1745-1748, 2007.

SEABRA, J.E.A. Avaliação técnico-ecônomica de opções para o aproveitamento integral da biomassa de cana no Brasil.Tese (Doutorado) - Universidade Estadual de Campinas, Campinas, 2008.

SEABRA, J.E.A.; MACEDO, I.C. Comparative analysis for Power generation and ethanol production from sugarcane residual biomass in Brazil. Energy Policy. 39, p. 421-428, 2011.

SHLYAKHIN, P.Steam Turbines: Theory and Design. University Press of the Pacific, 2005. 248p.

SIGNOR, D.; PISSIONI, L.L.M; CERRI, C.E.P. Emissões de gases de efeito estufa pela deposição de palha de cana-de-açúcar sobre o solo. Bragantia. 73(2), p. 113-122, 2014.

SILVA, A. L. R. Desenvolvimento de fatores de normalização de impactos ambientais regionais para Avaliação de Ciclo de Vida de produtos no Estado de São Paulo. São Carlos: Escola de Engenharia de São Carlos, Universidade de São Paulo, 2010.

SILVA, D.A.L.; DELAI, I.;MONTES, M.L.D.; OMETTO,A.R. (2014) Life cycle assessment of the sugarcane bagasse electricity generation in Brazil.Renewable and Sustainable Energy Reviews.32, p. 532-547, 2014. 
SILVA, G.A., KULAY, L. Disciplina PQI 5849: Fundamentos da Proteção Ambiental e Segurança de Processos Industriais. São Paulo: Programa de Pós-Graduação em Engenharia Química.

Universidade de São Paulo, 2012.

SILVA, G.A; KULAY, L.Avaliação do Ciclo de Vida. In: VILELA, A., DEMAJOROVIC, J. Modelos e ferramentas de gestão ambiental: desafios e perspectivas para as organizações. São Paulo: Editora SENAC, 2006.

SINGER, J. G. Combustion, Fossil Power: A Reference Book on Fuel Burning and Steam Generation. Combustion Engineering, Windsor, 1991. 140p.

SMEETS E. et al. The sustainability of Brazilian ethanol - an assessment of the possibilities of 693 certified production. Biomass and Bioenergy. 32, p. 781-813, 2008.

SOUSA, E.L.L.; MACEDO, I.C (Org.). Etanol e bioeletricidade: a cana-de-açúcar no futuro da matriz energética. São Paulo: Luc Projetos de Comunicação, 2010. 315p.

STOECKER, W. F. Design of Thermal Systems, $3^{\text {rd }}$ Edition, McGraw-Hill. 1989. pg.64-65.

SUGAWARA, E. T. Comparação dos desempenhos ambientais do B5 etílico de soja e de óleo diesel, por meio da avaliação do ciclo de vida (ACV). Dissertação (Mestrado) - Escola Politécnica, Universidade de São Paulo, São Paulo, 242 p., 2012.

TSATSARONIS, G.; PARK, M. On Avoidable and Unavoidable Exergy destructions and Investment Costs in Thermal Systems. Energy Conversion \& Management. 43, p. 1259-1270, 2002.

UNEP/SETAC, L. C. Towards a Life Cycle Sustainability Assessment: Making informed choices. United Nations Environmental Programme (UNEP). 2012.

UNICA - União da Indústria de Cana-de-Açúcar. Informações sobre o setor sucroalcooleiro. Disponível em: <http://www.unica.com.br/default.asp>. Acesso em: 30 nov. 2016.

VAN der VOET, E et al. Allocation Issues in LCA Methodology: A Case Study of Corn Stover-Based Fuel Ethanol. Int J Life Cycle Assess. 14, p. 529-539, 2009.

VILELA, F. S. V. Avaliação do ciclo de vida da produção industrial de etanol e açúcar. Estudo de Caso: Usina Jalles Machado S/A. Dissertação (Mestrado) - Engenharia Mecânica, Universidade de Brasília, Brasília, DF, 107 p., 2013.

VILELA, F. S., CALDEIRA-PIRES, A., LUZ, S. M. Economic and environmental impacts assessment along the supply chain of anhydrous ethanol from sugarcane in Brazil. In: V International Conference on Life Cycle Assessment in Latin-America (9 p.). Mendoza, Argentina: CILCA. 2013.

WEIDEMA, B.P. Environmental assessments of products: a textbook on Life Cycle Assessment.Helsinki: The Finnish Association of Graduate Engineers TEK, 1997. 93 p. 
APÊNDICE A

CÓDIGO ELABORADO PARA MODELAGEM DO SISTEMA DE COGERAÇÃO CICLO RANKINE COM REAQUECIMENTO 


\section{1: "MODELAGEM TERMODINÂMICA DO CENÁRIO COM REAQUECIMENTO"}

2:

3: "Dados da Safra"

4:

5: M_dot_cana $=$ Cana_safra/Período_safra*1000/24[kg/h]

"TaxadeMoagem de cana"

6: m_dot_bagaço=Y_bagaço/100*M_dot_cana*Utilização_Bagaço/100

"Alimentação de bagaço decana"

7: m_dot_palha=Y_palha/100*M_dot_cana*Utilização_Palha/100

"Alimentaçã o de palha decana"

8: Razão|vapor_biomassa=m_dot_vapor/m_dot_bagaço

"Razão entre produção de vapor e

consumo debiomassa"

9: m_bar_bagaço $=$ m_dot_bagaço $/ 1000[$ ton $/ \mathrm{h}]$

10: m_bar_palha=m_dot_palha $/ 1000[$ ton $/ \mathrm{h}]$

11:

12: "GERADOR DE VAPOR - Modelagem de conservação de matéria e energia"

13: "Balanço de massa caldeira"

14:

15: m_dot_agua $=$ m_dot_vapor + m_dot_purga

16: m_dot_purga $=Y$ Ypurga*m_dot_vapor

17:Y_purga $=0,03$

"Taxadepurga considerada $=3 \% "$

18: M_bar_vapor=m_dot_vapor $/ 1000[$ ton $/ \mathrm{h}]$

19:

20: "Balanço de massa Reaquecimento"

21:

22: m_dot_vap.reaq=m_dot_vapor

"Todovaporsuperaquecido retorna para reaquecimento"

23: m_bar_vap.reaq=m_dot_vap.reaq / 1000[ton /h]

"Conversãoda vazão mássica de vapor de $\mathrm{Kg} / \mathrm{h}$ para ton/h"

24:

25: "Balanços de energia"

26:

27: m_dot_agua*h[7]+ Q_dot_c $=$ m_dot_vapor*h[1]+m_dot_purga*h_purga + Q_dot_reaq

28: Q_dot_c=(m_dot_bagaço*PCI_bagaço+m_dot_palha*PCI_palhaumid $) *$ eta_c "Energia utilizada na fornecida na fornalha para evaporação daágua"

29: Q_dot_reaq=m_dot_vap.reaq*(h[9]-h[8])

30: $\mathrm{h}[1]=$ enthalpy(water; $\mathrm{T}=\mathrm{T}[1] ; \mathrm{P}=\mathrm{P}[1]): \mathrm{h} \_$purga $=$enthalpy(water;T=T_purga;x=0) 31: $\mathrm{P}[7]=1,20 * \mathrm{P} \_\mathrm{c}$ : T_purga $=T_{\text {_SAT }}\left(\right.$ water $\left.; \mathrm{P}=\mathrm{P} \_\mathrm{c}\right): \mathrm{P} \_$purga $=\mathrm{P} \_\mathrm{c}: \mathrm{P}[1]=\mathrm{P} \_\mathrm{c}$ :

32: PCI_bagaço=7565:PCI_palha $=12960[\mathrm{~kJ} / \mathrm{kg}]$

"Poder calorífico inferior do bagaço (51\%

umidade)edapalha de cana (15\% deumidade)"

33: PCS_palha $=17000[\mathrm{~kJ} / \mathrm{kg}]$

34: PCI_palhaseca= $($ PCS_palha*1/4,1869-5400*Y_Hpalha / 100)

secaemkcal/kg"35: PCI_palhasec=PCI_palhaseca*4,1868

secaemkJ/kg"36:Y_Hpalha=6,2

37: PCI_palhaumida=PCI_palhaseca-4680*Umid_palha / 100 emkcal/kg"

38: PCI_palhaumid=PCI_palhaumida $* 4,1868$

39: "Umid_palha $=15[\%] "$

40:T[1]=T_SAT (water; $\left.\mathrm{P}=\mathrm{P} \_c\right)+\mathrm{G} \_$super

41: G_super $=200[\mathrm{C}]$

"Poder Calorífico superior dapalha"

"Poder calorífica inferior da palha

"Poder calorífico inferior da palha

"Fração de hidrogênio napalha"

"Poder calorífico inferior da palha úmida

42: EEXP_FR=GeraçãoEletric.Espec.Excedente*m_biomassaFR/m_biomassa "Eletricidade exportadaporFluxodeReferência"

43: m_palha $=(0,140 *($ Utilização_palha/100) $) /(1-($ Umid_palha/100) $)$ "Massa depalha"

44: $\mathrm{m} \_$bagaço $=0,28$

"Poder calorífico inferior da palha úmida emkJ/kg"

" Umidade dapalha"

"Temperatura do vaporsuperaquecido"

"Grau desuperaqucimento"

" Massa debagaço" 
45: m_biomassa $=$ m_palha + m_bagaço

46: m_biomassaFR $=$ m_biomassa $* 151,46925$

47: eletricidade_moerpalha $=68,3 *$ m_palha $/ 1000$

48:

49:

50: "BOMBA 02 - ALIMENTAÇÃO DA CALDEIRA"

51:

52: $\mathrm{P}[6]=\mathrm{P}[2]$

53: eta_B2 $=\left(\mathrm{h}[6]-\mathrm{h} 7 \_\right.$iso $) /(\mathrm{h}[6]-\mathrm{h}[7])$

líquidonadescargadabomba"

54: h7_iso=enthalpy(water;s=s[6];P=P[7])

55: h[6]=enthalpy (water; $\mathrm{P}=\mathrm{P}[6] ; \mathrm{T}=\mathrm{T}[6])$

"Pressão de descarga da bomba igual a pressão dovapordeescape"

"Determinação da entalpia real da vazão de

"Entalpia para condição idealisentrópica"

"Entalpia na saída dodesaerador"

56:s[6]=entropy(water; $\mathrm{P}=\mathrm{P}[6] ; \mathrm{T}=\mathrm{T}[6])$ "Entropia na saída do desaerador é entropia do líquidosaturado"

57: $\mathrm{T}[7]=$ temperature $($ water $; \mathrm{h}=\mathrm{h}[7] ; \mathrm{P}=\mathrm{P}[7]) \quad$ "Temperatura derecalque"

58: $\mathrm{s}[7]=\operatorname{entropy}($ water $; \mathrm{h}=\mathrm{h}[7] ; \mathrm{P}=\mathrm{P}[7])$ "Entropia da água de alimentação dacaldeira"

59:

60: "BOMBA 01 - CONDENSADO"

61:

62: $\mathrm{P}[5]=\mathrm{P}[2]$

63: eta_B1 $=\left(\mathrm{h}[4]-\mathrm{h} 5 \_\right.$iso $) /(\mathrm{h}[4]-\mathrm{h}[5])$

64: h5_iso $=$ enthalpy (water;s $=\mathrm{s}[4] ; \mathrm{P}=\mathrm{P}[5])$

65: $\mathrm{s}[4]=\operatorname{entropy}($ water $; \mathrm{P}=\mathrm{P}[4] ; \mathrm{x}=0)$

66: $\mathrm{T}[5]=$ temperature $($ water $; \mathrm{h}=\mathrm{h}[5] ; \mathrm{P}=\mathrm{P}[5])$

67: $\mathrm{h}[4]=$ enthalpy(water; $\mathrm{P}=\mathrm{P}[4] ; \mathrm{x}=0$ )
"Pressão de descarga da bomba igual a pressão dovapordeescape"

"Determinação da entalpia real do líquido na descarga dabomba"

"Entalpia para condição idealisentrópica"

"Entropia na saída do condensador - líquidosaturado"

"Temperatura de recalque paradesaerador"

"Entalpia da saída do condensador é a entalpiadelíquidosaturado"

68: $\mathrm{T}[4]=\mathrm{T}[3] \quad$ "Temperatura de Entrada = temperatura de saída-->Somentetroca calorlatente"

69: $\mathrm{P}[4]=\mathrm{P}[3]$

"Pressão de sucção da bomba = pressão da cauda daturbina"

$70: \mathrm{s}[5]=$ entropy(water; $\mathrm{P}=\mathrm{P}[5] ; \mathrm{T}=\mathrm{T}[5])$ "Entropia da água de recalque da bomba01"

71:

72:

73: "REAQUECIMENTO"

74: "Extração de vapor da turbina"

75:

76: $\mathrm{P}[8]=\mathrm{P}[9]$

77: eta_t $=(\mathrm{h}[1]-\mathrm{h}[8]) /\left(\mathrm{h}[1]-\mathrm{h} 8 \_\right.$iso $)$

extraído,atravésdaeficiênciaisentrópica"

78: h8_iso $=$ enthalpy $($ water $; \mathrm{s}=\mathrm{s}[1] ; \mathrm{P}=\mathrm{P}[8])$

79: $\mathrm{T}[8]=$ temperature $($ water $\mathrm{h}=\mathrm{h}[8] ; \mathrm{P}=\mathrm{P}[8])$

80: $\mathrm{s}[8]=$ entropy (water; $\mathrm{h}=\mathrm{h}[8] ; \mathrm{P}=\mathrm{P}[8]$ )

$81: \mathrm{x}[8]=$ quality $($ water $; \mathrm{h}=\mathrm{h}[8] ; \mathrm{T}=\mathrm{T}[8])$

82:

83:

84: "TURBINA"

85: "Retorno de vapor da turbina"

86:

$87: \mathrm{T}[9]=\mathrm{T}[1]$

88: $\mathrm{s}[9]=\operatorname{entropy}($ water $; \mathrm{T}=\mathrm{T}[9] ; \mathrm{P}=\mathrm{P}[9])$

89: $\mathrm{h}[9]=$ enthalpy(water; $\mathrm{T}=\mathrm{T}[9] ; \mathrm{P}=\mathrm{P}[9])$

90:

91: "Rendimento da turbina"

92:

"Desprezadas perdas de carga no reaquecimento -ideal"

"Determinação da entalpia real do vapor

"Entalpia para condição ideal de expansãoisoentrópica"

"Temperatura de saída parareaquecimento"

"Título do vapor na saída parareaquecimento"

"Parâmetro definido de projeto doreaquecedor" 
93: eta_t $=(\mathrm{h}[9]-\mathrm{h}[2]) /\left(\mathrm{h}[9]-\mathrm{h} 2 \_\right.$iso $)$

"Determinação da entalpia real do vapor

extraídoparaodesaerador através da eficiênciaisoentrópica"

94: eta_t $=(\mathrm{h}[9]-\mathrm{h}[3]) /(\mathrm{h}[9]-\mathrm{h} 3$ _iso $)$

"Determinação da entalpia real do vapor

extraídoparaocondensador através da eficiênciaisoentrópica"

95: h2_iso=enthalpy (water;s=s[9];P=P[2])

"Entalpia da corrente de vapor de escape para

condiçãoidealdeexpansãoisoentrópica"

96: h3_iso=enthalpy (water;s $=\mathrm{s}[9] ; \mathrm{P}=\mathrm{P}[3])$

"Entalpia da corrente de vapor na cauda para

condiçãoidealdeexpansãoisoentrópica"

97:s[1] =entropy (water; $\mathrm{P}=\mathrm{P}[1] ; \mathrm{T}=\mathrm{T}[1])$

98: $\mathrm{T}[2]=$ temperature $($ water $; \mathrm{h}=\mathrm{h}[2] ; \mathrm{P}=\mathrm{P}[2])$

99: $\mathrm{T}[3]=$ temperature $($ water $; \mathrm{h}=\mathrm{h}[3] ; \mathrm{P}=\mathrm{P}[3])$

100: $\mathrm{s}[2]=$ entropy(water; $\mathrm{h}=\mathrm{h}[2] ; \mathrm{T}=\mathrm{T}[2])$

101: $\mathrm{s}[3]=$ entropy $($ water $; \mathrm{h}=\mathrm{h}[3] ; \mathrm{T}=\mathrm{T}[3])$

102: $\mathrm{x}[2]=$ quality $($ water $; \mathrm{h}=\mathrm{h}[2] ; \mathrm{T}=\mathrm{T}[2])$

103: $\mathrm{x}[3]=$ quality $($ water $; \mathrm{h}=\mathrm{h}[3] ; \mathrm{T}=\mathrm{T}[3])$

"Estado definido por 2 propriedadesindependentes"

"Temperatura do vapor deescape"

"Temperatura do vapor decauda"

"Entropia do vapor deescape"

"Entropia do vapor decauda"

"Título do vapor deescape"

"Título do vapor na cauda daturbina"

104:

105: "Balanço de massa na turbina"

106:

107: m_dot_vapor $=$ m_dot_vap.escape + m_dot_vap.cauda

108:

109:

110: "PURGA DE CONDENSADO ANTES DE SER USADO NO PROCESSO"

111:

112: "RETORNO DE CONDENSADO DO PROCESSO INDUSTRIAL"

113: $\mathrm{m} \_$dot_retorno $=\mathrm{m} \_$dot_vap.processo $* 0,90$

"Considerado perdas no processo de 10\% da vazão

devapor"

114: T_cond $=90[\mathrm{C}]$

"Considerado que todo condensado é coletado em

umtanquederecuperação e retorna para o ciclo a 90C"

115: P_cond=P[2]

"Pressão de retorno = pressão no desaerador $=$

Pressãodovapordeescape"

116:

117: $\mathrm{m} \_$agua.dessuper $=\mathrm{if}\left(\mathrm{x}[2] ; 100 ; 0 ; \mathrm{m} \_\right.$dot_agua.dessuper;0) $\quad$ "Seovaporde escape estiver superaquecido agua deve ser alimentada no dessuperaquecedor para obter vapor saturado para o processo de produção doetanol" 118: $\mathrm{m} \_$dot_purgador=if(x[2];100;-m_dot_agua.dessuper;0;0) $\quad$ "Seovaporde escape tiver $\mathrm{x}<1 \mathrm{o}$ condensado precisa ser retirado empurgadores"

119:

120: "DESSUPERAQUECEDOR E VAPOR DE PROCESSO"

121: "Balanços de massa"

122: m_dot_vap.escape $=$ m_dot_vap.dessuper + m_dot_vap.desaerador

123: m_dot_vap.processo=Cons.Vapor_processo*M_dot_cana*(1/1000) "Consumo de vapor para oprocesso"

124: m_dot_vap.processo $=$ m_dot_vap.dessuper + m_dot_agua.dessuper

125:

126: "Balanço de energia no dessuperaquecedor"

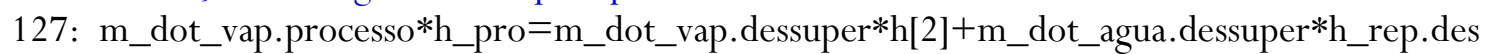

128: $\mathrm{h} \_$pro $=$enthalpy $\left(\right.$water $; \mathrm{T}=\mathrm{T} \_$pro; $\left.\mathrm{x}=1\right): \mathrm{T} \_$pro $=\mathrm{T} \_$sat $($water $; \mathrm{P}=\mathrm{P}[2]) \quad$ "Considerad o que o processo

industrial utiliza vaporsaturado"

129: 
130:

131:

132: "DESAERADOR"

133: "Balanço de massa no desaerador"

134:

135: m_dot_retorno + m_dot_vap.desaerador + m_dot_vap.cauda + m_dot_rep.desaerador + m_dot_purgador $=$ m_dot_agua 136:

137: "Balanço de energia no desaerador"

138:

139:

m_dot_retorno*h_cond $+\mathrm{m} \_$dot_vap.desaerador*h[2] $+\mathrm{m} \_$dot_vap.cauda*h[5]+m_dot_rep.desaerador*h_rep.des $+\mathrm{m} \_$dot_purgador*h_purgador $=\mathrm{m} \_$dot_agua*h[6]

140: h_cond $=$ enthalpy(water; $\mathrm{T}=\mathrm{T} \_$cond; $\mathrm{P}=\mathrm{P} \_$cond $)$: $\mathrm{h} \_$purgador $=$enthalpy(water; $\left.\mathrm{p}=\mathrm{p}[2] ; \mathrm{x}=0\right)$ :

h_rep.des $=$ enthalpy(water; $\mathrm{T}=\mathrm{T} \_\mathrm{amb} ; \mathrm{P}=\mathrm{P} \_$rep.des): $\mathrm{T} \_\mathrm{amb}=25$

141: P_rep.des $=\mathrm{P}[2]$

"Pressão no desaerador é a pressão de escape daturbina"

142:

143: "Conversão de unidades para ton/h"

144:

145: m_bar_vap.escape $=$ m_dot_vap.escape $/ 1000[$ ton $/ \mathrm{h}]$

146: m_bar_vap.cauda $=$ m_dot_vap.cauda $/ 1000$ [ton $/ \mathrm{h}$ ]

147: m_bar_vap.processo=m_dot_vap.processo $/ 1000$ [ton $/ \mathrm{h}]$

148: m_bar_vap.desaerador $=$ m_dot_vap.desaerador $/ 1000[\mathrm{ton} / \mathrm{h}]$

149: m_bar_rep.desaerador $=$ m_dot_rep.desaerador/1000 [ton $/ \mathrm{h}]$

150: m_bar_feed.water. $=$ m_dot_agua $/ 1000[\mathrm{ton} / \mathrm{h}]$

151: m_bar_purga $=$ m_dot_purga $/ 1000[$ ton $/ \mathrm{h}]$

152: m_bar_purgador $=$ m_dot_purgador $/ 1000[$ ton $/ \mathrm{h}]$

153:

154: "CONDENSADOR"

155:

156: Q_dot_out=m_dot_vap.cauda*(h[3]-h[4])

"Balanço de energia --> Calor transferido

dacondensaçãodovapor para a torre deresfriamento"

157:

158:

159: "TORRE DE RESFRIAMENTO"

160:

161: Q_dot_out $=$ m_dot_recirculação*(h_out-h_in)

162: h_out=enthalpy(water; $\mathrm{P}=\mathrm{P} \_$out $; \mathrm{T}=\mathrm{T} \_$out $): \mathrm{h} \_$in $=$enthalpy(water; $\mathrm{P}=\mathrm{P} \_$in; $\mathrm{T}=\mathrm{T} \_$in): $\mathrm{P} \_$in $=1: \mathrm{P} \_$out $=1$ :

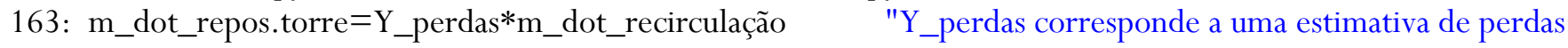
deáguaporevaporação, purga e arraste na torre deresfriamento"

164: m_dot_rep.total $=\mathrm{m}$ _dot_repos.torre $+\mathrm{m}$ _dot_rep.desaerador $+\mathrm{m} \_$dot_agua.dessuper

165: m_bar_repos.torre $=$ m_dot_repos.torre $/ 1000[$ ton $/ \mathrm{h}]$

166: m_bar_rep.total $=$ m_dot_rep.total $/ 1000[$ ton $/ \mathrm{h}]$

167: m_bar_vap.dessuper $=\mathrm{m} \_$dot_vap.dessuper $/ 1000[\mathrm{ton} / \mathrm{h}]$

168: Perc.torre $=\mathrm{m} \_$dot_repos.torre $/ \mathrm{m} \_$dot_rep.total $* 100$

169: Perc.desaerador $=\mathrm{m} \_$dot_rep.desaerador $/ \mathrm{m} \_$dot_rep.total $* 100$

170: Perc.dessuper $=\mathrm{m} \_$dot_vap.dessuper $/ \mathrm{m} \_$dot_rep.total $* 100$

171: Tap.water_torre $=\mathrm{m} \_$dot_repos.torre $/\left(\mathrm{m} \_\right.$dot_cana $\left./ 1000\right)$

172:Tap.water_deionised.processo $=\left(\mathrm{m} \_\right.$dot_agua.dessuper $) /\left(\mathrm{m} \_\right.$dot_cana $\left./ 1000\right)$

"Tap waterdoprocesso"

173: Tap.water_deionised.caldeira $=\left(\mathrm{m} \_\right.$dot_rep.desaerador $) /\left(\mathrm{m} \_\right.$dot_cana $\left./ 1000\right)$ "Tap waterdacaldeira"

174: 
175:

176:

177: "CÁLCULO DAS POTÊNCIAS ELÉTRICAS"

178: "Potência elétrica gerada"

179:

180: POT_elétr.gerada=(POT_1+POT_2+POT_reaq)*eta_g* ${ }^{*} \operatorname{convert}(\mathrm{kJ} / \mathrm{h} ; \mathrm{MW}) \quad$ "Potencia elétrica total gerada noturbogerador"

181: POT_reaq $=\mathrm{m}$ _dot_vap.reaq* $(\mathrm{h}[1]-\mathrm{h}[8])$

"Potencia gerada pelo vapor dacauda"

182: POT_1 $=$ m_dot_vap.escape* $(\mathrm{h}[9]-\mathrm{h}[2])$

"Potencia gerada pelo vapor de escape $\mathrm{aP}=2,5 \mathrm{bar} "$

183: POT_2 $=$ m_dot_vap.cauda* $(\mathrm{h}[9]-\mathrm{h}[3])$

"Potencia gerada pelo vapor dacauda"

184:

185: "Consumo das bombas do ciclo"

186:

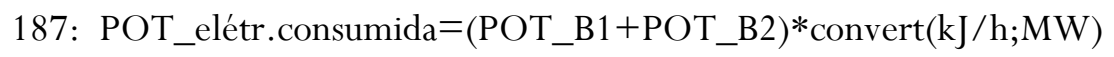

"Potência consumida pelasbombas"

188: POT_B1 $=$ m_dot_vap.cauda* $(\mathrm{h}[5]-\mathrm{h}[4])$

"Potência consumida pelabomba1"

189: POT_B2 $=$ m_dot_agua* $(\mathrm{h}[7]-\mathrm{h}[6])$

"Potência consumida pelabomba1"

190:

191:

192: "EFICIÊNCIA GLOBAL DA UNIDADE DE COGERAÇÃO COM REAQUECIMENTO"

193: "Cálculo da eficiência energética"

194:

195: eta_Energética.Global=(POT_elétr.líquida + POT_processo $) /$ POT_entrada*100

196:

197: "Potência líquida gerada na unidade de cogeração"

198:

199: POT_elétr.líquida = POT_elétr.gerada -POT_elétr.consumida

200:

201: "Potência utilizada no processo industrial"

202:

203: POT_processo=m_dot_vap.processo*(h_pro-h_sat)*convert $(\mathrm{kJ} / \mathrm{h} ; \mathrm{MW})$

204: POT_desaerador $=\mathrm{m} \_d o t \_v a p . d e s a e r a d o r *(h[2]-\mathrm{h}[6]) * \operatorname{convert}(\mathrm{kJ} / \mathrm{h} ; \mathrm{MW})$

205: POT_desaerador.perc $=$ POT_desaerador $/$ POT_entrada* 100

206: POT_processo.perc $=$ POT_processo $/$ POT_entrada*100

207: h_sat $=$ enthalpy $($ water $; \mathrm{x}=0 ; \mathrm{p}=2,5)$

208:

209:

210: "Alimentação energética na fornalha da caldeira"

211:

212: POT_entrada $=\left(\mathrm{m} \_\right.$dot_bagaço*PCI_bagaço $+\mathrm{m}$ _dot_palha*PCI_palhaumid $) * \operatorname{convert}(\mathrm{kJ} / \mathrm{h} ; \mathrm{MW})$

213:

214: "APLICAÇÃO DA 2A LEI DA TERMODINÂMICA - ANÁLISE EXERGÉTICA"

215: "Ambiente de referência considerado: $\mathrm{Po}=1$ bar e $\mathrm{To}=25 \mathrm{C}$ "

216:

217: $\mathrm{T} 0=25[\mathrm{C}]$

218: $\mathrm{P} 0=1[\mathrm{Bar}]$

219: P00_h20 $=0,0303$ [Bar]

220:

221: "LIMITE TEÓRICO DE EFICIÊNCIA - CICLO DE CARNOT"

222:

223: eta_Carnot $=(1-(\mathrm{T}[3]+273,15) /(\mathrm{T}[1]+273,15)) * 100$ "Trabalho máximoteórico" 
224:

225: "Trabalho útil final - saída do gerador"

226:

227: EXERGY.in_fuel=POT_entrada

228: EXERGY.out_electricity=POT_elétr.líquida

229: EXERGY.out_electricity.perc=POT_elétr.líquida/POT_entrada*100

230:

231: "BOILER"

232:

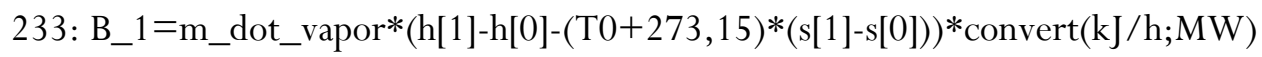

"Exergiadovapor de saída do gerador devapor"

234: $\mathrm{h}[0]=$ enthalpy(water; $\mathrm{t}=\mathrm{T} 0 ; \mathrm{P}=\mathrm{P0})$

235: $\mathrm{s}[0]=\operatorname{entropy}($ water $; \mathrm{t}=\mathrm{T} 0 ; \mathrm{P}=\mathrm{P} 0$ )

236: B_fuel=EXERGY.in_fuel

237:

238: "TURBINE"

239: "Exergia das correntes de vapor de escape e cauda"

240:

241: B_2=m_dot_vap.escape*(h[2]-h[0]-(T0+273, 15)*(s[2]-s[0]) $*$ convert $(\mathrm{kJ} / \mathrm{h} ; \mathrm{MW})$

"Exergiadovapor

deescape"

242: B_3 $=$ m_dot_vap.cauda*(h[3]-h[0]-(T0+273,15)*(s[3]-s[0]) $*$ convert $(\mathrm{kJ} / \mathrm{h} ; \mathrm{MW})$

"Exergiadovapor decauda"

243:

244: "Exergia da corrente de reaquecimento"

245:

246: B_8 $=$ m_dot_vapor* $(\mathrm{h}[8]-\mathrm{h}[0]-(\mathrm{T} 0+273,15) *(\mathrm{~s}[8]-\mathrm{s}[0])) * \operatorname{convert}(\mathrm{kJ} / \mathrm{h} ; \mathrm{MW})$

"Exergiadovapor

para reaquecimento na saída daturbina"

247: B_9=m_dot_vapor*(h[9]-h[0]-(T0+273,15)*(s[9]-s[0]) * $\operatorname{convert(kJ/h;MW)~}$

"Exergiadovapor

apósreaquecimento"

248:

249: "Balanço de exergia na turbina"

250:

251: Bdest_turbine=B_1+B_9 - (B_2+B_3+B_8+POT_elétr.gerada/eta_g)

"Exergia destruída na turbina"

252: Bdest_turbine.perc=Bdest_turbine/B_fuel*100

"Percentual

de exergia destruída na turbina"

253: B_2_perc=B_2/POT_entrada*100

"Percentual

de exergia no vapor de escape"

254:B_liq=POT_elétr.gerada/POT_entrada*100

"Percentual

de exergia (trabalho) na saída do gerador"

255:

256: "Consumo de exergia no processo industrial associado ao consumo específico de vapor"

257:

258: EXERGY.out_process $=$ m_dot_vap.processo* $\left(\mathrm{h} \_\right.$pro-h[0]-(T0+273,15)*(s_pro-s[0]))*convert $(\mathrm{kJ} / \mathrm{h} ; \mathrm{MW})$

259: s_pro $=\operatorname{entropy}($ water $; \mathrm{p}=2,5 ; \mathrm{t}=127,5)$

260: EXERGY.out_process.perc=EXERGY.out_process/POT_entrada*100

261: EXERGY.out_deaerator=B_2-EXERGY.out_process

262: EXERGY.out_deaerator.perc=EXERGY.out_deaerator/POT_entrada*100

263: 
264: "DESSUPERAQUECEDOR"

265: "Balanço de entropia no dessuper"

266:

267: S_ger.dessuper=m_dot_vap.processo*s_pro - (m_agua.dessuper*s_agua $+\left(\mathrm{m} \_\right.$dot_vap.dessuper-

m_dot_purgador $) *$ s[2] $268:$ s_agua $=\operatorname{entropy}($ water $; \mathrm{p}=2,5 ; \mathrm{t}=25)$

269: Bdest_dessuper $=(\mathrm{T} 0+273,15) *$ S_ger.dessuper*convert $(\mathrm{kJ} / \mathrm{h} ; \mathrm{MW}) \quad$ "Exergia

destruída nodessuperaquecedor"

270: Bdest_dessuper.perc $=$ Bdest_dessuper $/$ B_fuel $* 100$

"Percentual de

exergia destruída nodessuperaquecedor"

271:

272: "CONDENSADOR"

273:

274: B_4=m_dot_vap.cauda*(h[4]-h[0]-(T0+273,15)*(s[4]-s[0]))*convert $(\mathrm{kJ} / \mathrm{h} ; \mathrm{MW}) \quad$ "Exergianasaída

docondensador"

275: Bdest_condenser=B_3-B_4

"Exergia

destruída no condensador"

276: Bdest_condenser.perc=Bdest_condenser/B_fuel*100"Percentual de exergia destruída nocondensador"

277:

278: "BOMBA 1"

279:

280: B_5=m_dot_vap.cauda*(h[5]-h[0]-(T0+273,15)*(s[5]-s[0]) $*$ convert $(\mathrm{kJ} / \mathrm{h} ; \mathrm{MW})$

"Exergianasaída da bomba1"

281: Bdest_B1=B_4-B_5+W_B1

"Exergiadestruída

na bomba $1 "$

282: W_B1=m_dot_vap.cauda* $(\mathrm{h}[5]-\mathrm{h}[4]) * \operatorname{convert}(\mathrm{kJ} / \mathrm{h} ; \mathrm{MW})$

"Trabalho

realizado pela bomba $\mathrm{B} 1 "$

283: Bdest_B1.perc=Bdest_B1 $/$ B_fuel $* 100$

"Percentualde

exergia destruída na bomba 1"

284:

285: "DESAERADOR"

286: "Balanço de entropia no dessuperaquecedor"

287:

288: S_ger.desaerador $=m \_d o t \_a g u a * s[6]-$

(m_dot_retorno*s_cond $+\mathrm{m} \_$dot_vap.desaerador*s[2]+m_dot_vap.cauda*s[5]

+ m_dot_rep.desaerador*s_agua + m_dot_purgador*s_sat)

289: s_cond $=$ entropy (water; $\mathrm{T}=\mathrm{T} \_$cond $; \mathrm{P}=\mathrm{P} \_$cond $)$: $\mathrm{s} \_$sat $=$entropy $($water $; \mathrm{P}=2,5 ; \mathrm{x}=0$ )

290: Bdest_desaerador $=(\mathrm{T} 0+273,15) * \mathrm{~S} \_$ger.desaerador*convert $(\mathrm{kJ} / \mathrm{h} ; \mathrm{MW})$

"Exergia

destruída nodesaerador"

291: Bdest_desaerador.perc=Bdest_desaerador $/$ B_fuel*100

"Percentual de

exergia destruída nodesaerador"

292:

293:

294: "BOMBA 2"

295:

296: B_7=m_dot_agua*(h[7]-h[0]-(T0+273,15)*(s[7]-s[0]))*convert(kJ/h;MW) "Exergianasaída da bomba2"

297: B_6=m_dot_agua*(h[6]-h[0]-(T0+273,15)*(s[6]-s[0]) * ${ }^{2}$ convert(kJ/h;"Exergianaentrada da bomba2"

298: W_B2=m_dot_agua* $(\mathrm{h}[7]-\mathrm{h}[6]) * \operatorname{convert}(\mathrm{kJ} / \mathrm{h} ; \mathrm{MW}) \quad$ "Trabalho realizado pela bombaB2"

299: Bdest_B2=B_7-B_6+W_B2

"Exergia destruída na bomba 2" 
300: Bdest_B2.perc=Bdest_B2/B_fuel $* 100$

301:

302: "BOILER"

303:

304: B_7 + B_fuel +B_8=B_1 + B_purga + B_9+Bdest_boiler

305: Bdest_boiler.perc=Bdest_boiler/B_fuel*100

306: B_purga $=$ m_dot_purga*(h_purga-h[0]-(T0+273,15)*(s_purga-s[0] $) *^{*}$ convert $(\mathrm{kJ} / \mathrm{h} ; \mathrm{MW})$

307: s_purga $=$ entropy $\left(\right.$ water $; \mathrm{h}=\mathrm{h} \_$purga $; \mathrm{T}=\mathrm{T} \_$purga $)$

308:

309:

310: Total_exergy.dest=Bdest_B1+Bdest_B2+Bdest_desaerador+Bdest_condenser+Bdest_boiler+Bdest_turbine

311: Total_exergy.dest.perc=Total_exergy.dest/B_fuel*100

312:

313:

314: "Eficiência Exergética"

315: "Cálculo da eficiência exergética global"

316:

317: eta_EXergética.Global=(POT_elétr.líquida + EXERGY.out_process)/POT_entrada*100 318 :

319: eta_Ex.ref.Carnot=eta_EXergética.Global/eta_Carnot*100

320:

321:

322: "Distribuição de exergia entre vapor e eletricidade"

323:

324: Exergia_vapor.perc $=$ EXERGY.out_process/(POT_elétr.líquida + EXERGY.out_process)*100 325:

326: Exergia_eletricidade.perc $=$ POT_elétr.líquida/(POT_elétr.líquida + EXERGY.out_process)*100 327:

328:

329:

330: "ANÁllSE COMPLEMENTAR 1A LEI - PERDAS ENERGÉTICAS"

331: "Perdas na Caldeira e turbina"

332:

333: Boiler_losses=POT_entrada*(1-eta_c)

334: Boiler_losses.perc=Boiler_losses $/$ POT_entrada*100

335: Turbine_losses $=\left(\mathrm{POT}_{-} 1+\mathrm{POT} \_2+\mathrm{POT} \_\right.$reaq $) *\left(1-\mathrm{eta} \_\mathrm{t}\right) * \operatorname{convert}(\mathrm{kJ} / \mathrm{h} ; \mathrm{MW})$

336: Turbine_losses.perc=Turbine_losses/POT_entrada*100

337:

338: "Perdas no condensador"

339:

340: POT_condensador=Q_dot_out*convert $(\mathrm{kJ} / \mathrm{h} ; \mathrm{MW})$

"Energia perdida nocondensador"

341: POT_condensador.perc=POT_condensador/POT_entrada*100

342: Condenser_losses=POT_condensador

343:

344: "Perdas no processo"

345:

346: process_losses $=$ POT_entrada -

(POT_processo+POT_elétr.gerada+POT_condensador+Turbine_losses+Boiler_losses) 347:

process_losses.perc=process_losses/POT_entrada*100

348:

349:

350: "Cálculo da energia elétrica gerada por tonela de cana por tonelada de cana"

351:

"Percentualde exergia destruída na bomba 2"

"Balanço de exergia nacaldeira"

"Percentualde exergia destruída na caldeira" 
352: GeraçãoEletric.Espec.Total =POT_elétr.líquida*Período_safra*1000*24/Cana_safra

353: GeraçãoEletric.Espec.Excedente $=$ GeraçãoEletric.Espec. Total - ConsumoEletr.Processo 354:

355:

356:

357: "ALOCAÇ̃̃O"

358:

359: "Critério energético"

360: POT_específica_processo $=$ POT_processo*Período_safra*1000*24/Cana_safra

361: Alocação_energia_vapor $=$

POT_específica_processo/(POT_específica_processo+GeraçãoEletric.Espec.Excedente

+ ConsumoEletr.Processo)*100

362: Alocação_energia_eletr.exp = GeraçãoEletric.Espec.Excedente/(POT_específica_processo

+ GeraçãoEletric.Espec.Excedente+ConsumoEletr.Processo)*100

363: Alocação_energia_eletr.proc $=$

ConsumoEletr.Processo/(POT_específica_processo+GeraçãoEletric.Espec.Excedente

+ ConsumoEletr.Processo)*100

364:

365:

366: "Critério exergético"

367: EXERGY.out_específica_process = EXERGY.out_process*Período_safra*1000*24/Cana_safra 368:

Alocação_exergia_vapor $=$ EXERGY.out_específica_process $/($ EXERGY.out_específica_process

+ GeraçãoEletric.Espec.Excedente+ConsumoEletr.Processo)*100

369: Alocação_exergia_eletr.exp = GeraçãoEletric.Espec.Excedente/(EXERGY.out_específica_process

+ GeraçãoEletric.Espec.Excedente+ConsumoEletr.Processo)*100

370: Alocação_exergia_eletr.proc $=$ ConsumoEletr.Processo $/($ EXERGY.out_específica_process

+ GeraçãoEletric.Espec.Excedente + ConsumoEletr.Processo $) * 100$

371:

372:

373:

374:

375: "Distribuição de energia entre vapor e eletricidade"

376:

377: Energia_vapor.perc $=$ POT_processo $/($ POT_processo + POT_elétr.líquida $) * 100378$ :

379: Energia_eletricidade.perc $=$ POT_elétr.líquida $/($ POT_processo + POT_elétr.líquida $* 100380$ :

381 : 